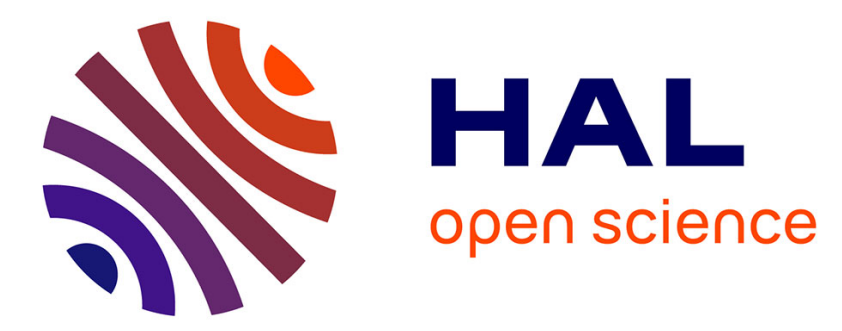

\title{
The Usefulness of Phosphorus Compounds in Alkyne Synthesis
}

\author{
Frédéric Eymery, Bogdan Iorga, Philippe Savignac
}

\section{To cite this version:}

Frédéric Eymery, Bogdan Iorga, Philippe Savignac. The Usefulness of Phosphorus Compounds in Alkyne Synthesis. Synthesis: Journal of Synthetic Organic Chemistry, 2000, 2000 (02), pp.185-213. 10.1055/s-2000-6241 . hal-03161387

\section{HAL Id: hal-03161387 https://hal.science/hal-03161387}

Submitted on 11 Mar 2021

HAL is a multi-disciplinary open access archive for the deposit and dissemination of scientific research documents, whether they are published or not. The documents may come from teaching and research institutions in France or abroad, or from public or private research centers.
L'archive ouverte pluridisciplinaire HAL, est destinée au dépôt et à la diffusion de documents scientifiques de niveau recherche, publiés ou non, émanant des établissements d'enseignement et de recherche français ou étrangers, des laboratoires publics ou privés. 


\title{
The Usefulness of Phosphorus Compounds in Alkyne Synthesis
}

Frédéric Eymery, Bogdan Iorga, and Philippe Savignac

Hétéroéléments et Coordination, UMR CNRS 7653, DCPH, Ecole Polytechnique, 91128

Palaiseau Cedex, France

e-mail : dcph@poly.polytechnique.fr

\begin{abstract}
Due to their versatility, $\beta$-keto ylides, $\alpha$-halo ylides, diazomethylphosphonates, halomethylphosphonates and enolphosphates constitute a class of useful phosphorus reagents for the synthesis of alkynes. This review attempts to summarize their applications and focus on the role of each reagent as synthetic intermediates.
\end{abstract}

\section{Introduction}

2. Phosphonium Ylides Precursors of Acetylenic Compounds

2.1. Thermal Decomposition of Phosphonium Ylides

2.2. Dibromomethylenetriphenylphosphorane

2.3. Halomethylenetriphenylphosphoranes

2.4. Iodomethyltriphenylphosphoniumphenacylide

2.5. Dibromoallyltriphenylphosphonium bromide

3. Phosphonates Precursors of Acetylenic Compounds

3.1. The 1-Diazomethylphosphonates

3.1.1. Dimethyl and Diethyl 1-Diazomethylphosphonates

3.1.2. Dimethyl 1-Diazo-2-Oxopropylphosphonate

3.2. The $\alpha$-Halogenated Methylphosphonates

3.2.1. Diethyl Trichloromethylphosphonate

3.2.2. Diethyl Dichloromethylphosphonate

3.2.3. Diethyl Dibromomethylphosphonate

3.2.4. Diethyl Diiodomethylphosphonate

3.3. The Dialkyl $\alpha$-Halobenzylphosphonates

3.4. Triethyl $\alpha$-Iodophosphonoacetate and Dialkyl 1-Chloro-2-Oxoalkylphosphonates

3.5. The Diethyl 2-Perfluoroalkenylphosphonate

4. Enol Phosphates Precursors of Acetylenic Compounds

5. Conclusion

6. Acknowledgments 


\section{References}

Key words: alkynes, $\beta$-keto ylides, thermal decomposition, $\alpha$-halo ylides, diazomethylphosphonates, halomethylphosphonates, enol phosphates, 1,1- or 1,2-elimination.

\section{Introduction}

The carbon-carbon triple bond is one of the simplest functional group in organic chemistry but its practical realization often represents major synthetic problems. The subject has been reviewed in several important pioneering books such as The Chemistry of Acetylene by Viehe $(1969)^{1}$, the Houben-Weyl-Müller Vol. V/2a (1977), ${ }^{2}$ the Patai series on The Chemistry of the Carbon-Carbon Triple Bond (1978), ${ }^{3}$ the numerous editions (1971, 1988 and 1992) of the experimental procedures developed or collected by Brandsma in Preparative Acetylenic Chemistry, ${ }^{4}$ and more recently the Modern Acetylene Chemistry edited by Stang and Diederich (1995). ${ }^{5}$ The purpose of this article is to provide an overview of the contribution of phosphorus reagents which have been designed to perform the synthesis of alkynes, simple or complex, with a terminal or internal triple bond. The main strategy for the production of alkynes using phosphorus reagents, which usually involve two-step operations, proceeds by a one carbon chain elongation of a carbonyl function concomitant with an elimination reaction. In such transformations, the Wittig reaction and its Horner-WadsworthEmmons modified version are merely a masked alkynes synthesis, and both of them have been developed so that aldehydes as well as ketones may be easily converted into alkynes. The preparation of specially tailor-made phosphorus reagents coupled with a judicious selection of bases has largely contributed to the intensive developement of the method. With the discovery of new bases, the unmasking of the latent triple bond by elimination of hydrogen halide or rearrangement has considerably been facilitated. Each base being effectively adapted to the substrats, each step is effected in a clean manner, minimizing the problems associated with the formation of byproducts and avoiding the partial destruction of the alkynes. The formation of alkynes from enol phosphates, a procedure whose synthetic utility remains undeveloped, has notably benefitted from the discovery of new bases. Today, phosphorus reagents play an important part in alkynes synthesis and more than ten precursors are commercially available. To enhance the practical value of the phosphorus route to alkynes, each section include synthetic protocols for the preparation of the phosphorus precursors and an application of each reagent.

\section{Phosphonium Ylides Precursors of Acetylenic Compounds}

Historically, the phosphonium ylides were the first phosphorus reagents to be used in alkynes synthesis. The $\beta$-keto ylides are the one category of phosphonium ylide that is predictably able to thermal decomposition. Since its discovery in 1959 , the reaction has induced a 
research which has continued unabated to this day. Because of their satisfying reactivity towards aldehydes, the halomethylenetriphenylphosphoranes are regularly employed as operational precursors of alkynes, although the phosphonates appear to have the greater synthetic utility. Despite everything, the major disadvantage which attends the use of phosphonium ylides remains the tedious formation of triphenylphosphine oxide.

\subsection{Thermal Decomposition of Phosphonium Ylides}

Early reported ${ }^{6}$ preparation of benzonitrile 3 by Staudinger and Hauser in 1921 included a thermal route using the decomposition at $220^{\circ} \mathrm{C}$ of benzoyliminotriphenylphosphorane 1 . By analogy with this reaction, it was reported in 1959 that "when $\alpha$ benzoylbenzylidenetriphenyl-phosphorane was heated above its melting point $\left(300^{\circ} \mathrm{C}\right.$ for 0.5 h), it gave triphenylphosphine oxide and diphenylacetylene quantitatively". ${ }^{7}$

At the same time and independently it was shown by two laboratories 8,9 that the pyrolysis of $\beta$-ketoalkylidenetriphenylphosphorane $\mathbf{4}$ constituted a general route to alkynes $\mathbf{5}$ provided that a) neither $\mathrm{R}^{1}$ nor $\mathrm{R}^{2}$ was hydrogen, and that $\left.\mathrm{b}\right) \mathrm{R}^{1}$ or $\mathrm{R}^{2}$ was a phenyl or carbonyl group or an other electron-withdrawing group (Scheme 1). ${ }^{10}$ At present, this thermal procedure appears as an important and useful technique for the construction of a variety of alkynes $\mathbf{5}$ containing an internal triple bond. It is called the "intramolecular Wittig reaction" and, just as in the traditional Wittig reaction, the elimination of triphenylphosphine oxide 2 constitutes probably the driving force of the reaction. ${ }^{11}$
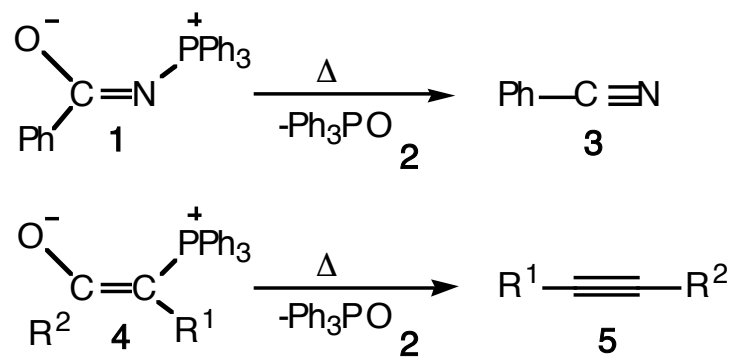

\section{Scheme 1.}

Facing these promising results, the conditions for a full utilization of the thermolysis reaction were investigated. In particular, by using both acyl halides and anhydrides, the $\alpha$-substituted methylenetriphenylphosphoranes $\mathbf{8}$ may be converted in fair yields to the necessary starting $\beta$-keto ylides 10. Owing to the suitable selection and arrangement of electron-withdrawing groups $\mathrm{R}^{1}$ and $\mathrm{R}^{2}$, the $\beta$-keto ylides $\mathbf{1 0}$ were conveniently modified to allow the preparation of an unlimited number of precursors. The generation of alkynes $\mathbf{5}$ from $\mathbf{1 0}$ was accomplished by heating the acylmethylenetriphenylphosphoranes 10 at $220-280^{\circ} \mathrm{C}$ under vacuum $(10-16$ $\mathrm{mm} \mathrm{Hg}$ ) with distillation of the alkynes 5 (Scheme 2). 


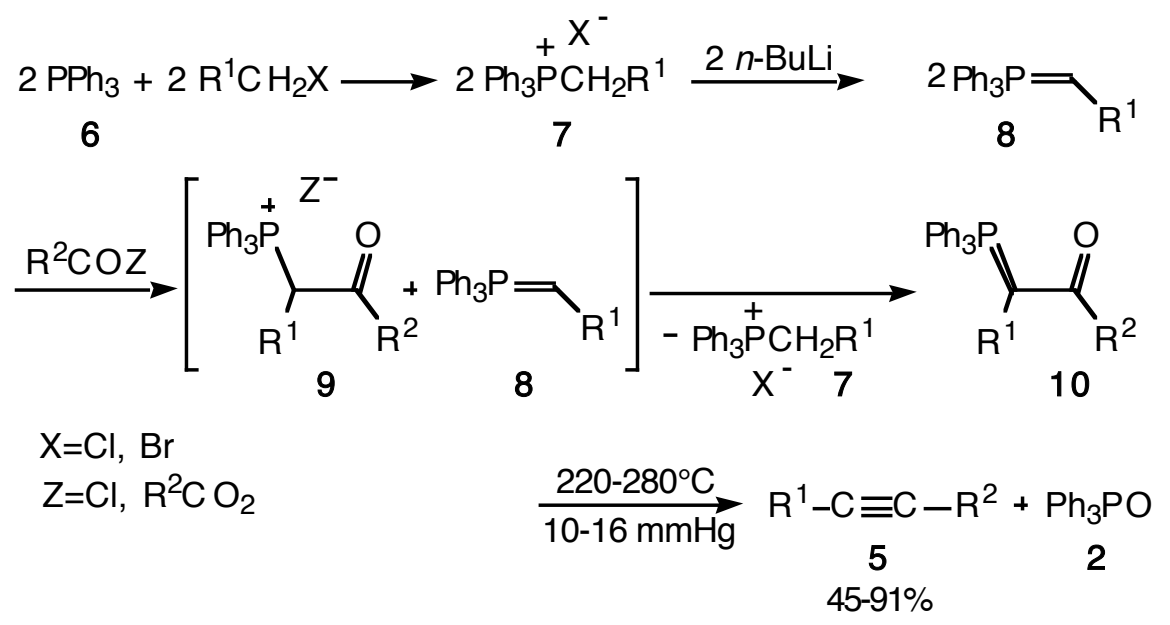

\section{Scheme 2.}

This elegant synthetic procedure has been successfully developed with phosphorane precursors 10 containing at least one electron-withdrawing group $\mathrm{R}^{1}\left(\mathrm{R}^{1}=\operatorname{aryl}, 7,8,12-17\right.$ $\left.\mathrm{CO}_{2} \mathrm{R},{ }^{8-10,18-35} \mathrm{COSMe},{ }^{36} \mathrm{CN}, 37-45 \mathrm{CHO},{ }^{46} \mathrm{COR},{ }^{20,47,48} \mathrm{SR},{ }^{49,50} \mathrm{SeR},{ }^{51,52} \mathrm{P}(\mathrm{O})(\mathrm{OPh})_{2}{ }^{53}\right)$ coupled with either an electron-withdrawing group $\mathrm{R}^{2}\left(\mathrm{R}^{2}=\right.$ alkynyl, aryl, substituted aryl, heteroaryl) or a releasing alkyl group; the reported yields are moderate to excellent (45 to $91 \%)$. For example, preparation of the ethyl $\left[4-{ }^{2} \mathrm{H}_{3}\right]$ but-2-ynoate has been accomplished by this method with $50 \%$ yield. ${ }^{54}$

1-Ethoxycarbonyl-2-oxopentylidenetriphenylphosphorane. ${ }^{10}$ Butyryl chloride $(3.1 \mathrm{~g}, 29.1 \mathrm{mmol})$ in benzene $(10 \mathrm{~mL})$ was added slowly to a stirred solution of ethoxycarbonylmethylenetriphenylphosphorane $(10 \mathrm{~g}$, $28.73 \mathrm{mmol})$ in benzene $(100 \mathrm{~mL})$, and the resulting solution set aside at room temperature overnight. The precipitate of ethoxycarbonylmethyltriphenylphosphonium chloride $\left(4.8 \mathrm{~g}, 12.48 \mathrm{mmol}, 43.4 \%\right.$, m.p. $\left.90-91^{\circ} \mathrm{C}\right)$ was filtered off and the filtrate evaporated. Crystallisation of the residue from aqueous EtOH gave 1-ethoxycarbonyl-2-oxopentylidenetriphenylphosphorane $(4.0 \mathrm{~g}, 9.57 \mathrm{mmol}, 33.3 \%)$, m.p. $130-131^{\circ} \mathrm{C}$.

Pyrolysis of 1-Ethoxycarbonyl-2-oxopentylidenetriphenylphosphorane. ${ }^{10}$ The phosphorane $(3.32 \mathrm{~g}, 7.94$ $\mathrm{mmol}$ ) was heated for $1 \mathrm{~h}$ at $280^{\circ} \mathrm{C} / 10 \mathrm{mmHg}$ in a $50 \mathrm{~mL}$ Claisen flask immersed in a Wood's metal bath, the distillate being collected in a receiver cooled in liquid nitrogen. Redistillation gave ethyl hex-2-ynoate $(0.87 \mathrm{~g}$, $6.21 \mathrm{mmol}, 78 \%$ ), b.p. $93^{\circ} \mathrm{C} / 24 \mathrm{mmHg}$.

Ethyl 3-(2-Thienyl)propiolate. ${ }^{32}$ Thiophene-2-carboxylic acid (20 g, $\left.0.16 \mathrm{~mol}\right)$ was treated with $\mathrm{SOCl}_{2}(57$ $\mathrm{mL}$ ) under reflux for $2 \mathrm{~h}$. Evaporation under reduced pressure of the remaining $\mathrm{SOCl}_{2}$ left the corresponding acyl chloride $(20 \mathrm{~g}, 0.14 \mathrm{~mol})$ which was dissolved in dry benzene $(150 \mathrm{~mL})$ and added dropwise to a solution of (ethoxycarbonylmethylidene)triphenylphosphorane $(76 \mathrm{~g}, 0.22 \mathrm{~mol})$ in dry benzene $(500 \mathrm{~mL})$. The mixture was refluxed for $12 \mathrm{~h}$. After cooling, the mixture was filtered and the solvent removed under reduced pressure. The betaine, dissolved in $\mathrm{CHCl}_{3}$, was filtered through $\mathrm{SiO}_{2}$ and then crystallized twice from EtOAc to give pure betaine (46 g, $0.1 \mathrm{~mol})$. Pyrolysis of the betaine in a bulb-to-bulb apparatus under reduced pressure $(10 \mathrm{mmHg})$ at $240^{\circ} \mathrm{C}$ gave pure title compound $(16 \mathrm{~g}, 0.09 \mathrm{~mol}, 64 \%)$ as a dense oil.

However, the major disadvantage which attended the full utilization of the thermolysis reaction was the formation, during the preparation of the phosphorane precursors $\mathbf{1 0}$, of a mixture of the desired phosphorane $\mathbf{1 0}$ and the starting quaternary phosphonium salts $\mathbf{7}$ as depicted in Scheme 2. Consequently the production of suitable quantities of alkynes $\mathbf{5}$ was often handicapped by the rather cumbersome regeneration of the phosphonium salt. 
Fortunately, a useful and mild method for the complete consumption of the starting phosphonium salt 7 is available. 55,56

Typically, the $\beta$-keto ylides $\mathbf{1 0}$ are prepared by treatment of $\alpha$-substituted methylenephosphoranes $\mathbf{8}$ with acyl chlorides or anhydrides to afford an equimolecular mixture of the desired phosphorane $\mathbf{1 0}$ and the starting phosphonium salt $\mathbf{7}$ (Scheme 2). Acylation of the phosphorane $\mathbf{8}$ gives the intermediate phosphonium salt $\mathbf{9}$, which reacts with the more basic phosphorane $\mathbf{8}$ via a transylidation reaction, to afford the desired phosphorane 10 and the starting phosphonium salt 7. This 1:1 mixture of components must be separated prior to thermolysis, as appreciable amounts of the undesired phosphonium salt 7 can considerably lower the yield of alkynes $\mathbf{5}$ in the thermolysis step. At least half of the starting phosphorane $\mathbf{8}$ is lost by conversion to phosphonium salt $\mathbf{7}$. In principle, the presence of a suitable base in the reaction mixture could avoid transylidation.

This disadvantage has been overcome when the acyl halides commonly used in the preparation of the $\beta$-keto ylide do not give rise to the formation of ketenes in the presence of bases. Thus, it has been found that the addition of $\mathrm{Et}_{3} \mathrm{~N}$ ( 2 eq.) to the phosphonium salt 7 , followed by acyl chloride or anhydride ( 1 eq.) gives the $\beta$-keto ylide $\mathbf{1 0}$ in moderate to high yield (Scheme 3). 55,56
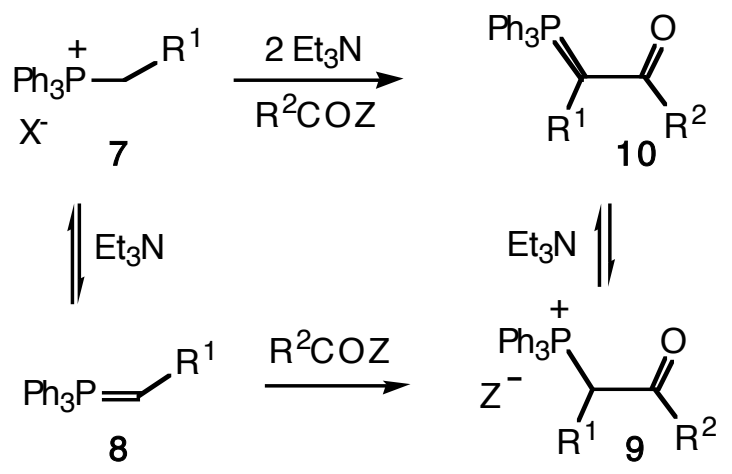

$\mathrm{Z}=\mathrm{Cl}, \mathrm{R}^{2} \mathrm{CO}_{2}$

\section{Scheme 3.}

The reaction was general for phosphonium salts with good electron-withdrawing group $\mathrm{R}^{1}$ $\left(\mathrm{R}^{1}=\mathrm{Ph}, \mathrm{SMe}, \mathrm{CO}_{2} \mathrm{R}, \mathrm{CN}\right)$ and afforded the highest yields with an ester or nitrile group (52-99\%). In this case, the conversion of phosphonium salts $\mathbf{7}$ to intermediate ylides $\mathbf{8}$ was nearly complete. Somewhat lower yields were observed when $\mathrm{R}^{1}$ was a phenyl or thiomethyl substituent. In these cases the equilibrium between $\mathbf{7}$ and $\mathbf{8}$ favors the phosphonium salt. Comparison of amine bases showed that DABCO resulted in a comparable yield of $\beta$-keto ylide 10 that with $\mathrm{Et}_{3} \mathrm{~N}$. This route was particularly attractive for large-scale synthesis of phosphoranes, since all reactions were nearly quantitative and the reagents inexpensive. For example, analytically pure ethyl 4,4,4-trifluorotetrolate has been prepared on large scale $(0.5 \mathrm{~mol})$ with $82 \%$ yield. 57,58 
General procedure for the preparation of phosphoranes. 4,4,4-Trifluoro-3-oxo-2(triphenylphosphoranylidene)butanoic acid, ethyl ester. ${ }^{55}$ A slurry of (carbethoxymethyl)triphenylphosphonium bromide $(215 \mathrm{~g}, 0.5 \mathrm{~mol})$ in $1.1 \mathrm{~L}$ of anhydrous THF was cooled in an ice-water bath and treated with $\mathrm{Et}_{3} \mathrm{~N}(150 \mathrm{~mL}, 1.1 \mathrm{~mol})$. After being stirred for $15 \mathrm{~min}$, the mixture was treated dropwise with trifluoroacetic anhydride $(78 \mathrm{~mL}, 0.55 \mathrm{~mol})$ and allowed to stir for $1 \mathrm{~h}$. The mixture was filtered, the precipitate washed three times with cold THF, and the filtrate concentrated in vacuo to afford a yellow oily residue. Trituration of the residue with $600 \mathrm{~mL}$ of water affords a crystalline product, which was collected, washed with water, and dried in vacuo to afford $192 \mathrm{~g} \mathrm{(86 \% )}$ of a cream colored solid. A small sample was recrystallized from $\mathrm{MeOH}-\mathrm{H}_{2} \mathrm{O}$ to afford a white crystalline solid.

An electrolytic method has also been described for the preparation of the bis( $\beta$-keto ylide). Thus, electrochemical oxidation of triphenylphosphine $\mathbf{6}$ in $\mathrm{CH}_{2} \mathrm{Cl}_{2}$ in the presence of 1,3dicarbonyl compounds, and 2,6-lutidinium pechlorate resulted in the formation of bis( $\beta$-keto ylide) in fair to excellent yields (30 to 100\%), in a single step.

Several developements have contributed to extend the scope and synthetic utility of the intramolecular Wittig reaction. For example, the chemistry of triphenylphosphonium 2-[(2oxo-1,2-diphenylethylidene)hydrazono]propylide has been fructuously developed on pyrolitic conditions to give various acetylenes such as, 3,4-diphenyl-6-(phenylethynyl)pyridazine, acetylenic azine and pyrazole. ${ }^{59-61}$ The use of the pyrolytic formation method of acetylenic bond was the only successful route to a series of dianthrylacetylenes, diphenanthrylacetylenes, dipyrenylacetylenes and 6,6'-dichrysenylacetylenes. ${ }^{62-64}$

Since alkynes of low nucleophilic character play a prominent role as dienophiles in cycloaddition reactions, there has been significant interest in developing efficient methods for their synthesis. For example, the synthesis of fluorinated alkynes, containing perfluoroalkyl or perfluoroaryl groups, by the pyrolysis of the corresponding $\beta$-keto ylides was of considerable importance. Thus, a large variety of phosphonium salts containing electronwithdrawing groups $\mathrm{R}^{1}\left(\mathrm{R}^{1}=\mathrm{CN}, 38,65-68 \mathrm{P}(\mathrm{O})(\mathrm{OPh})_{2},{ }^{53} \mathrm{CO}_{2} \mathrm{R},{ }^{69,70} \mathrm{CONR}_{2},{ }^{71} \mathrm{COSMe},{ }^{36}\right.$ $\mathrm{CHO},{ }^{72} \mathrm{COR},{ }^{73,74}$ alkenyl, ${ }^{75}$ aryl, ${ }^{12-17,76-78}$ aryloxy, ${ }^{79}$ 2-thienyl ${ }^{80}$ ) and perfluorinated groups $\mathrm{R}^{2}$ were prepared and thermally decomposed to give the corresponding alkynes in moderate to excellent yield.

In the Diels-Alder reaction between homophthalic anhydride and the dioxocycloalkylidenetributylphosphorane 11, the decisive step consisted in the elimination of tributylphosphine oxide $\mathbf{1 2}$ and transient formation of the cycloalkyn-2-ones $\mathbf{1 3}$ (Scheme 4). ${ }^{81}$ Thus, when a mixture of $\mathbf{1 1}$, homophthalic anhydride and $\mathrm{TMSCl}$ in toluene was heated at $150^{\circ} \mathrm{C}$ for $40 \mathrm{~h}$, the Diels-Alder adducts 14 were obtained in moderate yield. The present results supported the formation of cycloalkyn-2-ones $\mathbf{1 3}$ from the phosphoranes $\mathbf{1 1}$. 


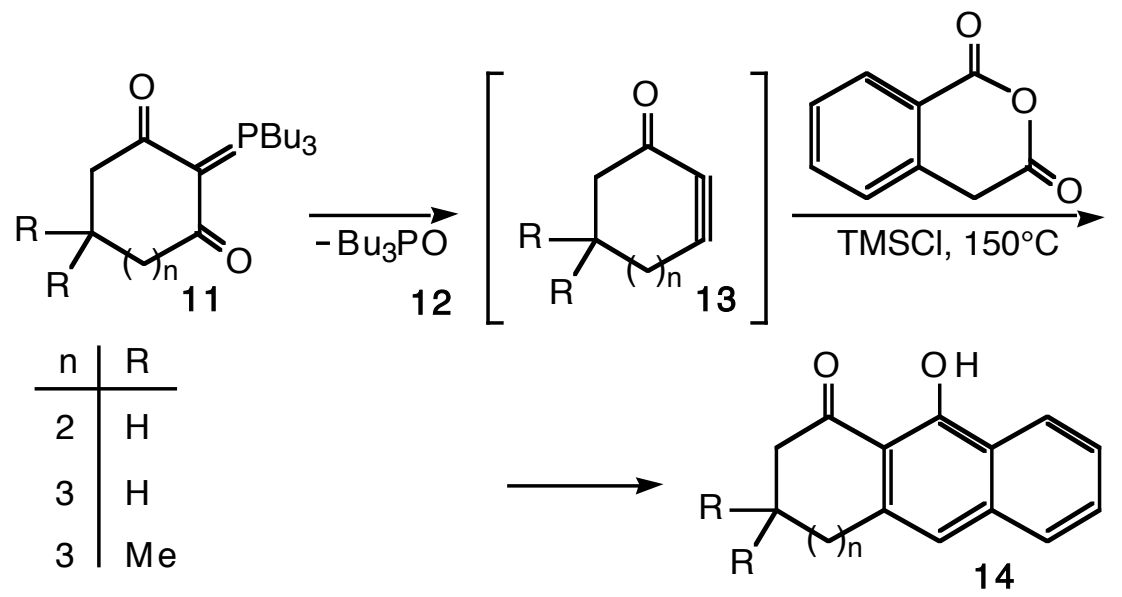

Scheme 4.

For a long period of time, however, the thermal elimination of triphenylphosphine oxide 2 from $\beta$-keto ylides $\mathbf{1 0}$, using standard pyrolysis techniques, was known for only cases in which $\mathrm{R}^{1}$ was an electron-withdrawing group. All attempts to obtain purely aliphatic or terminal alkynes from the corresponding ylides where $\mathrm{R}^{1}$ was an alkyl group or $\mathrm{H}$ failed completely. In 1983 and 1985 two innovations worthy of merit have been reported. The first one has featured the role of the temperature in the thermal decomposition of $\beta$-keto ylides $\mathbf{1 0}$, while the second has featured the use of reducing agents.

It has been reported that when the ylides $\mathbf{1 0}$ were subjected to flash vacuum pyrolysis (FVP), they sublimed unchanged at temperature up to $600^{\circ} \mathrm{C}$, but at $750^{\circ} \mathrm{C}$ and $10^{-2} \mathrm{mmHg}$ underwent complete reaction in the desired sense to give triphenylphosphine oxide $\mathbf{2}$ and the alkynes 5 where $\mathrm{R}^{1}=\mathrm{H}$ or primary alkyl and $\mathrm{R}^{2}=$ primary, secondary, tertiary, or cycloalkyl, alkenyl or phenyl. The feasibility of using this method to prepare multigram quantities of alkynes 5 by the FVP was currently demonstrated. In each example, the alkynes $\mathbf{5}$ were collected in pure form and in moderate to excellent yield (59-93\%) (Scheme 5). ${ }^{82,83}$

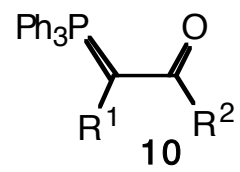

$$
\underset{-\mathrm{Ph}_{3} \mathrm{PO}}{\stackrel{\mathrm{FVP}, 750^{\circ} \mathrm{C}}{\longrightarrow}} \mathrm{R}^{1}-\underset{59-93 \%}{\mathrm{5}}=\mathrm{C}-\mathrm{R}^{2}
$$

$\mathrm{R}^{1}=\mathrm{H}, \mathrm{Me}, n-\mathrm{Pr}, n-\mathrm{Bu}$

$\mathrm{R}^{2}=\mathrm{Et}, n-\operatorname{Pr}, i-\operatorname{Pr}, n-\mathrm{Bu}, t-\mathrm{Bu}$, cyclohexyl

\section{Scheme 5.}

The clever use of the temperature as a tool is noteworthy and it has been judiciously employed to control the thermal transformation. When the $\alpha$-ethoxycarbonyl- $\beta$-oxo ylides $\mathbf{1 5}$ in which $\mathrm{R}^{2}=$ aryl, substituted aryl or heteroaryl were subjected to FVP at $500^{\circ} \mathrm{C}$, triphenylphosphine oxide $\mathbf{2}$ was again eliminated to afford the acetylenic esters $\mathbf{1 6}$. When working at the higher temperature of $750^{\circ} \mathrm{C}$ the rearrangement was accompanied by complete 
loss of the ethoxycarbonyl group to give the terminal alkynes $\mathbf{1 7}$ in moderate yields (16-66\%) (Scheme 6). ${ }^{84}$

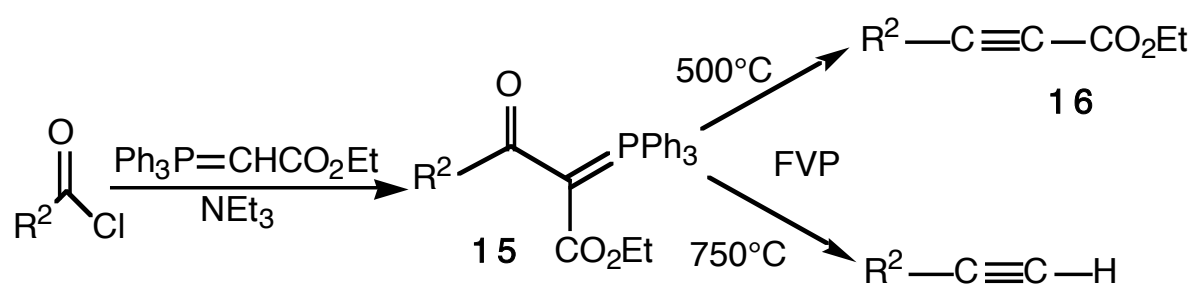

17

Scheme 6.

With the same technique, a number of functionalized alkynes were prepared in moderate yields including benzofurans via the 2-methoxyphenyl alkynes and benzothiophenes via 2methylthiophenyl alkynes, $, 85,86$ diacylalkynes, 87,88 terminal 1,3-diynes ${ }^{89}$ and unsymmetrical 1,3-diynes, ${ }^{90}$ 1,3-enynes, ${ }^{91}$ pyrroloisoindolediones, ${ }^{92}$ styrylalkynes and substituted naphtalenes, ${ }^{93,94}$ protected acetylenic amino acids. ${ }^{95}$ The limit of usefulness of the FVP technique has been reached with the pyrolysis of the tetraoxo ylides and hexaoxo bis(ylides). 96

Similarly with the pyrolysis of stabilized phosphoranes containing heteroatoms ( $\mathrm{S}, \mathrm{Se}$ ) attached to the ylide, the work has been extended to stabilized chloro- or bromophosphoranes. Pyrolysis of the halophosphoranes using a quartz tube heated to $800^{\circ} \mathrm{C}$ gives the chloro- or bromoalkynes in moderate yields. ${ }^{97}$

A variant to alkynes $\mathbf{5}$ from $\beta$-keto ylides $\mathbf{1 0}$ using reducing agents has been described. The ylide was first converted to an enol triflate ester $\mathbf{1 8}$ in high yield, then submitted to reduction with sodium amalgam in THF to give the alkyne $\mathbf{5}$ in moderate to good yield (45-80\%) along with triphenylphosphine $\mathbf{6}$ and sodium triflate (Scheme 7). ${ }^{98}$
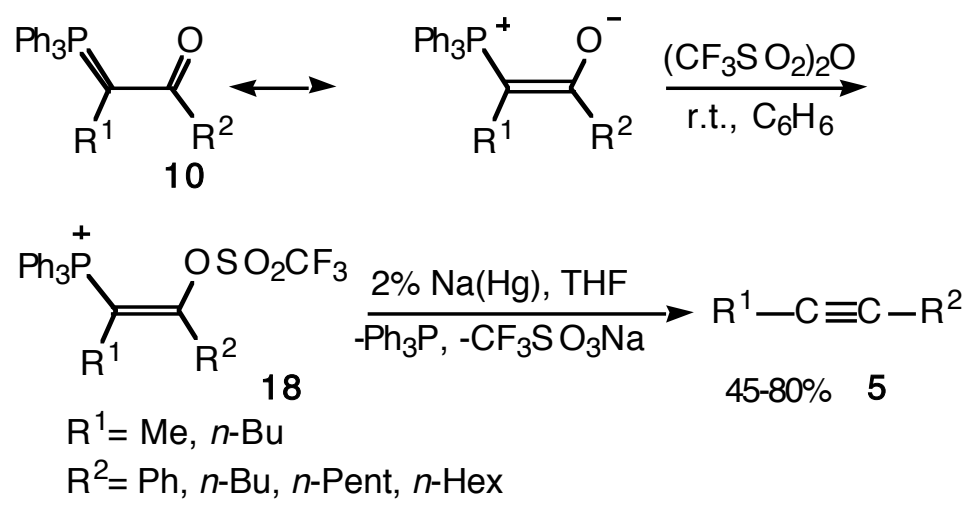

\section{Scheme 7.}

Several examples of allenic derivatives formation, using phosphorus precursors are described in the litterature. Generally, these products isomerized to produce the corresponding 
thermodynamic acetylenic compounds. The interest of the method is nevertheless limited by the availability of the starting materials. $99-104$

\subsection{Dibromomethylenetriphenylphosphorane}

In 1962 two laboratories reported independently a route to prepare the dichloro- 22a ${ }^{105}$ and dibromomethylenetriphenylphosphorane $\mathbf{2 2} \mathbf{b}^{106}$ by the reaction of triphenylphosphine $\mathbf{6}$ with the corresponding carbon tetrahalide 107,108 and a convenient one-step synthesis for gemdichloro- 23a and gem-dibromoolefins $23 \mathbf{b}$ according to a Wittig reaction. The first reaction was realized between triphenylphosphine $\mathbf{6}$, carbon tetrachloride and benzaldehyde on heating at $65^{\circ} \mathrm{C}$. It gave after work-up and distillation the gem-dichlorostyrene 23a and the dichlorotoluene in equal quantities (35\%). The competing formation of dichlorotoluene demonstrates that the dichlorotriphenylphosphorane $21(\mathrm{X}=\mathrm{Cl})$ produced in the reaction exchanges with benzaldehyde. The second reaction was realized with carbon tetrabromide and benzaldehyde in $\mathrm{CH}_{2} \mathrm{Cl}_{2}$ and gave the gem-dibromostyrene $\mathbf{2 3 b}$ in excellent yield (84\%) (Scheme 8).

The reaction between triphenylphosphine $\mathbf{6}$ and carbon tetrahalides is quite complex and can be summarized as it follows. It involves an attack by the triphenylphosphine $\mathbf{6}$ on "positive halogen", chlorine or bromine, of carbon tetrahalide leading to the intermediate 19, as depicted in Scheme 8, which evolute towards the trichloro- or tribromomethyltriphenylphosphonium adduct $\mathbf{2 0}$ which has been isolated in the chloro case. Reaction of the trichloro- or tribromomethyltriphenylphosphonium $\mathbf{2 0}$ with the second molecule of triphenylphosphine $\mathbf{6}$ generates in situ a nucleophile, the stabilized dichloro- 22a or dibromomethylides $\mathbf{2 2} \mathbf{b}$, and an electrophile, the chloro- or bromotriphenylphosphoranes 21. These results show that under mild conditions and depending on the carbon tetrahalide, considerable control of the product may be obtained (Scheme 8). ${ }^{106}$

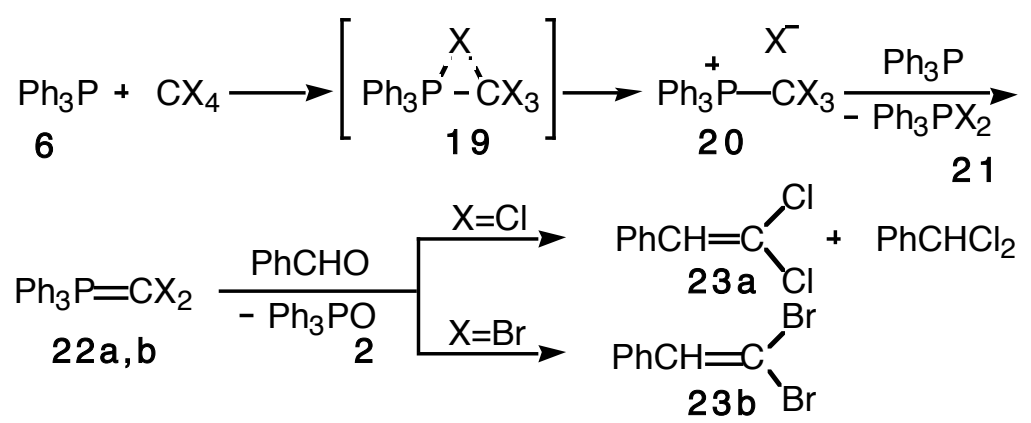

\section{Scheme 8.}

The Wittig reaction of the stabilized dichloromethylide 22a with aldehydes being sluggish, requiring high temperatures, and giving undesirable byproducts, has only a limited synthetic potential. In marked contrast, the stabilized dibromomethylide 22b, which utilizes carbon tetrabromide as source of positive halogen, has been largely used for the conversion of 
aldehydes into gem-dibromoolefines 24 (Scheme 9) by one carbon chain elongation (Wittig reaction) and has found a significant synthetic advantage in the synthesis of alkynes $\mathbf{5}$ (Ramirez-Corey reagent). ${ }^{109}$

The procedure is decomposed into two independent steps (Scheme 9). In the first step, the reaction of dibromomethylide $22 \mathbf{b}$ proceeded at $0^{\circ} \mathrm{C}$ in $\mathrm{CH}_{2} \mathrm{Cl}_{2}$ with a variety of aldehydes (aliphatic, aromatic, heteroaromatic, $\alpha, \beta$-insaturated) to give the gem-dibromoalkenes $\mathbf{2 4}$ in good to excellent yields (76 to 100\%). In the second step, the gem-dibromoalkene 24 was generally treated with $n$-BuLi109-115 (2 eq.) at low temperature in THF and more scarcely with $\mathrm{MeLi}^{116,117}$ or $t$ - $\mathrm{BuLi}^{118}$ to produce the lithium acetylide, which can be quenched with $\mathrm{MeOH}, \mathrm{H}_{2} \mathrm{O}$ or $\mathrm{D}_{2} \mathrm{O}$ to give the terminal alkyne 25 or trapped with various electrophiles $\left(\mathrm{R}^{2} \mathrm{X}\right)$ to give the corresponding derivatives 5 (Scheme 9 and Table 1).

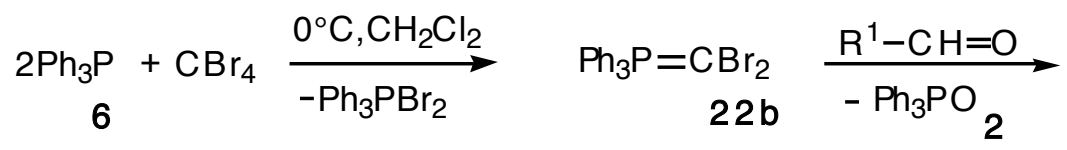

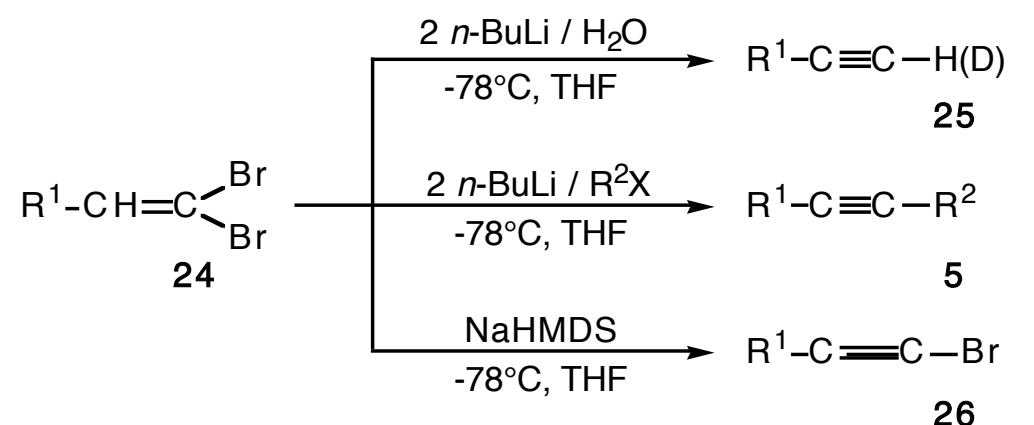

\section{Scheme 9.}

In the case of sensitive molecules the formation of alkynes from gem dibromoalkenes can be cumbersome. Since 1,2-elimination then halogen-metal exchange were the more probable steps in the formation of alkynes from gem dibromoalkenes and since trans-elimination of halogen across a double bond was a favored process, NaHMDS has proved to be the best base to give cleanly and quantitatively the bromoalkynes 26.119,120 Benzyltrimethylammonium hydroxyde in refluxing benzene has also been employed to produce bromoalkynes in the range of $35-80 \%$ yield. ${ }^{121}$ The bromine of bromoalkyne 26 was next exchanged with $n$-BuLi ( 1 eq.) to the corresponding lithiated alkyne. This two step sequence can also be performed in one pot.

Although widely used, the dibromoalkenes procedure suffers from serious drawbacks when applied to highly functionalized or sensitive aldehydes. The reaction medium is always contaminated by the dibromotriphenylphosphonium $21(\mathrm{X}=\mathrm{Br})$ generated in situ. which is known to be a strong electrophile as well as a brominating agent and therefore the probable source of side reactions. Consequently, it has been reported that simultaneous addition of the 
aldehyde and $\mathrm{Et}_{3} \mathrm{~N}$ (1 eq.) to the $\mathrm{PPh}_{3}-\mathrm{CBr}_{4}$ mixture in $\mathrm{CH}_{2} \mathrm{Cl}_{2}$ at $-60^{\circ} \mathrm{C}$ suppressed side reactions and allowed to prepare sensitive dibromoalkenes $\mathbf{2 4}$ in good to excellent yields. ${ }^{120}$ Another drawback results from the formation of triphenylphosphine oxide 2 . The separation of triphenylphosphine oxide $\mathbf{2}$ from the products is tedious especially when the reaction is realized on large scale. To overcome this difficulty an alternative route to gem-dibromoalkene 24 was developed. It is based upon the use of a combination of hexamethylphosphorous triamide (HMPT) and bromotrichloromethane, demonstrating that phosphine attack on bromine was probably involved. ${ }^{122}$ The gem-dichloroalkenes are generally obtained in good yields, but the hexamethylphosphoramide (HMPA) generated during the reaction is in turn a byproduct not easy to completely eliminate because of its retention in the final product.

Table 1

\begin{tabular}{|c|c|c|c|c|}
\hline 5 & $\mathbf{R}^{\mathbf{1}}$ & $\mathbf{R}^{2}$ & Yield (\%) & Ref. \\
\hline $\mathbf{a}$ & $n-\mathrm{C}_{7} \mathrm{H}_{15}$ & $\mathrm{H}$ & 95 & 109 \\
\hline b & $n-\mathrm{C}_{7} \mathrm{H}_{15}$ & $\mathrm{CO}_{2} \mathrm{H}$ & 87 & 109 \\
\hline c & 2-thienyl & $\mathrm{H}$ & 68 & 110 \\
\hline d & 5-methyl-2-thienyl & $\mathrm{H}$ & 68 & 110 \\
\hline e & 3-methyl-2-thienyl & $\mathrm{H}$ & 48 & 110 \\
\hline f & 3-thienyl & $\mathrm{H}$ & 56 & 110 \\
\hline $\mathbf{g}$ & & $\mathrm{H}$ & 70 & 112 \\
\hline h & & $\mathrm{H}$ & 74 & 115 \\
\hline $\mathbf{i}$ & & $\mathrm{H}$ & 65 & 113 \\
\hline $\mathbf{j}$ & & TMS & 69 & 118 \\
\hline $\mathbf{k}$ & & $\mathrm{H}$ & 75 & 116 \\
\hline 1 & & $\mathrm{H}$ & 69 & 116 \\
\hline
\end{tabular}


$\mathbf{m}$

$\mathbf{n}$

$\mathbf{0}$

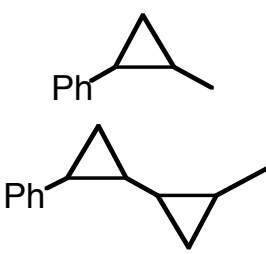

$4-\mathrm{MeO}-\mathrm{C}_{6} \mathrm{H}_{4}$
$\mathrm{D}$

53

$\mathrm{D}$

$\mathrm{CO}_{2} \mathrm{M}$
111

111

114

e

1,1-Dibromo-2-(4-methoxyphenyl)ethene 24o. ${ }^{114}$ A solution of $\mathrm{CBr}_{4}(122 \mathrm{~g}, 368 \mathrm{mmol})$ in $\mathrm{CH}_{2} \mathrm{Cl}_{2}(500 \mathrm{~mL})$ under $\mathrm{N}_{2}$ at $0^{\circ} \mathrm{C}$ was treated with $\mathrm{PPh}_{3}(193 \mathrm{~g}, 736 \mathrm{mmol})$ and stirred $1 \mathrm{~h}$ at $0^{\circ} \mathrm{C}$. The mixture was treated with $p$-anisaldehyde $(25 \mathrm{~g}, 184 \mathrm{mmol})$ stirred $1 \mathrm{~h}$ at $0^{\circ} \mathrm{C}$ and quenched with $\mathrm{H}_{2} \mathrm{O}(100 \mathrm{~mL})$. The organics were washed with brine $(100 \mathrm{~mL})$, dried $\left(\mathrm{MgSO}_{4}\right)$ and concentrated in vacuo. The residue was poured into hexane (3 L) and the supernatant was collected. The residue was redissolved in $\mathrm{CH}_{2} \mathrm{Cl}_{2}(200 \mathrm{~mL})$ and poured into hexane $(3 \mathrm{~L})$. The supernatant was collected and this process repeated once more. The combined supernatant were passed through silica gel $(150 \mathrm{~g})$ and the eluent was concentrated to afford the title compound; yield: $40 \mathrm{~g}$ $(80 \%)$.

Methyl 3-(4-Methoxyphenyl)propiolate 5o. ${ }^{114}$ A solution of 1,1-dibromo-2-(4-methoxyphenyl)ethene (30 g, $103 \mathrm{mmol})$ in anhydrous THF $(350 \mathrm{~mL})$ under $\mathrm{N}_{2}$ at $-78^{\circ} \mathrm{C}$ was treated slowly dropwise with $n$-BuLi $(141 \mathrm{~mL}$, $226 \mathrm{mmol}, 1.6 \mathrm{M}$ ) and stirred $30 \mathrm{~min}$ at $-78^{\circ} \mathrm{C}$ and $30 \mathrm{~min}$ at $0^{\circ} \mathrm{C}$. The mixture was quenched with methyl chloroformate $(11.6 \mathrm{~mL}, 150 \mathrm{mmol})$ at $-78^{\circ} \mathrm{C}$ and warmed to $0^{\circ} \mathrm{C}$ for $1 \mathrm{~h}$. The mixture was diluted with $1: 1$ sat. $\mathrm{NaHCO}_{3} / \mathrm{NH}_{4} \mathrm{Cl}(124 \mathrm{~mL})$ and the aqueous layer was extracted with $\mathrm{Et}_{2} \mathrm{O}(125 \mathrm{~mL})$. The combined organics were dried $\left(\mathrm{MgSO}_{4}\right)$ and concentrated in vacuo. The oil was chromatographed over silica gel $(500 \mathrm{~g})$, eluting with $10 \% \mathrm{EtOAc/hexane} \mathrm{to} \mathrm{give} 16.7 \mathrm{~g}(85 \%)$ of the title compound.

2-(2,2-Dibromoethenyl)thiophene 24c. ${ }^{110}$ Triphenylphosphine (100 mmol, $\left.26.2 \mathrm{~g}\right)$ and $\mathrm{CBr}_{4}(50 \mathrm{mmol}, 16.6$ g) were placed in a well-dried, $500 \mathrm{~mL}$ round-bottomed flask equipped with a magnetic stirrer and a gas inlet. Anhydrous $\mathrm{CH}_{2} \mathrm{Cl}_{2}(100 \mathrm{~mL})$ was added under nitrogen, the mixture was stirred at $0^{\circ} \mathrm{C}$ (ice bath) for $5 \mathrm{~min}$, and 2-thiophenecarboxaldehyde (40 mmol, $4.48 \mathrm{~g}$ ) was added. After stirring for $1 \mathrm{~h}$ at r.t. under nitrogen, the reaction mixture was extracted with pentane $(4 \mathrm{vol})$ according to the original report. Chromatography on silica gel 60-200 mesh (10 g/g; eluent: hexane- $\left.\mathrm{CHCl}_{3}, 9: 1\right)$ yielded $10.3 \mathrm{~g}(96 \%)$ of the title compound.

2-Ethynylthiophene 5c. ${ }^{110}$ A solution of 2-(2,2-Dibromoethenyl)thiophene (30 mmol, $\left.8.04 \mathrm{~g}\right)$ in $300 \mathrm{~mL}$ of dry $\mathrm{Et}_{2} \mathrm{O}$ was cooled to $-78^{\circ} \mathrm{C}$ under nitrogen, and $n$-BuLi $(66 \mathrm{mmol})$ was added dropwise. After stirring for $1 \mathrm{~h}$ at $78^{\circ} \mathrm{C}$, the mixture was allowed to warm to r.t., and was stirred for $1 \mathrm{~h}$ longer. The mixture was treated as usual and finally distilled to produce $2.2 \mathrm{~g}(68 \%)$ of the title compound.

\subsection{Halomethylenetriphenylphosphorane}

All of the halomethyltriphenylphosphonium salts are known. Only those containing chlorine, bromine and iodine are used in alkynes synthesis, but the most common and perhaps most generally useful reagents that have been developed for the synthesis of alkynes were the chloro- and bromomethyltriphenylphosphonium salts.

There are a number of synthetic procedures which allow the preparation of halomethyltriphenylphosphonium salts. However, those using chlorocarbene ${ }^{123-125}$ or triphenylphosphine 6 in the presence of a controlled amount of water ${ }^{126}$ are somewhat complicated. Perhaps the most convenient transformation for the synthesis of these precursors involves the quaternarisation reaction of triphenylphosphine 6 with methylene dihalides (Scheme 10). For example, using chloroiodomethane as electrophile, the 
chloromethyltriphenylphosphonium iodide $\mathbf{2 7}$ was obtained upon its reaction with triphenylphosphine $\mathbf{6}$ and isolated in $70 \%$ yield. The reaction has been studied in several solvents and at different temperatures (Table 2). ${ }^{127}$ When the reaction was carried out in THF, the salt 27 began to precipitate as white solid in the course of the initial $0.5 \mathrm{~h}$ heating at reflux. The phosphonium salt $\mathbf{2 7}$ amounted to a $60 \%$ isolated yield after a $8 \mathrm{~h}$ reaction, and to a $70 \%$ yield after $20 \mathrm{~h}$.

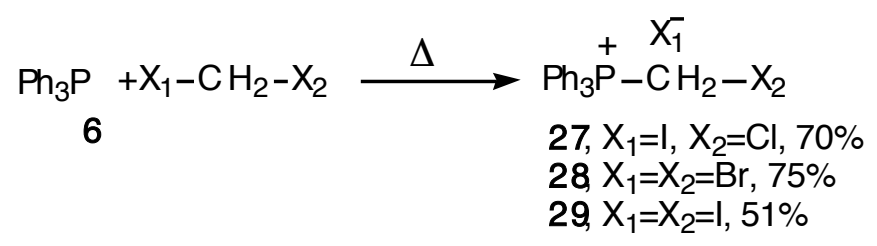

Scheme 10.

Table $2^{127}$

\begin{tabular}{ccccccc}
\hline $\begin{array}{c}\mathbf{P h}_{3} \mathbf{P} \\
(\mathbf{m m o l})\end{array}$ & $\begin{array}{c}\mathbf{I C H}_{2} \mathbf{C l} \\
(\mathbf{m m o l})\end{array}$ & Solvent & $\begin{array}{c}\text { Solvent } \\
(\mathbf{m L})\end{array}$ & $\begin{array}{c}\text { Temp } \\
\left({ }^{\circ} \mathbf{C}\right)\end{array}$ & $\begin{array}{c}\text { Time } \\
(\mathbf{h})\end{array}$ & $\begin{array}{c}\text { Yield } \\
(\boldsymbol{\%})\end{array}$ \\
\hline 10 & 12 & $\mathrm{Et}_{2} \mathrm{O}$ & 20 & $20-25$ & 20 & 8 \\
10 & 11 & $\mathrm{THF}$ & 10 & 50 & 20 & 34 \\
120 & 150 & $\mathrm{THF}$ & 150 & 67 & 8 & 60 \\
120 & 150 & $\mathrm{THF}$ & 150 & 67 & 20 & 70 \\
50 & 70 & $t$-BuOH & 50 & 83 & 6 & 72 \\
100 & 110 & $\mathrm{DMF}$ & 120 & 100 & 8 & 0 \\
\hline
\end{tabular}

The same quaternarization reaction has been applied to the preparation of bromomethyltriphenylphosphonium bromide ${ }^{128} \mathbf{2 8}$ and iodomethyltriphenylphosphonium iodide ${ }^{129} 29$ with 75 and 51\% yield respectively, by reaction between triphenylphosphine 6 and the corresponding methylene dihalides.

Preparation of chloromethyltriphenylphosphonium iodide $27.1^{127}$ Triphenylphosphine (120 mmol) was dissolved in $150 \mathrm{~mL}$ of THF in a $500 \mathrm{~mL}$ round-bottomed flask equipped with a magnetic stirrer, a pressureequilibrating dropping funnel, a thermometer, and a Widmer reflux condenser topped with a nitrogen inlet tube. The mixture was stirred rapidly while chloroiodomethane $(150 \mathrm{mmol})$ was added. The flask was immersed in an oil bath and the mixture was heated at reflux for ca. $20 \mathrm{~h}$. The resulting white precipitate was filtered, and the solids were washed thoroughly with $5 \times 50 \mathrm{~mL}$ of THF in a nitogen atmosphere. The phosphonium salt was dried in vacuo at $50-60^{\circ} \mathrm{C}$ for several hours; it was stored in a Schlenk tube under nitogen. The dried product weighed $37 \mathrm{~g}$ (70\% yield based on triphenylphosphine).

Preparation of bromomethyltriphenylphosphonium bromide $28 .^{128}$ A solution of $60.0 \mathrm{~g}(0.228$ mole $)$ of triphenylphosphine and $89.2 \mathrm{~g}(0.460$ mole $)$ of methylene bromide in $500 \mathrm{~mL}$ of dry toluene was refluxed for 24 h. The mixture was cooled to $0^{\circ} \mathrm{C}$ and the salt crystals were collected by filtration and washed with toluene. The filtrate was refluxed for another $24 \mathrm{~h}$, and a second crop of crystals was collected. The combined solids were dried in vacuo and weighed $77.4 \mathrm{~g} .(75 \%)$.

Preparation of iodomethyltriphenylphosphonium iodide 29.129 A solution of 0.115 mole of triphenylphosphine and 0.15 mole of methylene iodide in $30 \mathrm{~mL}$ of benzene in a flask equipped with a reflux 
condenser and a drying tube and protected from the light by an aluminium foil was heated at $45-50^{\circ} \mathrm{C}$. After a few minutes the solution became cloudy and small crystals formed. After $4 \mathrm{~h} 18.2 \mathrm{~g}$ of white crystals were isolated. A second yield of $12.6 \mathrm{~g}$ was isolated after $12 \mathrm{~h}$ more at $45^{\circ} \mathrm{C}$. The product was not very soluble in $\mathrm{MeOH}$, isopropyl alcohol, acetone or $\mathrm{CH}_{2} \mathrm{Cl}_{2}$. It was washed thoroughly with benzene and dried in vacuo to give material of m.p. $228-230^{\circ} \mathrm{C}(\mathrm{dec})$ (turns yellow at about $\left.200^{\circ} \mathrm{C}\right)(51 \%)$.

An alternate route to chloro- or bromomethyltriphenylphosphonium salts utilizes as precursors the readily available hydroxymethyltriphenylphosphonium chloride or bromide $\mathbf{3 0}$ prepared from triphenylphosphine 6, paraformaldehyde and the corresponding anhydrous halohydric acid (Scheme 11). The hydroxymethyltriphenylphosphoniums salts 30 undergo nucleophilic chlorination with thionyl chloride in $\mathrm{CH}_{2} \mathrm{Cl}_{2}$, to give the chloromethyltriphenylphosphonium chloride 31 with $63 \%$ yield, ${ }^{130-135}$ or bromination with phosphorus tribromide to give the bromomethyltriphenylphosphonium bromide $\mathbf{2 8}$ with $60 \%$ yield. ${ }^{129}$

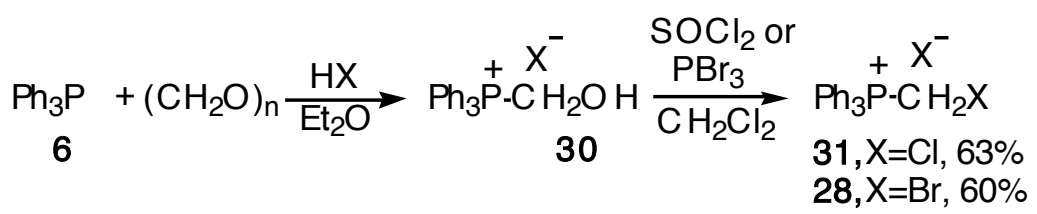

\section{Scheme 11.}

Preparation of hydroxymethyltriphenylphosphonium bromide $\mathbf{3 0}$ (X=Br). ${ }^{129}$ Triphenylphosphine $(0.2$ mole) was added in portions to a solution of 0.3 mole of $35 \%$ formalin and $45 \mathrm{~mL}(0.4$ mole) of $48 \%$ hydrobromic acid. The mixture was stirred; after a few minutes the hydroxymethyl-phosphonium salt began to precipitate. The mixture was allowed to stand for $2 \mathrm{~h}$, and the crystalline product was filtered and washed with acetone to give $51.5 \mathrm{~g}(69 \%)$, m.p. $202-204^{\circ} \mathrm{C}$. Recrystallization from isopropyl alcohol.

Preparation of Bromomethyltriphenylphosphonium bromide $28 .^{129}$ A mixture of 0.10 mole of hydroxymethyltriphenylphosphonium bromide and 0.0363 mole of phosphorus tribromide in $100 \mathrm{~mL}$ of benzene was heated at reflux for $23 \mathrm{~h}$ with stirring. After this time the solution was dark orange and an orange solid was present. The mixture was cooled to room temperature and $80 \mathrm{~mL}$ of $\mathrm{MeOH}$ was added. The solvent was removed at reduced pressure and the residue treated with $100 \mathrm{~mL}$ of $\mathrm{H}_{2} \mathrm{O}$ to extract the phosphonium salt. The aqueous extracts were saturated with solid potassium bromide and extracted with $\mathrm{CHCl}_{3}$. The phosphonium salts were crystallized from the hot, concentrated $\mathrm{CHCl}_{3}$ solution by addition of AcOEt. This procedure gave $26.3 \mathrm{~g}$ of product, m.p. $234-239^{\circ} \mathrm{C}$; recrystallization from $\mathrm{MeOH}-\mathrm{AcOEt}$ gave $25.7 \mathrm{~g}(60 \%)$ of product, 237 $240^{\circ} \mathrm{C}$

All of the monohalomethylides are known. The chloromethylenetriphenylphosphorane 32 was frequently utilized for the conversion of aldehydes into homologous alkynes via the corresponding chloroolefins. This ylide $\mathbf{3 2}$ was prepared from the chloromethyltriphenylphosphonium halides using, $\mathrm{PhLi}$ in $\mathrm{Et}_{2} \mathrm{O}$ at room temperature, ${ }^{123,135}$ $n$-BuLi in DME 132 or $\mathrm{THF}^{132,134}$ at $-70^{\circ} \mathrm{C}$, lithium piperidide in $\mathrm{Et}_{2} \mathrm{O}, 136,137 \mathrm{NaHMDS}$ in THF at $0^{\circ} \mathrm{C}^{138}$ or $t$-BuOK in $t$-BuOH at room temperature. ${ }^{127,139}$ In contrast to the bromoand iodomethyltriphenylphosphonium halides, the chloromethyltriphenylphosphonium halides do not undergo halogen-metal exchange and only hydrogen-metal exchange was observed, thus allowing the use of a large choice of metallation agent. Both hydrogen-metal and halogen-metal exchange with the bromide and solely halogen-metal exchange in the case of the iodoethylene were observed. Aldehydes undergo the Wittig reaction with the 
chloromethylenetriphenylphosphorane 32 leading to a mixture of $E$ - and $Z$-isomers generally in good to excellent yields (79-96\%). The dehydrohalogenation of the chloroolefins was next effected by treatment in situ with an excess of base or in a separate operation. Several procedures have been developed which include the use of either the same base, PhLi in $\mathrm{Et}_{2} \mathrm{O},{ }^{140-145} n$-BuLi at $-78^{\circ} \mathrm{C},{ }^{146-148}$ or two different bases, $n$-BuLi / MeLi at room temperature, ${ }^{149,150} n$-BuLi / LDA at $-70^{\circ} \mathrm{C}^{151}$ or $0^{\circ} \mathrm{C}^{152}$ (Scheme 12), $n$-BuLi-THF / $t$ BuOK-DMSO, ${ }^{315}$ lithium piperidide ${ }^{153}$ and $\mathrm{NaNH}_{2} / \mathrm{NH}_{3}$ at low temperature, ${ }^{153} \mathrm{NaHMDS}$ / $n$-BuLi in $\mathrm{THF}^{138}$ or $t$-BuOK in $t$-BuOH at room temperature. ${ }^{127,139,154}$ The alkynes were isolated in excellent yields (86-95\%).

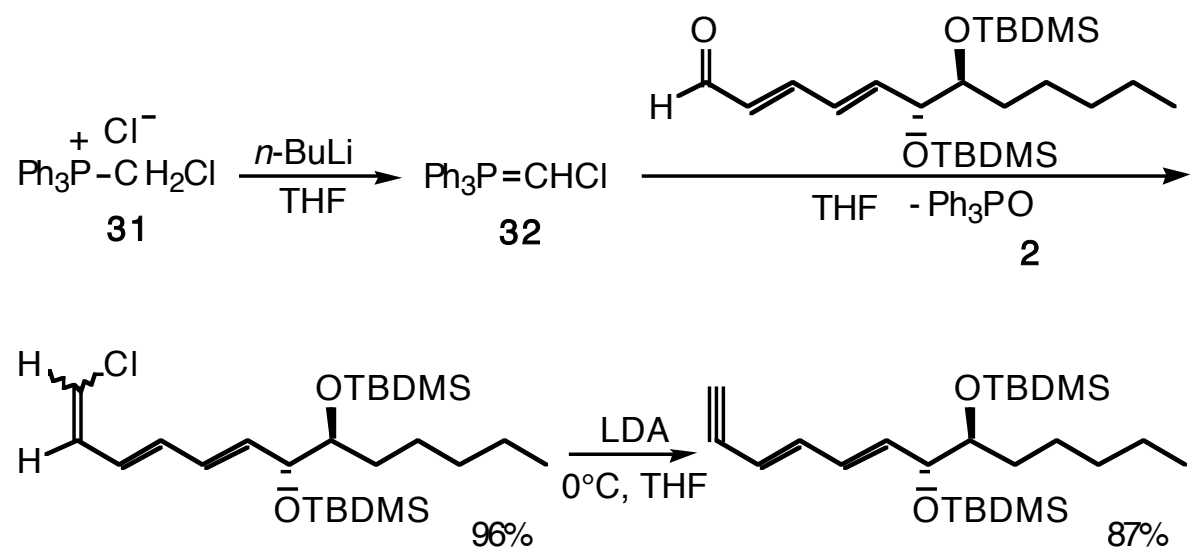

Scheme 12.

cis-1-cyclohexyl-2-trimethylsilylethynylethylene. ${ }^{149}$ To a cooled $\left(-78^{\circ} \mathrm{C}\right)$ suspension of chloromethyltriphenylphosphonium chloride $(1.30 \mathrm{~g}, 3.78 \mathrm{mmol})$ in $10 \mathrm{~mL}$ of THF was added $n$-BuLi (3.70 mmol) in hexane. After $0.75 \mathrm{~h}$ at $-78^{\circ} \mathrm{C}$, the cis-aldehyde $(167 \mathrm{mg}, 1.21 \mathrm{mmol})$ was added in $1 \mathrm{~mL}$ of THF. The cooling bath was removed and replaced by ice water. After $3 \mathrm{~h}$ the product was isolated by pentane extraction. Filtration through a short column of acidic alumina and evaporation distillation (b.p. $100^{\circ} \mathrm{C}$ (bath) and $0.7 \mathrm{~mm}$ ) afforded $173 \mathrm{mg}$ (83\% overall) of the chlorodiene.

To a cooled $\left(0^{\circ} \mathrm{C}\right)$ solution of chlorodiene $(60 \mathrm{mg}, 0.35 \mathrm{mmol})$ in $10 \mathrm{~mL}$ of dry THF was added $3 \mathrm{~mL}$ of $1.6 \mathrm{M}$ methyllithium. The cooling bath was removed, and the solution was stirred at room temperature for $12 \mathrm{~h}$. Addition of $\mathrm{TMSCl}(0.5 \mathrm{~mL})$ and isolation of the product by pentane extraction afforded after evaporative distillation $\left(130^{\circ} \mathrm{C}\right.$ (bath) at $\left.0.7 \mathrm{~mm}\right) 53 \mathrm{mg}$ of the desired cis-enyne.

The chloromethyltriphenylphosphonium halides are well suited to the one-pot conversion of aldehydes into homologous alkynes, especially when $t$-BuOK in $t$ - $\mathrm{BuOH}$ was used. Formation from 27 of the chloromethylenetriphenylphosphorane 32 was detected by the appearance at room temperature of a characteristic orange-red slurry. Addition of an aldehyde leads to conversion into the corresponding chloroolefines as a mixture of $E$ - and $Z$ - isomers in reasonable yields (45-81\%). According to the amount of base and the reaction time the course of the reaction can be modified to give either the chloroolefines or the alkynes. Thus, in the presence of an excess of $t$ - $\mathrm{BuOK}$ (2.5 eq.) in refluxing $t$ - $\mathrm{BuOH}$, both isomers issued of aromatic aldehydes are dehydrochlorinated to give phenylacetylene (Scheme 13). ${ }^{127}$ 


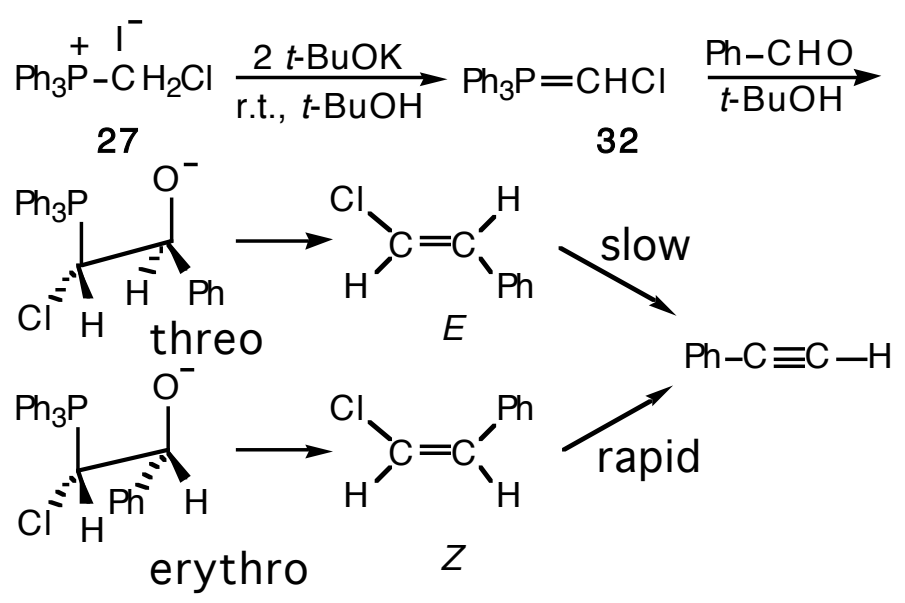

\section{Scheme 13.}

The chloromethylenetriphenylphosphorane $\mathbf{3 2}$ has also been reacted with $\alpha, \beta$-unsaturated ketones to give the corresponding chloroolefines. On treatement with $n$-BuLi, the chloroolefines gave carbenoids, stable at low temperature, which underwent on warming the Fritsch-Buttenberg-Wiechell rearrangement to give the isomeric enyne. ${ }^{155}$

Formation of the bromomethylenetriphenylphosphorane $\mathbf{3 3}$ from bromomethyltriphenylphosphonium bromide $\mathbf{2 8}$ was of peculiar interest because it was directly involved in the one-pot conversion of aldehydes into the homologous alkynes without the isolation of intermediates. However, there arises the critical issue of regioselectivity of attack to the $\alpha$-proton or $\alpha$-halogen by the base. Thus, when PhLi was employed to generate the ylide, not only was benzene recovered, but a large amount of bromobenzene was produced.129 With either $p$-tolyllithium or $p$-chlorophenyllithium appreciable quantities of $p$-bromotoluene and $p$-bromochlorobenzene were respectively obtained. 128 These observations demonstrate that initial bromine abstraction by the base competes favorably with proton abstraction to give a mixture of methylene- $\mathbf{3 4}$ and bromomethylene- 33 triphenylphosphorane. The use of Grignard reagents, sodium hydride or sodium methoxide generally gave little or no ylide, and lithium piperidide, ${ }^{136,137}$ which has been claimed to circumvent the problem of bromine exchange, did not improve the yields (Scheme 14). The use of NaH in DME containing a little DMSO has been reported in the conversion of nickel meso-formyloctaethylporphyrin into meso-ethynyl compound. 156,157

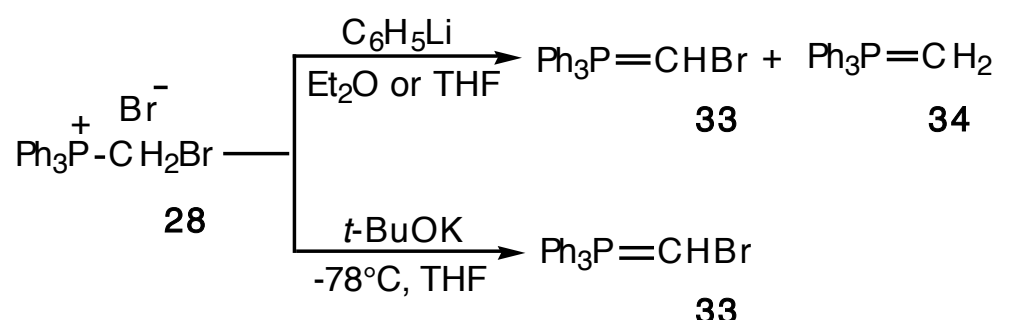

\section{Scheme 14.}


The preferred base for the one-pot synthesis of alkynes from aldehydes using $\mathbf{2 8}$ was found to be $t$-BuOK in THF. ${ }^{158-163}$ The use of $t$-BuOK in THF at low temperature increases regiospecificity, reaction rate and yield. Thus, when a suspension of the bromomethyltriphenylphosphonium bromide $\mathbf{2 8}$ in dry THF was treated with an excess of $t$ $\mathrm{BuOK}$ at low temperature, the yellow colored ylide $\mathbf{3 3}$ was formed then allowed to react with aldehydes (aliphatic, aromatic and $\alpha, \beta$-unsaturated) to produce directly the desired alkynes $\mathbf{2 5}$ in moderate to excellent yields (36-100\%) (Table 3). Unfortunately, the alkynes 25 were contaminated with the bromoolefins which are entirely $E$-isomers. In agreement with the Wittig reaction using nonstabilized ylides, the olefination reactions with aldehydes are not highly stereoselective, and mixtures of $Z$-and $E$-isomers are regularly obtained with a $Z$ dominance. In the formation of alkynes via dehydrobromination of the bromoolefins with a base, the $Z$-isomer reacting much faster than the $E$-counterpart is more rapidly consumed than the $E$-isomer which frequently contaminates the alkyne. The presence of unreacted bromoolefins being the major drawback, it is crucial to maintain the reaction mixture for an extended period of time to improve the yields of alkynes 25.158-163 
Table 3

\begin{tabular}{|c|c|c|c|}
\hline 25 & $\mathbf{R}^{1}$ & Yield (\%) & Ref. \\
\hline $\mathbf{a}$ & Phenyl & 58 & 158 \\
\hline $\mathbf{b}$ & $2-\mathrm{MeO}-\mathrm{C}_{6} \mathrm{H}_{4}$ & 65 & 160 \\
\hline c & $3-\mathrm{MeO}-\mathrm{C}_{6} \mathrm{H}_{4}$ & 54 & 158 \\
\hline d & $4-\mathrm{MeO}-\mathrm{C}_{6} \mathrm{H}_{4}$ & 79 & 158 \\
\hline $\mathbf{e}$ & $4-\mathrm{Cl}-\mathrm{C}_{6} \mathrm{H}_{4}$ & 39 & 158 \\
\hline $\mathbf{f}$ & $4-\mathrm{THPO}-\mathrm{C}_{6} \mathrm{H}_{4}$ & 74 & 162 \\
\hline g & 4-allylO- $\mathrm{C}_{6} \mathrm{H}_{4}$ & 60 & 161 \\
\hline $\mathbf{h}$ & $3,4-(\mathrm{OCH} 2 \mathrm{O})-\mathrm{C}_{6} \mathrm{H}_{4}$ & 38 & 158 \\
\hline $\mathbf{i}$ & $4-\mathrm{MeO}-\mathrm{C}_{6} \mathrm{H}_{4}$ & 80 & 158 \\
\hline $\mathbf{j}$ & 1-naphthyl & 77 & 158 \\
\hline $\mathbf{k}$ & & 100 & 158 \\
\hline 1 & & 65 & 159 \\
\hline $\mathbf{m}$ & & 40 & 158 \\
\hline $\mathbf{n}$ & & 45 & 158 \\
\hline $\mathbf{0}$ & & 36 & 158 \\
\hline $\mathbf{p}$ & & 62 & 158 \\
\hline
\end{tabular}

4-Tetrahydropyranyloxyphenacylacetylene 25f. ${ }^{162}$ To a suspension of bromomethyltriphenyl-phosphonium bromide $(21.3 \mathrm{~g}, 48.8 \mathrm{mmol})$ in anhydrous THF $(200 \mathrm{~mL})$ cooled to $-78^{\circ} \mathrm{C}$ was added $t$-BuOK $(10.9 \mathrm{~g}, 97.6$ $\mathrm{mmol}$ ) portionwise. The mixture was stirred at that temperature for $30 \mathrm{~min}$. To this ylide solution was added a solution of 4-tetrahydropyranyloxybenzaldehyde $(3.35 \mathrm{~g}, 16.3 \mathrm{mmol})$ in anhydrous THF $(80 \mathrm{~mL})$ over a period of $20 \mathrm{~min}$. The resulting mixture was stirred at $-78^{\circ} \mathrm{C}$ for $2 \mathrm{~h}$, and then warmed up to room temperature, being stirred for $2 \mathrm{~h}$ at room temperature. After dilution with $\mathrm{H}_{2} \mathrm{O}(200 \mathrm{~mL})$, the product was extracted with Et $\mathrm{E}_{2} \mathrm{O}$. The combined ethereal extracts were washed with water and brine, successively, dried over $\mathrm{MgSO}_{4}$, and concentrated in vacuo. Column chromatography on silica gel (YMC gel, $300 \mathrm{~g}, \mathrm{CH}_{2} \mathrm{Cl}_{2} / n$-hexane $2 / 3$ ) afforded the desired crystalline phenylacetylene $(2.42 \mathrm{~g}, 74 \%$ yield $)$.

General procedure for the synthesis of phenolic acetylenes 25g. 161 Potassium $t$-butoxide $(1 \mathrm{~g}, 25.6 \mathrm{mmol})$ was suspended in dry THF and the bromomethyltriphenyl-phosphonium bromide ( $5.45 \mathrm{~g}, 12.5 \mathrm{mmol})$ added to 
it at $-78^{\circ} \mathrm{C}$ under $\mathrm{N}_{2}$. The creamy mixture was stirred for $1 \mathrm{~h}$ before the aldehyde $(10 \mathrm{mmol})$ was slowly added to it. After $4 \mathrm{~h}$ at $-78^{\circ} \mathrm{C}$, the mixture was stirred at $25^{\circ} \mathrm{C}$ for $16 \mathrm{~h}$ and quenched with saturated $\mathrm{NH}_{4} \mathrm{Cl}$. After acidification with $2 \mathrm{M} \mathrm{HCl}$ and extraction with $\mathrm{Et}_{2} \mathrm{O}$, the $\mathrm{Ph}_{3} \mathrm{PO}$, which precipitated on concentrating the $\mathrm{Et}_{2} \mathrm{O}$, was filtered off. The residue afforded pure acetylene after column chromatography.

The iodomethylenetriphenylphosphorane $\mathbf{3 5}$ is the most recently prepared of the halomethylides. It has been effectively obtained from the iodomethyltriphenylphosphonium iodide 29 using NaHMDS as base. ${ }^{164,165}$ The possibility of making this phosphorane has been examinated using a variety of solvents and bases ( $t$-BuOK, LDA, LiHMDS, NaHMDS, lithium piperidide) and it has been found that the iodomethylenetriphenylphosphorane can be made readily by the use of NaHMDS in THF at room temperature. ${ }^{164}$ Effectively, the iodomethyltriphenylphosphonium salts undergo halogen-metal exchange as well as proton abstraction by the alkyl- or aryllithiums, and the former mode of attack is greatly favored in that case. ${ }^{129}$ It is especially gratifying that the reaction of this phosphorane $\mathbf{3 5}$ with a variety of aldehydes leads stereoselectively to the $Z$-isomers. The stereoselectivity of the iodoolefins depending on the reaction temperature, the ratio of $Z / E$-isomer increases markedly at low temperature. In a multi-step synthesis of 9-demethyl-5,6-dihydroretinol, an application from the area of vitamin A synthesis, the iodomethylenation of aldehyde 36 in the presence of $t$ $\mathrm{BuOK}$ in excess in THF at low temperature has been reported to afford the homologous alkyne 37 with $88 \%$ yield (Scheme 15). ${ }^{166}$

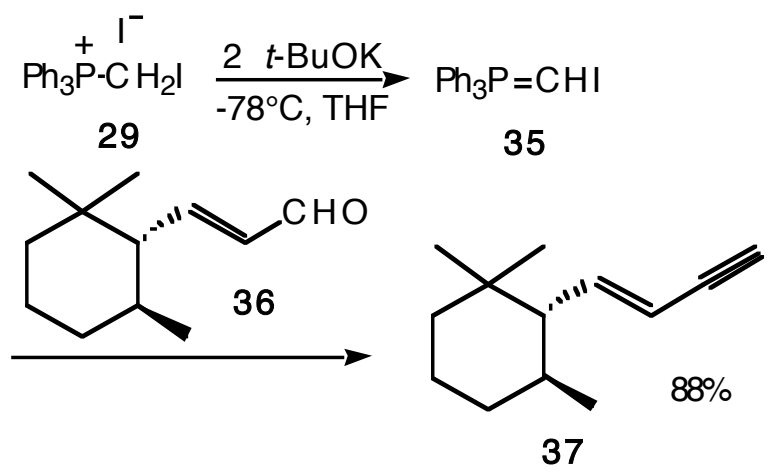

\section{Scheme 15.}

(2S,3S)-2-[(E)-But-1'-en-3'-yn-1'-yl]-1,1,3-trimethylcyclohexane 37.166 $t$-BuOK (1.06 g, 9.45 mmol) was added to a suspension of iodomethyltriphenylphosphonium iodide $(2.51 \mathrm{~g}, 4.74 \mathrm{mmol})$ in $\mathrm{THF}(90 \mathrm{~mL})$ at r.t. The resulting solution was cooled to $-78^{\circ} \mathrm{C}$, and then a solution of aldehyde $36(0.85 \mathrm{~g}, 4.74 \mathrm{mmol})$ in THF (10 $\mathrm{mL}$ ) was added. After stirring at $-78^{\circ} \mathrm{C}$ for $2 \mathrm{~h}$, the solution was allowed to reach room temperature, diluted with hexane and washed with brine and water. The organic layer was dried over $\mathrm{MgSO}_{4}$ and the solvent was removed under vacuum. Chromatography $\left(\mathrm{SiO}_{2}, 90 / 10\right.$ hexane/ether) afforded $0.73 \mathrm{~g}(88 \%)$ of the title compound.

Owing to all these investigations a number of factors which may affect the regioselectivity of the attack by bases have been recognized. Especially it has been found that attack at bromine was more likely than at chlorine, and that halogen attack was more likely using bases in the order $t$-BuLi $>n$-BuLi $>$ PhLi $>$ lithium piperidide. The difficulties which attend the preparation of alkynes involving $\alpha$-halo ylides being closely related to the choice of the 
precursor and deprotonating agent, these observations have significantly extended the knowledge on the role of bases and the scope of these reagents.

\subsection{Iodomethyltriphenylphosphoniumphenacylide}

Phosphonium ylides have been shown to react with a variety of halogenating agents, providing direct access to $\alpha$-halo ylides. However, halogenations have essentially been investigated with stabilized ylides, usually $\beta$-keto or $\beta$-carbalkoxy ylides. Generally, reaction of carboalkoxymethylenetriphenylphosphorane with chlorine, bromine or iodine leads to mixtures of desired halo ylides and the conjugate acid of the starting ylide. ${ }^{167-169}$ This resulted of a deprotonation or transylidation of the generated halo ylide by the more basic starting ylide. Thus, there is loss of one-half of the starting ylide. For example, bromination of stabilized phosphonium ylides proceeds as described to give a $77 \%$ yield of one-half

equivalent of $\alpha$-bromo ylide. ${ }^{167,169,170}$ However, the (ethoxycarbonyliodomethyl)triphenylphosphonium iodide 39 was obtained in high yield, $80 \%$, from commercial (ethoxycarbonylmethyl)triphenylphosphonium bromide $\mathbf{3 8}$ by direct iodination in $\mathrm{MeOH}$ in the presence of potassium carbonate (Scheme 16). ${ }^{171}$ An interesting variation using treatment of the $\alpha$-bromo ylide with methanolic potassium iodide for the direct preparation of the $\alpha$-iodo ylide in high yield (80-84\%) has also been reported. ${ }^{167}$

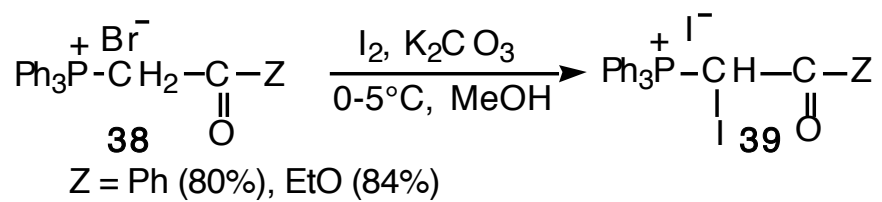

\section{Scheme 16.}

Together with its innovations, the $\alpha$-iodo ylides $\mathbf{4 0}$ appear as useful reagents for the two carbon chain elongation of aromatic aldehydes to propiolic esters, acids and benzoylalkynes 41 (Scheme 17). 171,172 The process is divided into two independent steps, iodination of the ylide in the first one, and Wittig reaction to a vinyliodide followed by elimination of $\mathrm{HI}$ in the second one. The reaction works well with aromatic and $\alpha, \beta$-unsaturated aldehydes, but no reaction was observed with aliphatic aldehydes. ${ }^{171,172}$ Halogenation of ylides has also been realized with reagents such as phenyliodide dichloride. ${ }^{167,173,174}$
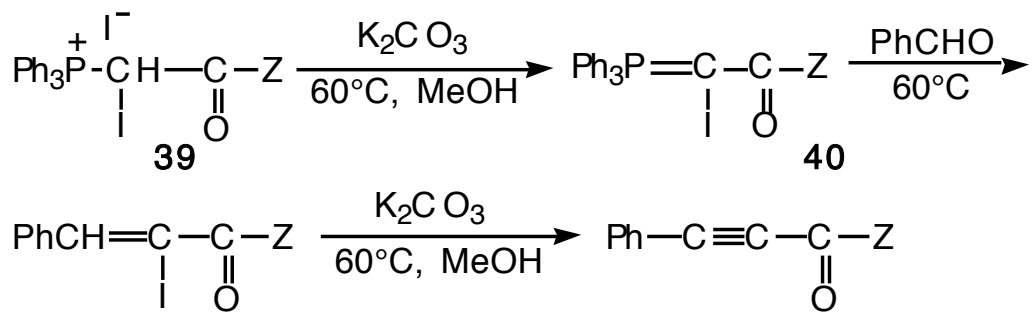

$\mathrm{Z}=\mathrm{EtO}, \mathrm{OH}, \mathrm{Ph}$<smiles>[Z]C(=O)C#CPC(C)C(C)(C)C</smiles> 


\section{Scheme 17.}

This halogenation reaction appears effective for the preparation of synthetically useful ylides, but full utilization of these reagents as precursors of alkynes remains handicapped by the lost of one half of the ylide during transylidation reaction.

(Ethoxycarbonyliodomethyl)triphenylphosphonium iodide 39 (Z=OEt). ${ }^{171}$ A solution of iodine $(8.89 \mathrm{~g}$, $0.035 \mathrm{~mol})$ in $\mathrm{MeOH}(35 \mathrm{~mL})$ is added dropwise at $0-5^{\circ} \mathrm{C}$ to a well-stirred, two-phase system consisting of solid potassium carbonate $(4.83 \mathrm{~g}, 0.035 \mathrm{~mol})$ and (ethoxycarbonylmethyl)triphenylphosphonium bromide $(15.0 \mathrm{~g}$, $0.035 \mathrm{~mol})$ in $\mathrm{MeOH}$ solution $(35 \mathrm{~mL})$. The temperature is then maintained between 0 and $5^{\circ} \mathrm{C}$ during $4 \mathrm{~h}$. A lemon-yellow precipitate appears. After the reaction mixture has warmed to room temperature, the precipitate is collected by filtration and washed with cold $\mathrm{MeOH}(100 \mathrm{~mL})$. The crude product is stirred in water $(2 \times 200$ $\mathrm{mL}$ ) until the water remains neutral. The product is stored at $0^{\circ} \mathrm{C}$ in the dark; yield: $17 \mathrm{~g}(80 \%)$.

Synthesis of $\beta$-substituted propiolic acids $41 .^{171}$ A solution of aldehyde $(0.0175 \mathrm{~mol})$ in $\mathrm{MeOH}(25 \mathrm{~mL})$ is added dropwise to a well stirred suspension of (ethoxycarbonyliodomethyl)triphenylphosphonium iodide 39 $(10.5 \mathrm{~g}, 0.0175 \mathrm{~mol})$ in a two-phase system consisting of $\mathrm{MeOH}(25 \mathrm{~mL})$ and $\mathrm{K}_{2} \mathrm{CO}_{3}(2.415 \mathrm{~g}, 0.0175 \mathrm{~mol})$. The mixture is heated during $4 \mathrm{~h}$ at $60^{\circ} \mathrm{C}$ (until discoloration occurs). After return to room temperature, the reaction mixture is filtrated and the filtrate evaporated under reduced pressure. The solid residue obtained can be worked up as follows. To the residue, water $(50 \mathrm{~mL})$ and $50 \% \mathrm{NaOH}$ solution $(20 \mathrm{~mL})$ are added, and steam is injected until $500 \mathrm{~mL}$ of water is condensed into a distillation receiver. After the reaction mixture is cooled in an ice-bath, $\mathrm{Ph}_{3} \mathrm{PO}$ is filtered off. The aqueous phase is extracted with $\mathrm{C}_{6} \mathrm{H}_{6}(2 \times 100 \mathrm{~mL})$ to eliminate unreacted aldehyde and traces of $\mathrm{Ph}_{3} \mathrm{PO}$. Acidification of the aqueous layer by concentrated $\mathrm{HCl}$ gives the title compound. The precipitate is collected by filtration and dried under reduced pressure. The solid is recrystallized from water or $\mathrm{CHCl}_{3}$ /ligroin (52-70\% yield).

\subsection{Dibromoallyltriphenylphosphonium bromide}

Phosphacumulenes ylides are established precursors in the preparation of aryl and halogensubstituted [3] cumulenes. Though they are generally unstable, the halo [3] cumulenes can be handled without difficulty and they have been used in the preparation of 1,4-disubstituted 1,3diynes 43. The entire formation of 1,3-diynes was performed in one reaction vessel and involved the 1,4-elimination of $\mathrm{HBr}$ from 1-bromo-1,2,3-butatienes $\mathbf{4 4}$ resulting of a Wittig reaction between an aldehyde, aliphatic or aromatic, and the (trans-2,3-dibromo-3-phenyl-2propen-1-yl)triphenylphosphonium bromide 42 (Scheme 18). ${ }^{175}$ The $E$-isomer of the phosphonium salt was prepared with $88 \%$ yield by treatment of the $E$-isomer of the 1,2,3tribromo-3-phenylprop-2-ene with triphenylphosphine $\mathbf{6}$ in toluene for $36 \mathrm{~h}$ at room temperature. 175 


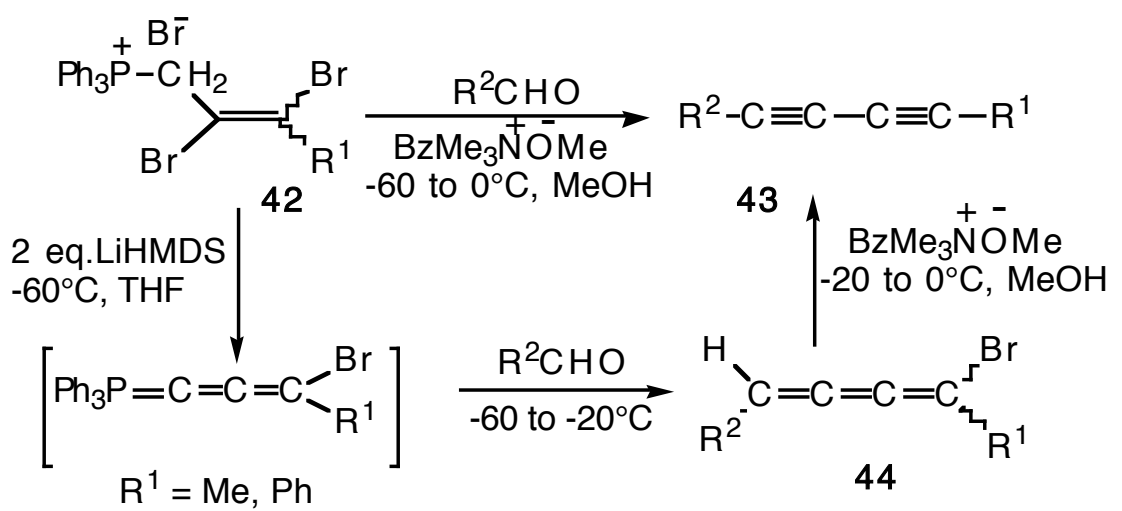

\section{Scheme 18.}

In a typical reaction excess benzyltrimethylammonium methoxide was slowly added to a methanolic solution of the triphenylphosphonium bromide and the aldehyde at $-60^{\circ} \mathrm{C}$. Product diynes are obtained on warming the reaction mixture to $20^{\circ} \mathrm{C}$ followed by standard workup and purification. The overall yields of the pure diynes $\mathbf{4 3}$ are in the range of 43-91\%. They are presumably formed via the reaction sequence shown in Scheme 18. The choice of LiHMDS in THF at $-70^{\circ} \mathrm{C}$ used when $\mathrm{R}^{1}=\mathrm{Ph}$ facilitates the isolation of the unstable 1-bromo1,4-diphenylbutatriene $44\left(\mathrm{R}^{1}=\mathrm{R}^{2}=\mathrm{Ph}\right)$ which was the only product as a mixture of $E$ - and $Z$ - isomers. Subsequent treatment with excess benzyltrimethylammonium methoxide in $\mathrm{MeOH}$ at $-30^{\circ} \mathrm{C}$ resulted in an extremely facile 1,4-dehydrobromination of both $E$ and $Z$ components to give diphenylbutadiyne with $47 \%$ yield. ${ }^{175}$

\section{Phosphonates Precursors of Acetylenic Compounds}

Phosphonates being considerably more nucleophilic than their phosphorane counterparts play an important part in modern alkynes synthesis. They are present in the field with about ten readily available reagents among which some are commercially available. The synthetic approach to alkynes is based on a two-step combination of a Horner-Wadsworth-Emmons carbonyl olefination and a 1,2- or 1,1-elimination reaction. By using the more nucleophilic anions of phosphonate reagents, both aldehydes and ketones are successfully converted to alkenes in generally good to excellent yields, and the subsequent formation of alkynes via the alkenes thus produced is frequently achieved in mild conditions. The phosphonate reagents appear to be well fitted to deliver common alkynes in high yields and in large scale or to introduce a triple bond in a complex molecular architecture.

\subsection{The 1-Diazomethylphosphonates}

Two types of phosphonate reagents containing a diazomethyl group are known, the dimethyl176 47 and diethyl 1-diazomethylphosphonates ${ }^{177} \mathbf{5 0}$ and the dimethyl 1-diazo-2oxopropylphosphonate ${ }^{178} \mathbf{5 3}$. Both can be regarded as reagents containing a latent alkyne function. Their metallated derivatives on reaction with the carbonyl group of aldehydes or 
ketones undergo olefination reaction followed by subsequent unmasking of the alkyne by an alkylidenecarbene rearrangement. In this regard, the transformation which allows the introduction of a triple bond in one sequence at the carbonyl carbon of the starting aldehyde or ketone is precious and of great importance.

\subsubsection{Dimethyl and Diethyl 1-Diazomethylphosphonates}

Possibly the most frequently used and most widely known phosphorus reagent for efficient, one-carbon homologation of aldehydes and ketones to terminal or internal alkynes, is the dimethyl diazomethylphosphonate 47 (Seyferth-Colvin-Gilbert reagent). ${ }^{176}$ Early reported preparation of $\mathbf{4 7}$ includes the diazotation of the unisolated dimethyl aminomethylphosphonate $\mathbf{4 6}$ prepared on protected form by a Michaelis-Arbuzov reaction between the trimethylphosphite and the bromomethylphthalimide 45 (Scheme 19). Dimethyl diazomethylphosphonate $\mathbf{4 7}$ was isolated in $46 \%$ yield as a distillable yellow liquid which was stable indefinitely when stored in a refrigerator. ${ }^{176}$ To minimise the chance of explosive decomposition on distillation it was recommanded to filter an ethereal solution of the crude product through a short column of alumina prior to distillation. ${ }^{179}$

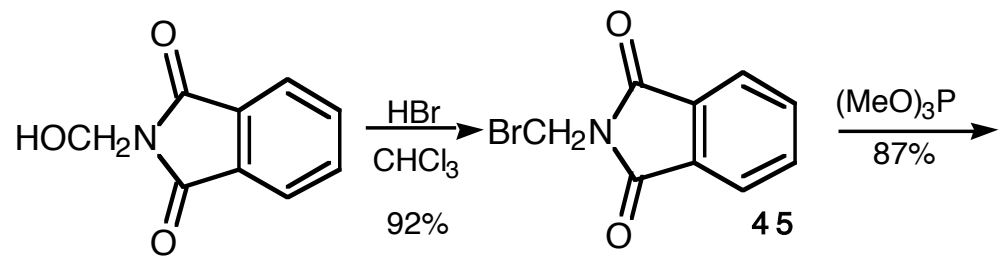

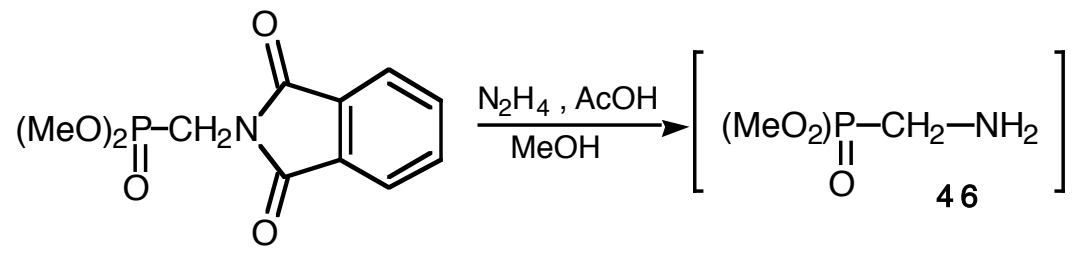

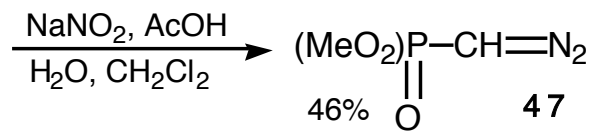

\section{Scheme 19.}

Dimethyl diazomethylphosphonate 47.176 A solution of $53.8 \quad \mathrm{~g} \quad(0.20 \mathrm{~mol})$ of dimethyl phthalimidomethylphosphonate and $95 \%$ anhydrous hydrazine $(0.21 \mathrm{~mol})$ in $400 \mathrm{~mL}$ of $\mathrm{MeOH}$ was stirred at r.t. under nitrogen for $45 \mathrm{~h}$. Then $20 \mathrm{~mL}$ of $\mathrm{AcOH}$ was added and the mixture was stirred 5 min longer and filtered. The precipitated phthalhydrazide was dried, $29.7 \mathrm{~g}(92 \%)$. The filtrate was evaporated at reduced pressure and the residue was dissolved in $50 \mathrm{~mL}$ of $\mathrm{AcOH}$. A solution of sodium nitrite $\left(21.7 \mathrm{~g}, 0.30 \mathrm{~mL}\right.$, in $50 \mathrm{~mL}$ of $\left.\mathrm{H}_{2} \mathrm{O}\right)$ was added dropwise over 5 min while the flask was being swirled in an ice bath. The flask was kept in the ice bath, with occasional swirling for another $5 \mathrm{~min}$, and then $53 \mathrm{~g}$ of sodium carbonate was added slowly in portions, followed by $200 \mathrm{~mL}$ of ice water. The reaction mixture was extracted with $\mathrm{CH}_{2} \mathrm{Cl}_{2}(3 \times 100 \mathrm{~mL})$. The combined organic layers were extracted with $100 \mathrm{~mL}$ of a saturated $\mathrm{NaHCO}_{3}$ solution, dried $\left(\mathrm{Na}_{2} \mathrm{SO}_{4}\right)$, and concentrated at reduce pressure. The orange liquid residue was short-path distilled to give $13.77 \mathrm{~g}(46 \%)$ of the diazo compound, b.p. $59^{\circ} \mathrm{C}(0.42 \mathrm{~mm})$, as a yellow liquid. 
Although most workers have opted for the original route (Scheme 19), an alternative procedure for the preparation of the aminomethylphosphonate has been described. It involves the hydrogenolytic debenzylation of the phosphonate obtained by reaction of the 1,3,5tribenzyl-hexahydro-1,3,5-triazine 48 with a dialkylphosphite. This method, offering the advantages of easy deprotection and high yields, has been applied to the preparation of the stable and distillable diethyl aminomethylphosphonate $\mathbf{4 9}$ with $95 \%$ yield (Scheme 20). After diazotization of the amine the diethyl diazomethylphosphonate $\mathbf{5 0}$ was obtained with $\mathbf{7 3 \%}$ yield as a stable (at $4^{\circ} \mathrm{C}$ ) compound..$^{177}$
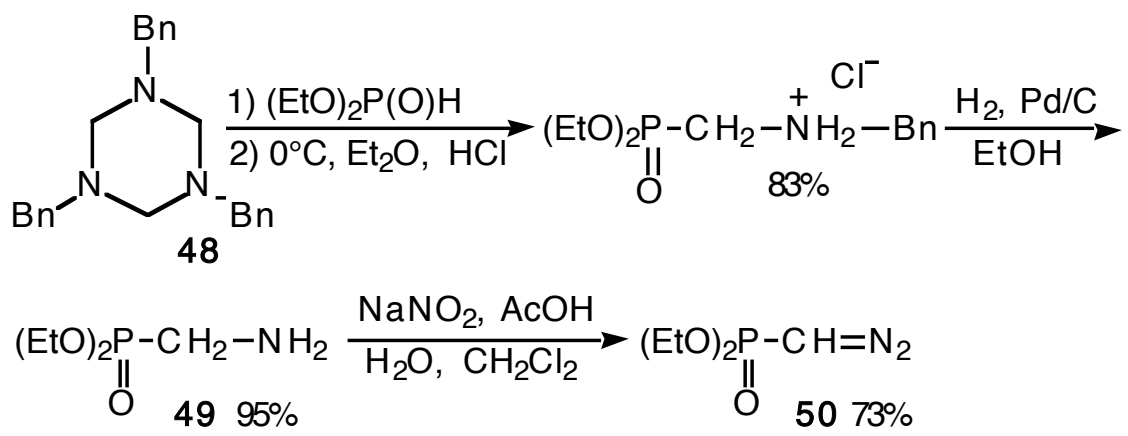

\section{Scheme 20.}

Diethyl diazomethylphosphonate 50. ${ }^{177}$ To a solution of diethyl aminomethylphosphonate 49 (39.0 g, 232 $\mathrm{mmol})$, in $\mathrm{CH}_{2} \mathrm{Cl}_{2}(217 \mathrm{~mL})$ at $-5^{\circ} \mathrm{C}$ was added with stirring aqueous sodium nitrite $(19.33 \mathrm{~g}, 280 \mathrm{mmol}, 108$ $\mathrm{mL} \mathrm{H}_{2} \mathrm{O}$ ), followed by glacial $\mathrm{AcOH}(28 \mathrm{~g}, 462 \mathrm{mmol})$ dropwise over $10 \mathrm{~min}$. On stirring at $0^{\circ} \mathrm{C}$ for $4 \mathrm{~h}$ the $\mathrm{CH}_{2} \mathrm{Cl}_{2}$ layer became bright yellow. The mixture was transfered to a chilled separating funnel, and the $\mathrm{CH}_{2} \mathrm{Cl}_{2}$ layer run into cold aqueous potassium carbonate $\left(75 \mathrm{~g}\right.$ in $100 \mathrm{~mL}$ of $\left.\mathrm{H}_{2} \mathrm{O}\right)$. The aqueous layer was extracted once with $\mathrm{CH}_{2} \mathrm{Cl}_{2}$, and the combined organic phases shaken with potassium carbonate until well neutralized. The layers were separated, and the organic phase dried $\left(\mathrm{K}_{2} \mathrm{CO}_{3}\right)$, filtered through a short pad of neutral alumina, and the solvent stripped at reduced pressure below $40^{\circ} \mathrm{C}$. Distillation of the residual oil afforded diethyl diazomethylphosphonate $\mathbf{5 0}$ as a bright yellow liquid $(30.5 \mathrm{~g}, 73 \%)$, stable at $4^{\circ} \mathrm{C}$ under an argon atmosphere. b.p. $86-88^{\circ} \mathrm{C} / 0.2$ torr.

The two previous preparations included an aminomethylphosphonate intermediate. A recently reported procedure offers a shorter, more convenient route to $\mathbf{4 7}$ from the readily available dimethyl methylphosphonate $\mathbf{5 1}$ and a diazo transfer reagent $\mathbf{5 2}$ (Scheme 21). ${ }^{180}$ The synthesis was based upon a diazo transfer reaction coupled with a deacylation step. The keto form was certainly the reactive species in the diazo transfer and deacylation steps. However, the overall yield $(50 \%)^{180}$ was quite identical to that reported previously (46\%) (Scheme 19). ${ }^{176}$ 


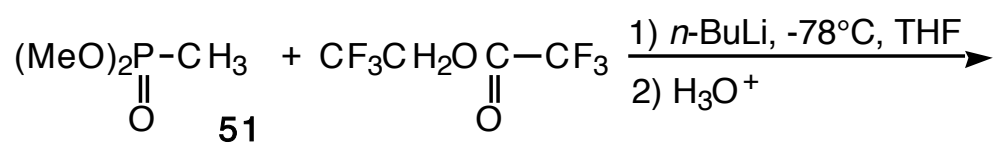<smiles>COP(=O)(CC(=O)C(F)(F)F)OP(=O)(CC(O)(O)CP(C)(F)(F)F)C(F)(F)F</smiles>

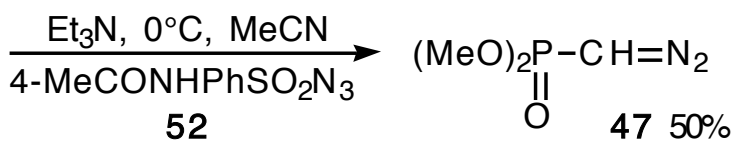

\section{Scheme 21.}

As part of a general study on the synthetic utility of trimethylsilyldiazomethane and dimethyl diazomethylphosphonate 47, it was reported in 1973 that the base-induced reaction of these reagents with carbonyl compounds, mainly diaryl ketones and electrophilic aryl aldehydes, leads directly to the corresponding homologous alkynes. ${ }^{179,181}$ Although these results were unexpected, they did promise considerable interest. The phosphorus diazomethanes were found to be rather more stable and more easy to handle than diazomethyltrimethylsilane. Surprisingly, the corresponding anions were found much less stable and had to be generated at $-78^{\circ} \mathrm{C}$; in THF they merely converted benzophenone into diphenylacetylene in higher yield (94\% using $n$-BuLi and $77 \%$ using $t$-BuOK) than the silicon-based reagent (80\% using $n$ BuLi and 50\% using $t$-BuOK). Quickly, the dimethyl diazomethylphosphonate 47 was recognized as a highly versatile synthetic intermediate and simple innovations have significantly enhanced the breadth and efficiency of this type of transformation. ${ }^{179,181}$

Potassium tert-butoxide was selected as base instead of $n$-BuLi in order to make the counterion of $\mathbf{5 3}$ larger, to enhance the rate of decomposition of betaines and also to avoid undesired side reactions. Moreover, one of the difficulties which was encountered in this reaction being the slow conversion of carbonyl groups, the maintenance of the reaction mixture at low temperature for an extended period of time (16-20 h) has allowed complete consumption of the anion of $\mathbf{4 7}$ by reaction with a large variety of carbonyl compounds. These modifications were successful since even carbonyl groups issued of enolizable aldehydes and ketones and aryl aldehydes of low electrophilicity were homologated to alkynes (Table 4). In addition, it was possible to prove by low-temperature NMR analyses that the alkynes 5 are forming at $-78^{\circ} \mathrm{C} .182,183$ 

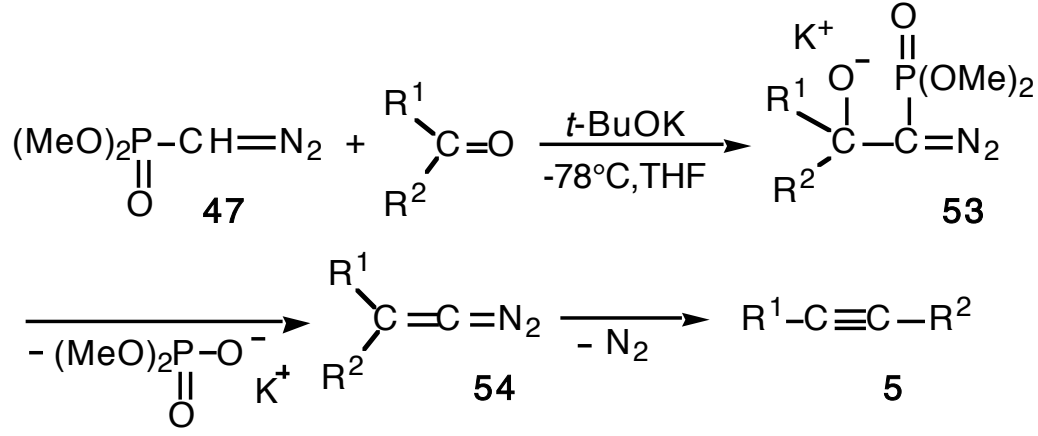

\section{Scheme 22 .}

As outlined in Scheme 22 the mechanism claimed for the reaction of $\mathbf{4 7}$ with aldehydes and ketones involves the sequential formation of several intermediates. It was established that the attack of the anion of dimethyl diazomethylphosphonate 47 on a carbonyl group is a reversible and relatively slow process leading to the primary adduct 53. The transient oxaphosphetane eliminates potassium dimethylphosphate to give the thermally unstable diazoalkene 54 which $\alpha$-eliminates in situ. Loss of nitrogen from 54 produces the alkylidenecarbene which rearranges smoothly at low temperature into the required alkyne 5.183

General procedure for preparation of alkynes. ${ }^{183} \mathrm{~A}$ magnetically stirred slurry of $t$-BuOK $(0.8 \mathrm{mmol})$ in 1.5 $\mathrm{mL}$ of THF was cooled to $-78^{\circ} \mathrm{C}$ under an atmosphere of dry nitrogen. A solution of $0.8 \mathrm{mmol}$ of dimethyl diazomethylphosphonate $\mathbf{4 7}$ in $2 \mathrm{~mL}$ of THF was added dropwise during $1 \mathrm{~min}$, and this mixture was stirred for $5 \mathrm{~min}$. During this time, the color of the reaction changed from pale yellow to brown, indicating formation of the anion of 47. Subsequently, a solution of the carbonyl substrate $(0.7 \mathrm{mmol})$ in $2 \mathrm{~mL}$ of THF was added over a 1 min period. Evolution of nitrogen was usually evident. The resulting solution was stirred at $-78^{\circ} \mathrm{C}$ for $12-24 \mathrm{~h}$ and then allowed to warm to r.t. Stirring was continued for an additional 2-4 $\mathrm{h}$, and then the reaction mixture was quenched with $25 \mathrm{~mL}$ of $\mathrm{H}_{2} \mathrm{O}$. Extraction with $\mathrm{CH}_{2} \mathrm{Cl}_{2}(3 \times 25 \mathrm{~mL})$, washing of the combined extracts with $25 \mathrm{~mL}$ of brine, drying $\left(\mathrm{Na}_{2} \mathrm{SO}_{4}\right)$, and removal of solvents by rotary evaporation afforded the crude product. A measured quantity of an internal standard (2-propanol, benzene, or $\mathrm{CH}_{2} \mathrm{Cl}_{2}$ ) was added, and the entire mixture was transferred to a ${ }^{1} \mathrm{H}$ NMR tube for spectroscopic analysis.

Table $4^{183}$

\begin{tabular}{cccc}
\hline $\mathbf{5}$ & $\mathbf{R}^{\mathbf{1}}$ & $\mathbf{R}^{\mathbf{2}}$ & Yield (\%) \\
\hline $\mathbf{a}$ & $\mathrm{C}_{6} \mathrm{H}_{5} \mathrm{CH}_{2}$ & $\mathrm{H}$ & 80 \\
$\mathbf{b}$ & $\mathrm{CH}_{3}\left(\mathrm{CH}_{2}\right)_{3} \mathrm{CH}(\mathrm{Et})$ & $\mathrm{H}$ & 79 \\
$\mathbf{c}$ & $4-\mathrm{MeO}-\mathrm{C}_{6} \mathrm{H}_{4}$ & $\mathrm{H}$ & 88 \\
$\mathbf{d}$ & $4-\mathrm{Cl}_{2} \mathrm{C}_{6} \mathrm{H}_{4}$ & $\mathrm{H}$ & 60 \\
$\mathbf{e}$ & $4-\mathrm{O}_{2} \mathrm{~N}_{4}-\mathrm{C}_{6} \mathrm{H}_{4}$ & $\mathrm{H}$ & 84 \\
$\mathbf{f}$ & $(E)-\mathrm{C}_{6} \mathrm{H}_{5} \mathrm{CH}=\mathrm{C}(\mathrm{Me})$ & $\mathrm{H}$ & 40 \\
$\mathbf{g}$ & $\mathrm{CH}_{3}$ & $\mathrm{C}_{6} \mathrm{H}_{5}$ & 67 \\
$\mathbf{h}$ & $\mathrm{CH}_{3}$ & $4-\mathrm{O}_{2} \mathrm{~N}_{-}-\mathrm{C}_{6} \mathrm{H}_{4}$ & 55 \\
$\mathbf{i}$ & $\mathrm{C}_{6} \mathrm{H}_{5}$ & $\mathrm{C}_{6} \mathrm{H}_{5}$ & 92 \\
$\mathbf{j}$ & $2-\mathrm{furyl}$ & $\mathrm{H}$ & 50 \\
\hline
\end{tabular}


Owing to the synthetic importance of alkynes, the sequence that allows the one-carbon chain homologation of aldehydes $\left(\mathrm{R}^{2}=\mathrm{H}\right)$ into terminal alkynes is especially useful and for that reason dimethyl diazomethylphosphonate $\mathbf{4 7}$ is frequently involved in the synthesis of natural products possessing complex molecular architecture. For example, 47 was employed in several multi-step syntheses of active compounds including modified forskolin, ${ }^{184}$ immunosuppressive agents, ${ }^{185-189}$ vitamin D3 metabolites, ${ }^{190-195}$ alkaloids of various activity, ${ }^{196-199}$ antibiotics, ${ }^{200-202}$ natural toxins, ${ }^{203}$ selective inhibitors of GABA transaminase, ${ }^{204}$ cytotoxic agents ${ }^{205-212}$ and others. ${ }^{213-217}$

In complement with the rearrangement of diazoalkenes $\mathbf{5 4}$ that produces terminal alkynes, dimethyl diazomethylphosphonate $\mathbf{4 7}$ has also been used in intramolecular C-H insertion ${ }^{218-}$ 223 that leads to cyclopentenes formation (Scheme 23), ${ }^{219}$ and intermolecular O-H insertion with an alcohol that gives an enol ether. ${ }^{224}$

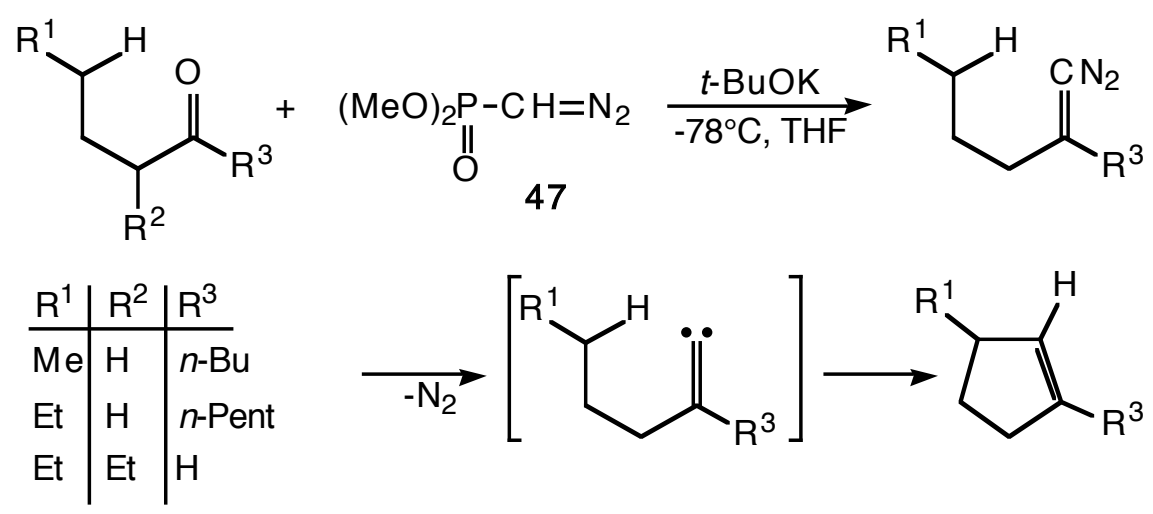

\section{Scheme 23.}

General procedure for the preparation of cyclopentenes. ${ }^{219}$ Potassium tert-butoxide $(1.12 \mathrm{~g}, 10 \mathrm{mmol})$ was dissolved in $30 \mathrm{~mL}$ of anhydrous THF contained in a $50 \mathrm{~mL}$ round-bottomed flask equipped with a magnetic stirring bar. The flask was purged with nitrogen, sealed with a rubber septum, and cooled to $-78^{\circ} \mathrm{C}$ (dry ice / 2propanol). A solution of dimethyl diazomethylphosphonate $\mathbf{4 7}(1.50 \mathrm{~g}, 10 \mathrm{mmol})$ in $3 \mathrm{~mL}$ of THF was added via syringe over a $5 \mathrm{~min}$ period. After this mixture had been stirred for an additional $5 \mathrm{~min}$, a solution of a ketone $(5.0 \mathrm{mmol})$ in $3 \mathrm{~mL}$ of THF was added during the course of $5 \mathrm{~min}$. Stirring was continued at $-78^{\circ} \mathrm{C}$ for $18 \mathrm{~h}$, with occasional venting to relieve internal pressure.

The solution was allowed to warm to r.t., and $50 \mathrm{~mL}$ of pentane was added. The resulting mixture was washed with water $(5 \times 100 \mathrm{~mL})$ and dried $\left(\mathrm{Na}_{2} \mathrm{SO}_{4}\right)$, and the solvent was removed by either rotary evaporation or simple distillation. The crude reaction mixture was chromatographed on neutral silica gel (pentane), all of the material eluting before the starting ketone being collected.

\subsubsection{Dimethyl 1-Diazo-2-Oxopropylphosphonate}

An ingenious and elegant improvement in the standard synthetic procedure for the preparation of alkynes 5 using dimethyl diazomethylphosphonate176 47 has featured the use of dimethyl 1-diazo-2-oxopropylphosphonate $\mathbf{5 6}$ (Ohira reagent) ${ }^{178}$ in the presence of basic $\mathrm{MeOH}$. The design of reagent $\mathbf{5 6}$ is based upon the structural analogy with the 2-diazo-1,2dicarbonyl compounds. The dimethyl 1-diazo-2-oxopropylphosphonate 56 was obtained in a single step with $83 \%$ yield by reaction of the $\alpha$-metallated derivative of the readily available dimethyl 2-oxopropylphosphonate 55 with tosylazide (Scheme 24).225 It has been observed 
that the sodium enolate prepared in $\mathrm{NaH} / \mathrm{THF} / \mathrm{C}_{6} \mathrm{H}_{6}$ solution gives superior results (80-96\% yields) to $t$ - $\mathrm{BuOK} / \mathrm{THF} / \mathrm{C}_{6} \mathrm{H}_{6}$ (20-50\% yields) or $\mathrm{Et}_{3} \mathrm{~N} / \mathrm{MeCN}$ (30-60\% yields). ${ }^{225}$

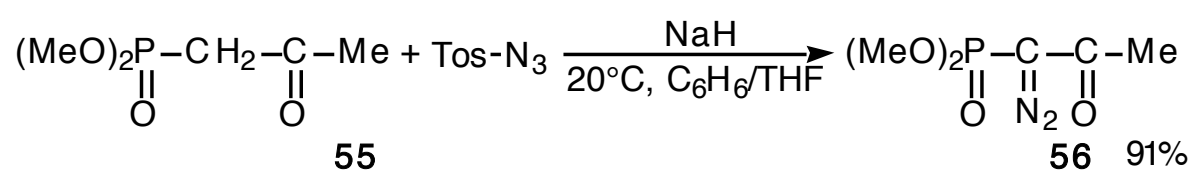

\section{Scheme 24.}

General procedure for synthesis of dimethyl 1-diazo-2-oxoalkylphosphonates 56.225 To a cold $\left(0-5^{\circ} \mathrm{C}\right)$ suspension of $\mathrm{NaH}(25.2 \mathrm{mg}, 1.05 \mathrm{mmol})$ in $\mathrm{C}_{6} \mathrm{H}_{6}(3 \mathrm{~mL})$ and THF $(0.5 \mathrm{~mL})$ is added a dimethyl 2oxoalkylphosphonate $55(1.0 \mathrm{mmol})$ in $\mathrm{C}_{6} \mathrm{H}_{6}(1 \mathrm{~mL})$. After stirring for $1 \mathrm{~h}, \mathrm{TosN}_{3}(207 \mathrm{mg}, 1.05 \mathrm{mmol})$ in $\mathrm{C}_{6} \mathrm{H}_{6}(0.5 \mathrm{~mL})$ is added and the reaction mixture is allowed to warm to $20^{\circ} \mathrm{C}$. After $2 \mathrm{~h}$ the mixture is filtered on a celite pad, concentrated in vacuo and chromatographed on silica gel (AcOEt / hexane, 1/1) affording dimethyl 1-diazo-2-oxoalkylphosphonates (80-91\%).

Facile hydrolysis of 2-diazo-1,3-dicarbonyl compounds to the corresponding deacetylated compounds, under mild basic conditions has long been known and employed in the preparation of diazocarbonyl compounds. The same protocol was applied to dimethyl 1diazo-2-oxopropylphosphonate $\mathbf{5 6}$ which was cleanly transformed in almost quantitative yield into the anion of $\mathbf{5 6}$ by acyl cleavage with excess $\mathrm{K}_{2} \mathrm{CO}_{3}$ in $\mathrm{MeOH}$ at $0^{\circ} \mathrm{C}$. The in situ generated anion undergoes reactions with both aldehydes $\left(R^{2}=H\right)$ and ketones $\left(R^{2} \neq H\right)$ to give the alkynes $\mathbf{2 5}$ or the enol ethers 57 (Scheme 25). The use of potassium carbonate in $\mathrm{MeOH}$ was crucial to the success of the reaction to exclude a too great concentration of the reactive potassium anion and thus preventing its decomposition. In marked contrast, no product or only trace of $\mathbf{4 7}$ was obtained when using $\mathrm{NaOH}$ in aqueous $\mathrm{MeCN}$ probably because of the decomposition of the corresponding unstable anion formed in high concentration. ${ }^{178}$
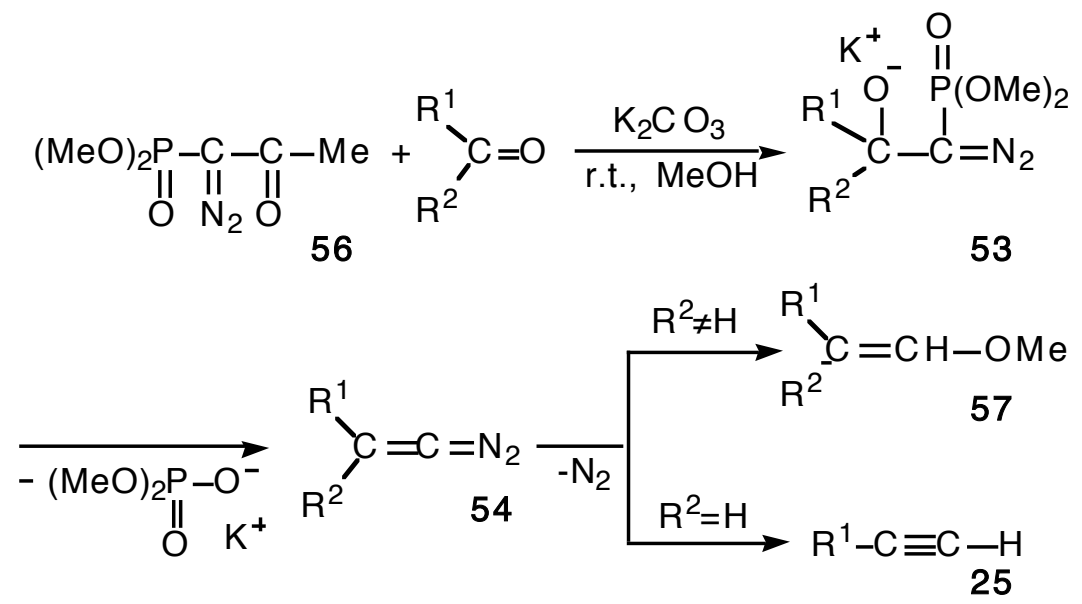

Scheme 25.

A clear illustration of the advantages of this novel synthetic procedure was provided by the one-pot conversion of decyl aldehyde to 1-undecyne with $62 \%$ yield and of cyclohexanone 
into the corresponding methyl enol ether with $63 \%$ yield. ${ }^{178}$ Several recent results have significantly extended the scope and synthetic utility of this advantageous one-pot procedure. Testing a variety of different aldehydes, the desired alkynes were obtained in good to excellent yields and in analytically pure form after simple aqueous work-up (Table 5). ${ }^{226}$ The reaction works with aryl- and alkylsubstituted aldehydes as well as with hindered substrates. For example, dialdehydes give rise to diynes and the transformation of chiral aldehydes occurred without racemisation. A variety of functional groups such as ethers, methyl esters, acetals and non-conjugated double-bond are tolerated. This method avoids the use of strong bases, low temperature and inert gas techniques. ${ }^{226}$

Typical experimental procedure. ${ }^{226}$ To a solution of $290 \mathrm{mg}(1.00 \mathrm{mmol})$ of aldehyde and $276 \mathrm{mg}(2.00$ $\mathrm{mmol}$ ) of $\mathrm{K}_{2} \mathrm{CO}_{3}$ in $15 \mathrm{~mL}$ of dry $\mathrm{MeOH}$ are added $230 \mathrm{mg}(1.20 \mathrm{mmol})$ of dimethyl 1-diazo-2oxopropylphosphonate $\mathbf{5 6}$ and stirring is continued until the reaction is complete as indicated by TLC (4 h). The reaction mixture is diluted with $\mathrm{Et}_{2} \mathrm{O}(23 \mathrm{~mL})$, washed with an aqueous solution of $\mathrm{NaHCO}_{3}(5 \%)$ and dried over $\mathrm{MgSO}_{4}$. Evaporation of the solvent yields $217 \mathrm{mg}(76 \%)$ of alkynes as a slightly yellow oil in analytically pure form.

Table $5^{226}$

\begin{tabular}{|c|c|c|}
\hline 25 & $\mathbf{R}^{1}$ & Yield (\%) \\
\hline $\mathbf{a}$ & & 76 \\
\hline $\mathbf{b}$ & & 77 \\
\hline c & & 80 \\
\hline d & $\mathrm{MeO}_{2} \mathrm{C}$ & 83 \\
\hline $\mathbf{e}$ & $\mathrm{C}_{6} \mathrm{H}_{5}$ & 73 \\
\hline $\mathbf{f}$ & 4- $\mathrm{MeO}-\mathrm{C}_{6} \mathrm{H}_{4}$ & 78 \\
\hline $\mathbf{g}$ & $4-\mathrm{Cl}-\mathrm{C}_{6} \mathrm{H}_{4}$ & 97 \\
\hline $\mathbf{h}$ & $1,3-\mathrm{C}_{6} \mathrm{H}_{4}$ & 74 \\
\hline $\mathbf{i}$ & 2-thienyl & 80 \\
\hline $\mathbf{j}$ & $n-\mathrm{C}_{11} \mathrm{H}_{23}$ & 96 \\
\hline $\mathbf{k}$ & $\mathrm{Me}$ & 96 \\
\hline 1 & $\mathrm{MeO}_{2} \mathrm{C}-\left(\mathrm{CH}_{2}\right)_{7-}$ & 82 \\
\hline $\mathbf{m}$ & $\mathrm{C}_{6} \mathrm{H}_{5}-\mathrm{CH}(\mathrm{Me})-$ & 72 \\
\hline
\end{tabular}


Starting from easily available reagents, this simple procedure described by Ohira can be effected at ambient temperature, is not sensitive to stoichiometry and constitutes an expedious route for the synthesis of alkynes by one carbon chain elongation from aldehydes. $227-232$

\subsection{The $\alpha$-Halogenated Methylphosphonates}

Several dialkyl $\alpha$-halogenated methylphosphonates containing one, two or three halogen atoms, essentially chlorine, bromine and iodine are known. ${ }^{233}$ They owe their synthetic utility to their use in preparation of mono- or dihaloalkenes which are masked alkynes. The facile formation of a carbanion in the $\alpha$-position to the phosphoryl group coupled to a geminal disubstitution operation of the carbonyl group (Horner-Wadsworth-Emmons reaction) results in production of mono- or dihaloalkenes able to provide access to internal or terminal alkynes by 1,2-, or 1,1-elimination reactions. The carbanions are usually obtained by proton-metal exchange reaction with primary alkyllithiums and lithium amides, or by halogen-metal exchange reaction with primary alkyllithiums.

\subsubsection{Diethyl Trichloromethylphosphonate}

The diethyl trichloromethylphosphonate $234 \mathbf{5 8}$ is obtained in pure form with almost quantitative yield $(93.6 \%)$ by simply refluxing triethylphosphite with dry tetrachloride in large excess (Scheme 26). The reaction is realized without difficulty on molar scale.

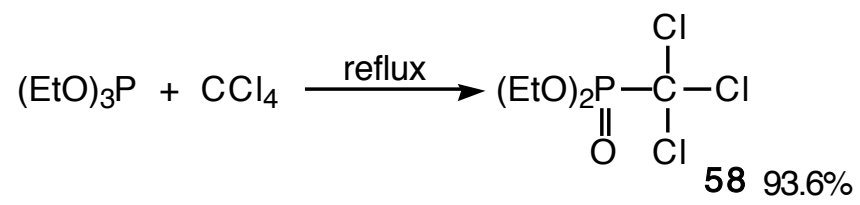

\section{Scheme 26.}

Diethyl trichloromethylphosphonate 58.234 Triethylphosphite $(50 \mathrm{~g})$ was refluxed overnight with $250 \mathrm{~mL}$ (large excess) of dry carbon tetrachloride. The colourless solution was distilled under reduce pressure to yield 72 $\mathrm{g}(93.6 \%)$ of diethyl trichloromethylphosphonate, as a colourless mobile liquid, bp, $135-137^{\circ} \mathrm{C}$ at $16 \mathrm{~mm} \mathrm{Hg}$, $127-128^{\circ} \mathrm{C}$ at $13 \mathrm{~mm} \mathrm{Hg}$.

Another route to trichloromethylphosphonyl derivatives which has been occasionally employed involves the trichloromethylphosphonyl dichloride 59 obtained by a KinnearPerren reaction. ${ }^{235}$ It offers the advantage over the previously reported procedure to leave the investigators free to choose the two phosphorus appendages. Alcoholysis $236-242$ of 59 in anhydrous conditions yields the desired trichloromethylphosphonates 60 (Scheme 27).

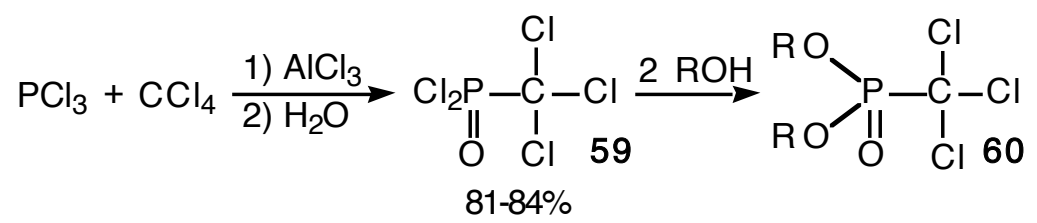




\section{Scheme 27.}

From the diethyl trichloromethylphosphonate 58, a relatively general procedure for the conversion of large amounts of carbonyl compounds to higher terminal alkynes via the gemdichloroalkenes has been developed. This sequence (Scheme 28$)^{243}$ is initiated by the addition of the diethyl 1,1-dichloro-1-lithiomethylphosphonate $\mathbf{6 1}$, generated at $-100^{\circ} \mathrm{C}$ by halogen-metal exchange reaction between $\mathbf{5 8}$ and $n$-BuLi, to an aldehyde to give on warming the gem-dichloroalkenes 62 in good to excellent yields (75-97\%). Further treatment of these gem-dichloroalkenes 62 with an alkyllithium (ethyl or butyl) in $\mathrm{Et}_{2} \mathrm{O}$ or THF at a suitable temperature $\left(-10^{\circ} \mathrm{C}\right.$ or $\left.-70^{\circ} \mathrm{C}\right)$ affords the corresponding lithium alkynides 63 which can be hydrolysed or directly alkylated (Scheme 28). ${ }^{243,244}$ Table 6 shows that a wide variety of acetylenic compounds such as enynes or thioenynes are readily available; moreover the $Z / E$ stereochemistry of the starting 2-alkenals is preserved. Alkylation of metallated terminal acetylenes is restricted mainly to primary alkylating agents, the introduction of $\alpha$-branched chains or vinylic moieties being more difficult.
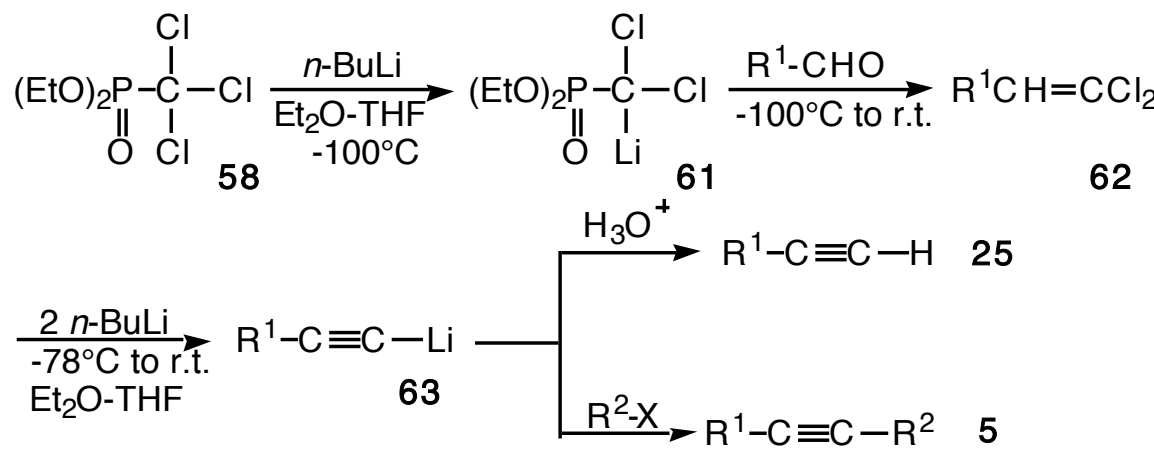

Scheme 28 .

Table 6

\begin{tabular}{ccccc}
\hline 5 or 25 & $\mathbf{R}^{\mathbf{1}}$ & $\mathbf{R}^{\mathbf{2}}$ & Yield(\%) & Ref. \\
\hline $\mathbf{a}$ & $\mathrm{C}_{9} \mathrm{H}_{19}$ & $\mathrm{H}$ & 94 & 243 \\
$\mathbf{b}$ & $\left(\mathrm{C}_{2} \mathrm{H}_{5}\right)_{2} \mathrm{CH}$ & $\mathrm{H}$ & 83 & 243 \\
$\mathbf{c}$ & $c-\mathrm{C}_{6} \mathrm{H}_{11}$ & $\mathrm{MeOCH}_{2}$ & 88 & 243 \\
$\mathbf{d}$ & $c-\mathrm{C}_{6} \mathrm{H}_{9}$ & $\mathrm{MeOCH}_{2}$ & 88 & 243 \\
$\mathbf{e}$ & $\mathrm{CH}_{3}-\mathrm{CH}=\mathrm{CH}$ & $\mathrm{MeOCH}_{2}$ & 76 & 243 \\
$\mathbf{f}$ & $\mathrm{C}_{6} \mathrm{H}_{5}-\mathrm{CH}=\mathrm{CH}$ & $\mathrm{H}$ & 57 & 243 \\
$\mathbf{g}$ & $2-\mathrm{MeO}_{2} \mathrm{C}_{6} \mathrm{H}_{4}$ & $\mathrm{H}$ & 91 & 243 \\
$\mathbf{h}$ & $4-\mathrm{MeO}-\mathrm{C}_{6} \mathrm{H}_{4}$ & $\mathrm{H}$ & 86 & 243 \\
$\mathbf{i}$ & $2-\mathrm{Cl}-\mathrm{C}_{6} \mathrm{H}_{4}$ & $\mathrm{H}$ & 73 & 243 \\
$\mathbf{j}$ & $4-\mathrm{Cl}-\mathrm{C}_{6} \mathrm{H}_{4}$ & $\mathrm{H}$ & 83 & 243 \\
$\mathbf{k}$ & $\left(\mathrm{C}_{2} \mathrm{H}_{5}\right)\left(\mathrm{CH}_{3}\right) \mathrm{CH}$ & $\mathrm{H}$ & 68 & 245
\end{tabular}




\begin{tabular}{lllll} 
l & $\mathrm{C}_{2} \mathrm{H}_{5} \mathrm{~S}-\mathrm{CH}=\mathrm{CH}$ & $\mathrm{H}$ & 78 & 243 \\
\hline
\end{tabular}

4-Methoxyphenylethyne (typical experimental procedure) 25g: ${ }^{243}$ In the absence of moisture and under a nitrogen atmosphere $n$ - $\mathrm{BuLi}\left(80 \mathrm{~mL}\right.$ of $1.44 \mathrm{M}$ solution in $\left.\mathrm{Et}_{2} \mathrm{O}, 0.11 \mathrm{~mol}\right)$ is added to a mixture of $\mathrm{Et}_{2} \mathrm{O}(70$ $\mathrm{mL})$ and THF $(70 \mathrm{~mL})$ at $-40^{\circ} \mathrm{C} .1,1$-Dichloro-2-(4'-methoxyphenyl)ethene $(10.15 \mathrm{~g}, 0.05 \mathrm{~mol})$ is introduced at $70^{\circ} \mathrm{C}$ and the reaction mixture is allowed to warm to room temperature. It is then hydrolysed with aqueous $1 \mathrm{M}$ sulfuric acid. The alkyne is extracted with pentane, the extracts washed with water, and dried with $\mathrm{MgSO}_{4}$. The solvent is removed and the product $25 \mathrm{~g}$ distilled at reduced pressure; yield $5.7 \mathrm{~g}(86 \%)$; b.p. $95^{\circ} / 12$ torr.

1-Cyclohexyl-2-(methoxymethyl)ethyne (typical experimental procedure) $5 \mathbf{c}^{243}$ The procedure is the same as that described previously. Before hydrolysis, chlorodimethyl ether $(4 \mathrm{~g}, 0.05 \mathrm{~mol})$ are added to the lithium acetylenide at $-70^{\circ} \mathrm{C}$ with stirring for $10 \mathrm{~min}$. After the same work-up as above the product $\mathbf{5 c}$ is distilled; yield $6.7 \mathrm{~g}(88 \%)$; b.p. $90^{\circ} / 13$ torr.

1,1-Dichloro-2-alkenes 62, when treated with lithium amides, for example $\mathrm{Et}_{2} \mathrm{NLi}$, give 1-chloro-1-alkynes 64 in high yields (Scheme 29 and Table 7). ${ }^{243}$

$$
\begin{gathered}
\mathrm{R}^{1}-\mathrm{CH}=\underset{62}{\mathrm{CCl}_{2}} \frac{\mathrm{Et}_{2} \mathrm{NLi}}{-25^{\circ} \mathrm{C}, \mathrm{Et}_{2} \mathrm{O}-\mathrm{THF}} \mathrm{R}^{1}-\mathrm{C} \equiv \mathrm{C}-\mathrm{Cl} \\
64
\end{gathered}
$$

Scheme 29.

Table 7243

\begin{tabular}{ccc}
\hline $\mathbf{6 4}$ & $\mathbf{R}^{\mathbf{1}}$ & Yield (\%) \\
\hline $\mathbf{a}$ & $\mathrm{C}_{9} \mathrm{H}_{19}$ & 90 \\
$\mathbf{b}$ & $\left(\mathrm{C}_{2} \mathrm{H}_{5}\right)_{2} \mathrm{CH}$ & 75 \\
$\mathbf{c}$ & $c-\mathrm{C}_{6} \mathrm{H}_{11}$ & 80 \\
$\mathbf{d}$ & $c-\mathrm{C}_{6} \mathrm{H}_{9}$ & 87 \\
$\mathbf{e}$ & $\mathrm{C}_{6} \mathrm{H}_{5} \mathrm{CH}=\mathrm{CH}$ & 78 \\
$\mathbf{f}$ & $2-\mathrm{MeO}_{-} \mathrm{C}_{6} \mathrm{H}_{4}$ & 67 \\
$\mathbf{g}$ & $4-\mathrm{MeO}-\mathrm{C}_{6} \mathrm{H}_{4}$ & 73 \\
$\mathbf{h}$ & $2-\mathrm{Cl}-\mathrm{C}_{6} \mathrm{H}_{4}$ & 66 \\
$\mathbf{i}$ & $4-\mathrm{Cl}-\mathrm{C}_{6} \mathrm{H}_{4}$ & 87 \\
\hline
\end{tabular}

An illustration of the advantages of this synthetic procedure is provided by the preparation of optically active 1-alkynes from chiral aldehydes,245 substituted butenynes, 246,247 sesquiterpenes 248,249 and annulenes. ${ }^{250,251}$

The synthesis of 1-alkynes $\mathbf{2 5}$ proceeds generally well with aldehydes according to Scheme 28 but subsequent experiments indicated that the course of the reaction depends both on the temperature and especially on the presence of $\mathrm{LiBr}$ in the reaction medium. In fact, using commercial or purified $n$-BuLi in hexane without salts, the resulting carbanion 61 gives essentially the diethyl $\alpha$-chlorovinylphosphonate $\mathbf{6 5}$ instead of the desired gemdichloroalkenes 245,252 62. By contrast, using LiBr-containing $n$-BuLi prepared in $\mathrm{Et}_{2} \mathrm{O}$, and operating in the previously described conditions, the gem-dichloroalkenes $\mathbf{6 2}$ are produced in 
good yields without contamination by the vinylphosphonate $\mathbf{6 5}$. Thus, the use of commercial $n$-BuLi (the only deviation from the experimental conditions originally described) in the reaction sequence seems not compatible with the formation of gem-dichloroalkenes 62 which may be attended by considerable amounts of undesired side products (Scheme 30). ${ }^{245,252}$

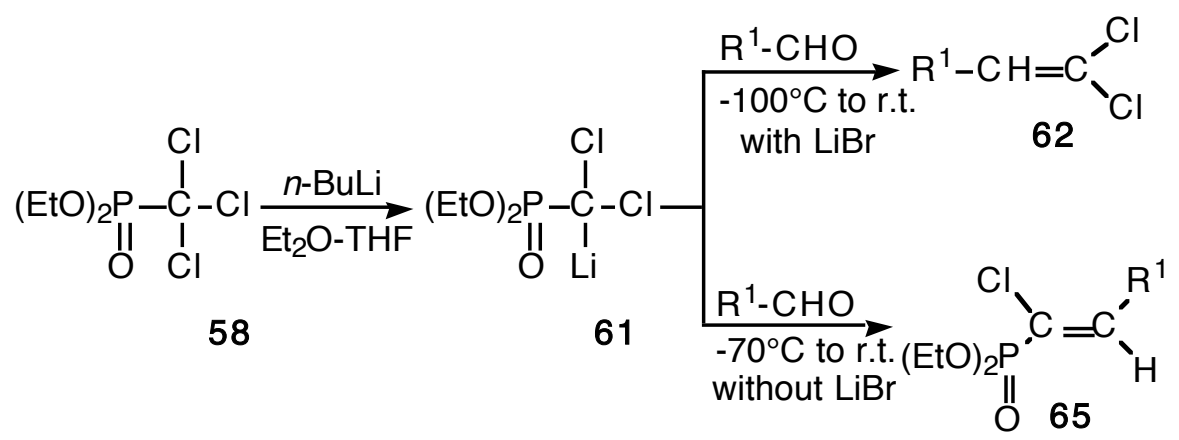

Scheme 30.

In the optimum situation, each of the steps of this reaction sequence may be conveniently executed in one pot without isolation of the intermediates.

\subsubsection{Diethyl Dichloromethylphosphonate}

The diethyl dichloromethylphosphonate $\mathbf{6 6}$ is obtained either by monodechlorination of the diethyl trichloromethylphosphonate $253-260 \mathbf{5 8}$ or by chlorination of the diethyl chloromethylphosphonate $\mathbf{6 8}$. The first route has been envisaged by many authors who attempted optimization of the synthesis of $\mathbf{6 6}$ from the readily available diethyl trichloromethylphosphonate 58. Various approaches have been tried, for instance abstraction or exchange of one chlorine atom with a base or reductive procedures (Table 8). Thus, the reactions of 58 with covalent organic bases (such as $(\mathrm{EtO})_{3} \mathrm{P}^{253}$ and $\left(\mathrm{Me}_{2} \mathrm{~N}\right)_{3} \mathrm{P}^{254}$ ), charged organic bases (such as $n$-BuLi $243,255-257$ and $s$-BuLi), with $\mathrm{Bu}_{3} \mathrm{SnH}, \mathrm{Cl}_{3} \mathrm{SiH} \mathrm{Et}_{3} \mathrm{~N}^{258}$ or molecular hydrogen have been studied. In each of these cases the reaction gave the required product 66, often in reasonable yield, but always contaminated by undesirable side products. Finally, it has been found that magnesium-chlorine exchange reaction by means of isopropylmagnesium chloride in THF at low temperature results in the formation of pure $\mathbf{6 6}$ (Scheme 31). ${ }^{259,260}$ The use of the Grignard reagent favours the metal-halogen exchange reaction and avoids problems such as attack at phosphorus and carbene formation because of the increased thermal stability of the dichloroanion. The desired product $\mathbf{6 6} 6$ being easily purified by means of a simple distillation is obtained in excellent yield (80-94\%). ${ }^{259,260}$

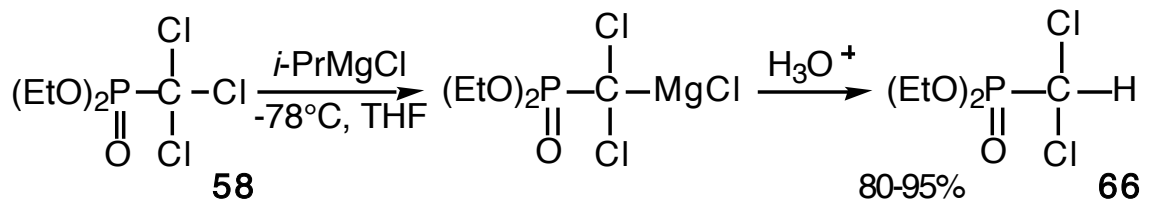




\section{Scheme 31.}

Diethyl dichloromethylphosphonate 66..$^{259}$ To a stirred mixture of previously standardised $1.9 \mathrm{M}$ solution of isopropylmagnesium chloride $(83 \mathrm{~mL}, 158 \mathrm{mmol})$ and THF $(400 \mathrm{~mL})$ cooled to $-78^{\circ} \mathrm{C}$, was added dropwise a solution of diethyl trichloromethylphosphonate $\mathbf{5 8}(38.3 \mathrm{~g}, 150 \mathrm{mmol})$ in THF $(50 \mathrm{~mL})$ over a period of $15 \mathrm{~min}$. The resulting mixture was stirred at $-78^{\circ} \mathrm{C}$ for further $15 \mathrm{~min}$ and then a solution of absolute EtOH $(12 \mathrm{~g}, 260$ $\mathrm{mmol})$ in THF (15 mL) was added dropwise to the mixture. After $5 \mathrm{~min}$ the mixture was allowed to warm to $40^{\circ} \mathrm{C}$ and was then poured into a beaker containing a mixture of $3 \mathrm{M} \mathrm{HCl}(70 \mathrm{~mL})$, an equal volume of crushed ice, and $\mathrm{CH}_{2} \mathrm{Cl}_{2}$. The phases were separated and the aqueous phase was extracted with $\mathrm{CH}_{2} \mathrm{Cl}_{2}(2 \times 60 \mathrm{~mL})$. The combined organic phases were dried $\left(\mathrm{MgSO}_{4}\right)$, filtered and evaporated to yield a yellow oil which when distilled gave the title compound as a colourless oil. (32 g, 94\%; bp $133^{\circ} \mathrm{C}$ at $10 \mathrm{~mm} \mathrm{Hg}$ ).

Table $\mathbf{8}^{259}$

\begin{tabular}{ccc}
\hline Base used & Conditions & Yield (\%) \\
\hline$n$ - $\mathrm{BuLi}$ & $-78^{\circ} \mathrm{C}, \mathrm{THF}, 3 \mathrm{M} \mathrm{HCl}$ quench & 85 \\
$n$ - $\mathrm{BuLi}$ & $\mathrm{LiCl} / \mathrm{LiBr}, 3 \mathrm{M} \mathrm{HCl}$ quench & 85 \\
$s-\mathrm{BuLi}$ & $-78^{\circ} \mathrm{C}, \mathrm{THF}, \mathrm{EtOH}, 3 \mathrm{M} \mathrm{HCl}$ quench & 80 \\
$s-\mathrm{BuLi}$ & $\mathrm{LiCl} / \mathrm{LiBr}, 3 \mathrm{M} \mathrm{HCl}$ quench & 80 \\
$(\mathrm{EtO})_{3} \mathrm{P}$ & $\mathrm{Hexanol}$ reflux & 65 \\
$\left(\mathrm{Me}{ }_{2} \mathrm{~N}\right)_{3} \mathrm{P}$ & r.t., THF, EtOH, 4M HCl quench & 92 \\
$i-\mathrm{PrMgCl}$ & $-78^{\circ} \mathrm{C}, \mathrm{THF}, 3 \mathrm{M} \mathrm{HCl}$ quench & 94 \\
\hline
\end{tabular}

The second route to diethyl dichloromethylphosphonate $\mathbf{6 6}$ uses the diethyl chloromethylphosphonate $\mathbf{6 8}$ as precursor. This route involves the intermediacy of the chloromethylphosphonyl dichloride $\mathbf{6 7}$ prepared in up to $67 \%$ yield by reaction between phosphorus trichloride and formaldehyde at $250^{\circ} \mathrm{C} .{ }^{233,261-266}$ Further treatment of 67 with anhydrous ethanol produces diethyl chloromethylphosphonate 68 (Scheme 32). ${ }^{233}$

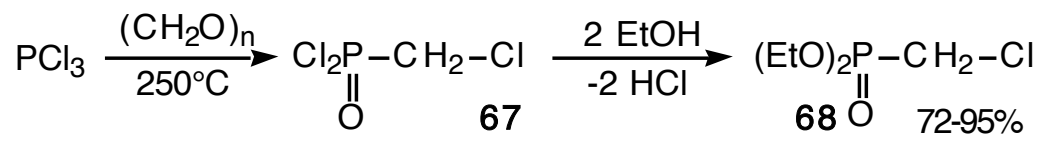

Scheme 32 .

When the diethyl 1-chloro-1-lithiomethylphosphonate 69 is generated from 68 using $n$-BuLi at low temperature, it reacts smoothly with a variety of chlorinating agents, $\mathrm{CCl}_{4}$ or $\mathbf{5 8}$ (Scheme 33) to produce the diethyl dichloromethylphosphonate 66 in large scale and with good yields. 267,268 It has been demonstrated that the use of lithium salts, $\mathrm{LiCl}$ and $\mathrm{LiBr}$, increases stability of the lithium carbenoid 69 and thus 66 can be isolated in yields up to 60$90 \% .267$ 

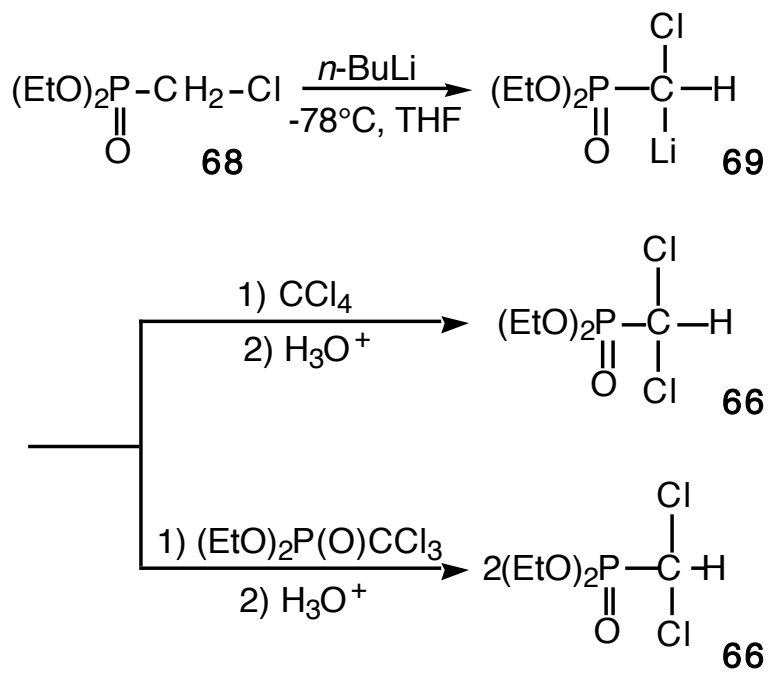

\section{Scheme 33.}

From diethyl dichloromethylphosphonate 66, a variety of alkynes, chloroalkynes 64 and symmetrical or unsymmetrical diarylalkynes 5 (Table 9) were synthesized. The initial step is the olefination of the carbonyl group into gem-dichloroalkenes $\mathbf{6 2}$ by a Horner-WadsworthEmmons reaction between the diethyl 1,1-dichloro-1-lithiomethylphosphonate 64 and aldehydes, aliphatic and aromatic, or ketones. The second step, which takes place on warming, is a 1,1- or a 1,2-trans elimination. The former occurs in the case of ketones whereas the latter occurs with aldehydes. 259

LiHMDS (2 eq.) appears as a well suited base for the one carbon chain extension of aromatic aldehydes to aromatic chloroalkynes 70. However, LiHMDS was insufficiently strong enough to effect the trans elimination when aliphatic aldehydes were used as starting materials. Thus, aliphatic chloroalkynes 64 were obtained from dichloromethylphosphonate $\mathbf{6 6}$ and aliphatic aldehydes in the presence of LDA (2 eq.) 259

Reaction of a mixture of $\mathbf{6 6}$ and an aldehyde, aliphatic or aromatic, in internal quench conditions with LDA ( 1 eq.) in THF at $-78^{\circ} \mathrm{C}$ followed by addition of $n$-BuLi (2.1 eq.) affords terminal alkynes $\mathbf{2 5}$ in high yields and high degree of purity. LDA, reformed from the second equivalent of $n$ - BuLi, effects the elimination on the intermediate dichloroalkenes while $n$ BuLi effects the chlorine-lithium exchange reaction to lead to the lithiated alkynes hydrolyzed into alkynes $\mathbf{2 5}$ after acidic work-up (Scheme 34). 259 


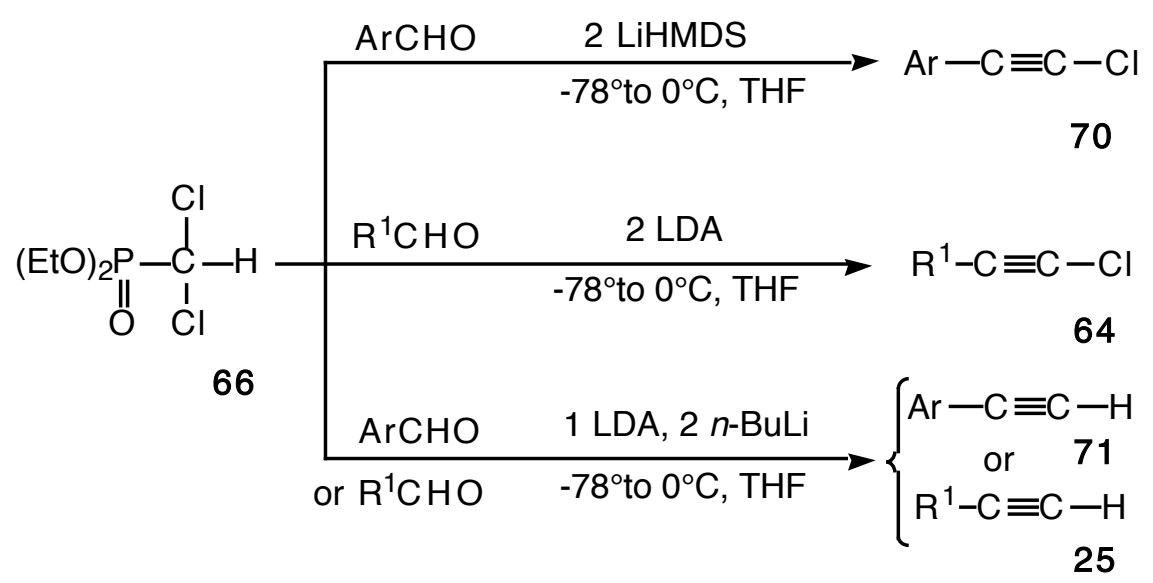

Scheme 34 .

General Procedure for the Preparation of 1-Alkyl- or 1-aryl-2-chloroalkynes 64 or 70.259 To a stirred mixture of a previously standardised $1.38 \mathrm{M}$ solution of $n$-BuLi $(37 \mathrm{~mL}, 50 \mathrm{mmol})$ and $\mathrm{THF}(40 \mathrm{~mL})$ at $-78^{\circ} \mathrm{C}$ was added a solution of HMDS (8.96 g, $56 \mathrm{mmol}$, with aromatic aldehydes), or a solution of diisopropylamine (5.66 g, $56 \mathrm{mmol}$, with aliphatic aldehydes) in THF $(20 \mathrm{~mL})$ dropwise over several min. The mixture was stirred at $-78^{\circ} \mathrm{C}$ for $15 \mathrm{~min}$ and the a mixture of diethyl 1,1-dichloromethylphosphonate $(4.42 \mathrm{~g}, 20 \mathrm{mmol})$ and the aldehyde $(20 \mathrm{mmol})$ in THF $(10 \mathrm{~mL})$ was added dropwise maintaining the temperature at $-78^{\circ} \mathrm{C}$. After stirring for $15 \mathrm{~min}$ the temperature was allowed to rise to $0^{\circ} \mathrm{C}$ and the mixture was stirred for $2 \mathrm{~h}$ at this temperature. Water $(20 \mathrm{~mL})$ was then added dropwise, the phases separated and the aqueous phase washed with $\mathrm{CH}_{2} \mathrm{Cl}_{2}(2 \mathrm{x}$ $30 \mathrm{~mL})$. The combined organic phases were dried $\left(\mathrm{MgSO}_{4}\right)$, filtered and evaporated on a rotary evaporator. The crude residue was then passed through a silica plug with hexane as eluent to obtain the title compounds as mobile oils.

General Procedure for the Preparation of Arylalkynes 71. ${ }^{259}$ To a $1.5 \mathrm{M}$ solution of $n$-BuLi (14 mL, 21 $\mathrm{mmol})$ cooled to $-20^{\circ} \mathrm{C}$ was added a solution of diisopropylamine $(2.23 \mathrm{~g}, 22 \mathrm{mmol})$ in $\mathrm{THF}(30 \mathrm{~mL})$ dropwise with stirring over $15 \mathrm{~min}$. The resulting clear solution was then cooled to $-78^{\circ} \mathrm{C}$ and a solution of diethyl dichloromethylphosphonate $(4.42 \mathrm{~g}, 20 \mathrm{mmol})$ and the aldehyde $(20 \mathrm{mmol})$ in THF (30 $\mathrm{mL})$ was added dropwise over a $30 \mathrm{~min}$ interval. The resulting red solution was then stirred at $-78^{\circ} \mathrm{C}$ for a further 30 min and then allowed to slowly warm to $0^{\circ} \mathrm{C}$. The now brown mixture was then cooled to $-78^{\circ} \mathrm{C}$ and a $1.5 \mathrm{M}$ solution of $n$-BuLi $(28 \mathrm{~mL}, 42 \mathrm{mmol})$ was added dropwise over $30 \mathrm{~min}$. The solution was once again allowed to warm to $0^{\circ} \mathrm{C}$ and is then quenched by the dropwise addition of $3 \mathrm{M} \mathrm{HCl}(30 \mathrm{~mL})$ until the solution was $\mathrm{pH} 5-6$. The phase were separated and the aqueous phase was extracted with $\mathrm{Et}_{2} \mathrm{O}(2 \times 50 \mathrm{~mL})$. The combined organic phases were then washed with $\mathrm{H}_{2} \mathrm{O}(10 \mathrm{~mL})$ and dried $\left(\mathrm{MgSO}_{4}\right)$ and then filtered and evaporated. The crude alkynes were then distilled to give the title compounds as pure colourless oils.

Simultaneous addition of diethyl dichloromethylphosphonate $\mathbf{6 6}$ and a ketone to LiHMDS (1 eq.) in THF at low temperature affords on warming the non-isolated 1,1-dichloro-2,2diarylethenes 72 . This one on treatment with $n$-BuLi ( 2 eq.) at $-60^{\circ} \mathrm{C}$ undergo halogen-metal exchange to give a carbenoid 269,270 which rearranges to produce the required symmetrical or unsymmetrical diaryalkynes 5 (Fritsch-Buttenberg-Wiechell rearrangement). The reaction which has been investigated with a variety of symmetrical and unsymmetrical diaryl ketones on preparative scale produces the desired diarylalkynes $\mathbf{5}$ in good to excellent overall yields $(75-97 \%)$ (Scheme 35 and Table 9). ${ }^{271}$ 


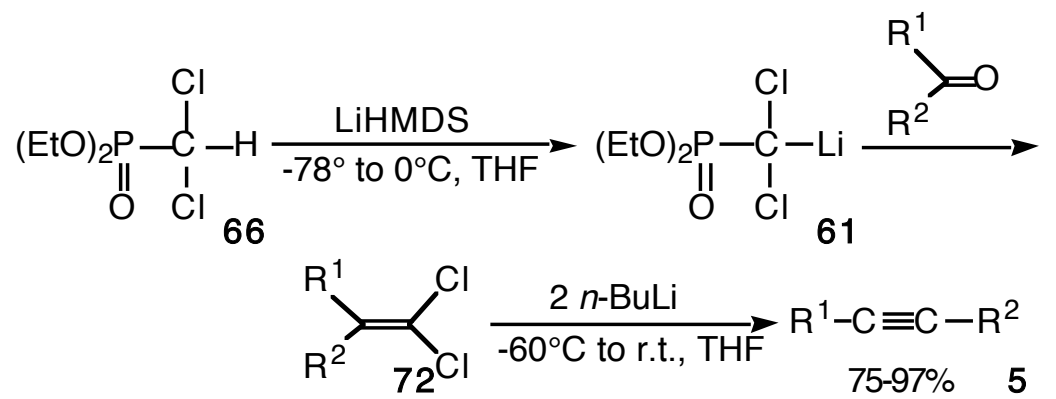

Scheme 35 .

Table $9^{271}$

\begin{tabular}{|c|c|c|c|}
\hline 5 & $\mathbf{R}^{1}$ & $\mathbf{R}^{2}$ & Yield $(\%)$ \\
\hline $\mathbf{a}$ & $\mathrm{C}_{6} \mathrm{H}_{5}$ & $\mathrm{C}_{6} \mathrm{H}_{5}$ & 95 \\
\hline $\mathbf{b}$ & $2-\mathrm{Me}-\mathrm{C}_{6} \mathrm{H}_{4}$ & $2-\mathrm{Me}-\mathrm{C}_{6} \mathrm{H}_{4}$ & 75 \\
\hline c & $2-\mathrm{Cl}-\mathrm{C}_{6} \mathrm{H}_{4}$ & $\mathrm{C}_{6} \mathrm{H}_{5}$ & 92 \\
\hline d & $2-\mathrm{Me}-\mathrm{C}_{6} \mathrm{H}_{4}$ & $\mathrm{C}_{6} \mathrm{H}_{5}$ & 89 \\
\hline $\mathbf{e}$ & $3-\mathrm{Me}-\mathrm{C}_{6} \mathrm{H}_{4}$ & $\mathrm{C}_{6} \mathrm{H}_{5}$ & 91 \\
\hline $\mathbf{f}$ & 4-Me- $\mathrm{C}_{6} \mathrm{H}_{4}$ & $\mathrm{C}_{6} \mathrm{H}_{5}$ & 93 \\
\hline $\mathbf{g}$ & $4-\mathrm{MeO}-\mathrm{C}_{6} \mathrm{H}_{4}$ & $\mathrm{C}_{6} \mathrm{H}_{5}$ & 88 \\
\hline $\mathbf{h}$ & $4-\mathrm{CF}_{3}-\mathrm{C}_{6} \mathrm{H}_{4}$ & $4-\mathrm{MeO}-\mathrm{C}_{6} \mathrm{H}_{4}$ & 97 \\
\hline $\mathbf{i}$ & $4-\mathrm{MeO}-\mathrm{C}_{6} \mathrm{H}_{4}$ & $4-\mathrm{MeO}-\mathrm{C}_{6} \mathrm{H}_{4}$ & 86 \\
\hline $\mathbf{j}$ & $4-\mathrm{F}-\mathrm{C}_{6} \mathrm{H}_{4}$ & $4-\mathrm{F}-\mathrm{C}_{6} \mathrm{H}_{4}$ & 89 \\
\hline $\mathbf{k}$ & $4-\mathrm{Cl}-\mathrm{C}_{6} \mathrm{H}_{4}$ & $4-\mathrm{Cl}-\mathrm{C}_{6} \mathrm{H}_{4}$ & 86 \\
\hline 1 & $4-\mathrm{Me}_{2} \mathrm{~N}-\mathrm{C}_{6} \mathrm{H}_{4}$ & $4-\mathrm{Me}_{2} \mathrm{~N}-\mathrm{C}_{6} \mathrm{H}_{4}$ & 87 \\
\hline m & 2-thienyl & 2-thienyl & 95 \\
\hline
\end{tabular}

Synthesis of diarylalkynes 5.271 $1.6 \mathrm{M} n$-BuLi in hexane (14 mL, $22 \mathrm{mmol})$ was added to THF (20 mL) and cooled to $-78^{\circ} \mathrm{C}$. A solution of HMDS $(3.90 \mathrm{~g}, 24 \mathrm{mmol})$ in THF $(20 \mathrm{~mL})$ was then slowly added at this temperature via a dropping funnel. The mixture was then allowed to slowly warm to $0^{\circ} \mathrm{C}$ before once again cooling to $-78^{\circ} \mathrm{C}$. A mixture of diethyl dichloromethylphosphonate $(4.42 \mathrm{~g}, 22 \mathrm{mmol})$ and the diaryl ketone $(20$ $\mathrm{mmol})$ in THF $(50 \mathrm{~mL})$ was then slowly added to the mixture maintaining the temperature at $-78^{\circ} \mathrm{C}$. Stirring was continued at this temperature for $10 \mathrm{~min}$ and then the reaction was allowed to warm to $0^{\circ} \mathrm{C}$ over a period of 30 min. The mixture was cooled to $-60^{\circ} \mathrm{C}$ and $n$-BuLi $(29 \mathrm{~mL}, 46 \mathrm{mmol})$ was added. The brownish mixture was then left to warm to $0^{\circ} \mathrm{C}$ over a period of $30 \mathrm{~min} . \mathrm{H}_{2} \mathrm{O}(20 \mathrm{~mL})$ was then added to the mixture with rapid stirring and the mixture was extracted with $\mathrm{Et}_{2} \mathrm{O}(3 \times 30 \mathrm{~mL})$ and the ethereal extracts washed with $\mathrm{H}_{2} \mathrm{O}(2 \times 20 \mathrm{~mL})$ then with $2 \mathrm{M} \mathrm{HCl}(3 \times 5 \mathrm{~mL})$ before drying $\left(\mathrm{MgSO}_{4}\right)$, filtration and evaporation to yield the crude compounds. These can be purified further by filtration through a silica gel plug using hexane as eluent or trituration with anhydrous hexane or column chromatography.

Depending upon the reaction conditions, the diethyl dichloromethylphosphonate $\mathbf{6 6}$ appears as an attractive synthetic reagent for the direct and selective transformation of carbonyl compounds to higher acetylenic derivatives by 1,1- or 1,2-elimination.

\subsubsection{Diethyl Dibromomethylphosphonate}


The diethyl dibromomethylphosphonate $\mathbf{7 6}$ was prepared from the diethyl chloromethylphosphonate $68 .^{272}$ The lithium carbenoid 69, generated by adding $n$-BuLi to 68 at $-75^{\circ} \mathrm{C}$, was treated at the same temperature with tetrabromomethane in the presence of lithium bromide for 40 min to give the 1-bromo-1-chloro-1-lithiomethylphosphonate 73. At $70^{\circ} \mathrm{C}$, due to metal-assisted ionization, $\mathbf{7 3}$ behaves as an electrophile and as such it reacts with $\mathrm{LiBr}$ to give mainly the 1,1-dibromo-1-lithiomethylphosphonate 74. Upon quenching with water the procedure leaves a crude mixture of 75 (90\%) and $76(10 \%)$ in $80-90 \%$ yield (Scheme 36). The olefination reaction for the synthesis of gem-dibromoalkenes from $\mathbf{7 6}$ has been applied to a variety of substrates including aldehydes and ketones. ${ }^{272}$ These gemdibromoalkenes $\mathbf{2 4}$ and $\mathbf{7 7}$ have mainly been used as source of alkylidene carbenes themselves generators of alkynes 5 by 1,2-migration. ${ }^{273-275}$

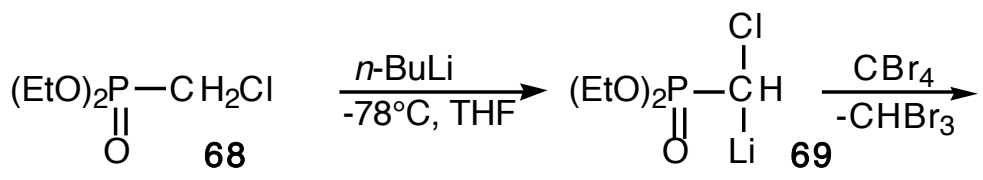<smiles>[Y][Te]C(Br)(Br)P(=O)(OCC)OCC</smiles><smiles>CCOP(=O)(OCC)C(Br)Br</smiles>

\section{Scheme 36.}

Diethyl dibromomethylphosphonate 76. ${ }^{272}$ Anhydrous $\mathrm{LiBr}(3.5 \mathrm{~g}, 0.04 \mathrm{~mol})$ is dissolved under nitrogen in THF $(100 \mathrm{~mL}), n$-BuLi $(0.02 \mathrm{~mol}+10 \%)$ in $\mathrm{Et}_{2} \mathrm{O}$ is added at $-10^{\circ} \mathrm{C}$, the mixture is cooled to $-75^{\circ} \mathrm{C}$, and diethyl chloromethylphosphonate $\mathbf{6 8}(3.7 \mathrm{~g}, 0.02 \mathrm{~mol})$ in THF $(20 \mathrm{~mL})$ is added dropwise with stirring. After $8 \mathrm{~min}$ stirring at $-75^{\circ} \mathrm{C}$, tetrabromomethane $\left(6.6 \mathrm{~g}, 0.02 \mathrm{~mol}\right.$ ) in $\mathrm{THF}(30 \mathrm{~mL})$ is added at $-70^{\circ} \mathrm{C}$ (sometimes the solution acquires a darkish colour). The stirring is continued for $40 \mathrm{~min}$ and water $(40 \mathrm{~mL})$ is the added. The resultant mixture is extracted with $\mathrm{CH}_{2} \mathrm{Cl}_{2}(2 \times 50 \mathrm{~mL})$. The organic layers are dried with anhydrous $\mathrm{MgSO}_{4}$ and the solvent and tribromomethane formed are removed under vacuum to leave a crude mixture of $\mathbf{7 5}+\mathbf{7 6}$; yield: $80-90 \%$.

The crude mixture of $\mathbf{7 5}$ and $\mathbf{7 6}$ is treated in THF at $-70^{\circ} \mathrm{C}$ with LDA in the presence of $\mathrm{LiBr}$. The lithiated reagents thus obtained react with carbonyl compounds at $-70^{\circ} \mathrm{C}$ but not as readily as the corresponding dichloro compound $\mathbf{6 1}$. Reaction with sterically hindered ketones affords the corresponding 1,1-dibromoalkenes 77 in good yields (45 to 70\%). ${ }^{272}$ The 1,1-dibromoalkenes $\mathbf{7 7}$ are generators of alkylidene carbenes, which are very reactive intermediates in organic synthesis. If the substituent $\mathrm{R}^{2}$ on the alkene of alkylidene carbene is a hydrogen or phenyl group, 1,2-migration occurs to give alkyne 5 (Scheme 37). ${ }^{274}$ Thus, when DMF solutions of dibromoalkenes $77\left(\mathrm{R}^{2}=\mathrm{H}\right.$ or $\left.\mathrm{Ph}\right)$ were treated with the stannyl anion 
$\mathrm{Bu}_{3} \mathrm{Sn}^{-}$, generated from $\mathrm{Me}_{3} \mathrm{SiSnBu}_{3}$ (3 eq.) in the presence of TASF $\left[\left(\mathrm{Et}_{2} \mathrm{~N}\right)_{3} \mathrm{~S}^{+} \mathrm{SiMe}_{3} \mathrm{~F}_{2}^{-}\right]$ ( 3 eq.) at room temperature for $3 \mathrm{~h}$, the desired alkynes 5 were obtained. When CsF was used instead of TASF, the yield of $\mathbf{5}$ decreased markedly. The reactions were carried out under several different conditions and THF can also be used as solvent. Various dibromoalkenes $\mathbf{7 7}$ were used for this reaction, and alkynes 5 were obtained in high yields (Table 10). ${ }^{275}$

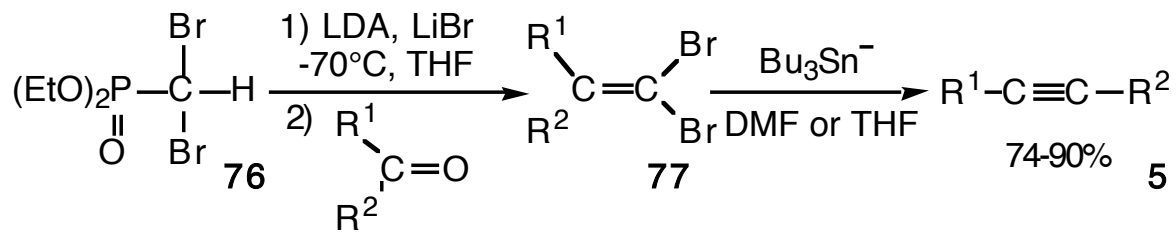

Scheme 37.

Table $10^{275}$

\begin{tabular}{cccc}
\hline $\mathbf{5}$ & $\mathbf{R}^{\mathbf{1}}$ & $\mathbf{R}^{\mathbf{2}}$ & Yield (\%) \\
\hline $\mathbf{a}$ & $\left(\mathrm{CH}_{3}\right)_{3} \mathrm{CCO}_{2}\left(\mathrm{CH}_{2}\right)_{5}$ & $\mathrm{C}_{6} \mathrm{H}_{5}$ & 74 \\
$\mathbf{b}$ & $\mathrm{C}_{8} \mathrm{H}_{17}$ & $\mathrm{C}_{6} \mathrm{H}_{5}$ & 90 \\
$\mathbf{c}$ & $\mathrm{CH}_{3}\left(\mathrm{CH}_{2}\right)_{3}$ & $4-\mathrm{Me}_{-} \mathrm{C}_{6} \mathrm{H}_{4}$ & 76 \\
$\mathbf{d}$ & $\mathrm{BzO}\left(\mathrm{CH}_{2}\right)_{3}$ & $\mathrm{H}$ & 76 \\
\hline
\end{tabular}

General procedure for the synthesis of alkynes 5:275 To a solution of $\mathrm{Me}_{3} \mathrm{SiSnBu}_{3}$ (3 equiv.) and 1,1dibromoalkene 77 ( 1 equiv.) in THF or DME (ca $0.25 \mathrm{M}$ solution) was added TASF (3 equiv.) at $0^{\circ} \mathrm{C}$ and the solution was stirred at the same temperature for an apropriate hour. To this solution AcOEt was added and the organic layer was washed with brine, dried over $\mathrm{Na}_{2} \mathrm{SO}_{4}$, and concentrated. The residue was purified by silica gel column chromatograhy to give the desired alkyne.

\subsubsection{Diethyl Diiodomethylphosphonate}

The diethyl diiodomethylphosphonate 79, reported in 1993, is the most recently described halomethylphosphonate. It is prepared from readily available diethyl iodomethyl-phosphonate 78, itself being obtained with $90 \%$ yield by a Michaelis-Arbuzov reaction (Scheme 38) between triethyl phosphite and diiodomethane. 276

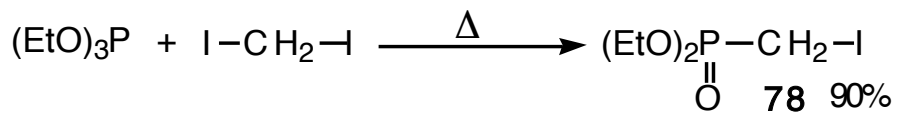

\section{Scheme 38 .}

Diethyl iodomethylphosphonate 78. ${ }^{276}$ Triethylphosphite $(83 \mathrm{~g}, 1 \mathrm{~mol})$ was added to $\mathrm{CH}_{2} \mathrm{I}_{2}(200 \mathrm{~g}, 1.5 \mathrm{~mol})$ at $185^{\circ} \mathrm{C}$ which was refluxing half-way up a column (10") containing glass helices and a condenser set for distillation. The rate of addition was adjusted so that distillation $\left(70-110^{\circ} \mathrm{C}\right)$ occurred steadily and the temperature increased, finally to $220^{\circ} \mathrm{C}$. Heating was continued for a further $10 \mathrm{~min}$. The products were ethyl iodide (74 g, 95\%), $\mathrm{CH}_{2} \mathrm{I}_{2}(68 \mathrm{~g}, 34 \%)$, and diethyl iodomethylphosphonate 78 (120 g, 90\%).

Addition of diethyl iodomethylphosphonate $\mathbf{7 8}$ to a mixture of LiHMDS and IHMDS, prepared in situ from LiHMDS and iodine in THF at $-70^{\circ} \mathrm{C}$, gave access to diethyl 1,1-diiodo- 
1-lithiomethylphosphonate $\mathbf{7 9}$ which was hydrolyzed to give diethyl diiodomethylphosphonate in $95 \%$ yield or which could be directly transformed into diiodoolefines $\mathbf{8 0}$ by reaction with carbonyl compounds. The in situ formation of diiodoolefines $\mathbf{8 0}$ gives successful results starting from aldehydes as well as from aliphatic, aromatic and functionalized ketones. It is also worth noting that starting from aldehydes and using this method in the presence of an excess of base (LiHMDS or KHMDS), leads to in situ dehydrohalogenation of diiodoalkenes $\mathbf{8 0}$, thus yielding iodoacetylenes $\mathbf{8 1}$ in good yields (58$85 \%$ ) (Scheme 39). ${ }^{277}$
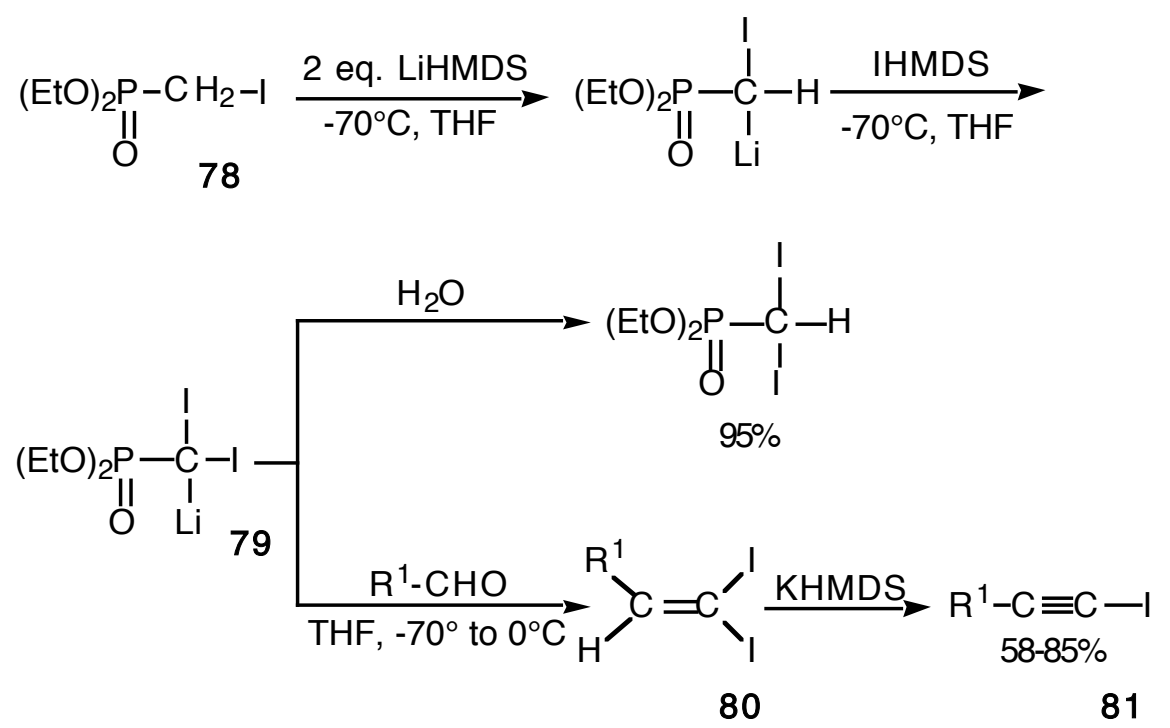

Scheme 39.

1,1-Diiodoalkenes 80: ${ }^{277} n$-BuLi $(0.90 \mathrm{~mL}$ of a $2.5 \mathrm{M}$ solution in hexane, $2.23 \mathrm{mmol})$, freshly titrated, was added at $0^{\circ} \mathrm{C}$ to a solution of 1,1,1,3,3,3-hexamethyldisilazane (HMDS) $(0.36 \mathrm{~g}, 2.23 \mathrm{mmol})$ in THF $(6 \mathrm{ml})$. The solution was stirred $30 \mathrm{~min}$ at $0^{\circ} \mathrm{C}$, then cooled to $-70^{\circ} \mathrm{C}$. A solution of $\mathrm{I}_{2}(0.26 \mathrm{~g}, 1.02 \mathrm{mmol})$ in $\mathrm{THF}(2 \mathrm{~mL})$ was added, then after $5 \mathrm{~min}$, a solution of diethyl iodomethylphosphonate $78(0.28 \mathrm{~g}, 1.02 \mathrm{mmol})$ in THF (2 mL) was added. After $90 \mathrm{~min}$ at $-70^{\circ} \mathrm{C}$, the carbonyl compound $(1.02 \mathrm{mmol})$ in THF $(1 \mathrm{~mL})$ was added. The mixture was stirred $5 \mathrm{~min}$ at $-70^{\circ} \mathrm{C}$, then warmed $1 \mathrm{~h}$ at $0^{\circ} \mathrm{C}$ and $2 \mathrm{~h}$ at r.t. After addition of water $(2 \mathrm{~mL})$, the aqueous solution was extracted with $\mathrm{Et}_{2} \mathrm{O}(5 \mathrm{x} 35 \mathrm{~mL})$. The combined organic layers were dried $\left(\mathrm{MgSO}_{4}\right)$ and evaporated. The diiodoalkenes were chromatographed over silica gel [light petroleum (b.p. 50-55 $\left.{ }^{\circ} \mathrm{C}\right) / \mathrm{Et}_{2} \mathrm{O}, 3 / 1$ ] .

\subsection{The Dialkyl $\alpha$-Halobenzylphosphonates}

Among the classical phosphorus reagents that have been frequently reported as precursors of internal acetylenes are metallated halobenzylphosphonates. For example, the $\alpha$-chlorostilbenes formed upon reaction of aldehydes with $\alpha$-metallated chlorobenzylphosphonate by a Horner-Wadsworth-Emmons reaction are readily converted under very mild conditions into internal alkynes 84 by 1,2-elimination reaction (Scheme 40). ${ }^{278,279}$ This approach permits sensitive functional groups to be part of the acetylenes. Since some difficulties may be encountered in the two first steps of this sequence, formation of $\alpha$-hydroxyphosphonates $\mathbf{8 2}$ and $\alpha$-halophosphonates $\mathbf{8 3}$, they have been investigated in depth. 280 
Numerous significant synthetic efforts have been devoted to the investigation of methods for the generation of $\alpha$-hydroxyphosphonates $\mathbf{8 2}$ from dialkylphosphites and aldehydes (aryl, substituted aryl and heteroaryl) by the Pudovik reaction. The more common procedure involved the addition of a small amount of alcoholic alkoxide ion to the reaction mixture. An alternative to the use of anionic bases is the use of neutral amines, the most commonly employed amine being triethylamine. It is apparent that amine bases will only catalyse adduct formation if the resulting adduct can be induced to precipitate from solution by suitable choice of solvent. For that reason, another innovation which has been developed in recent years is the use of a solid phase material as a basic catalyst. The advantage of such an approach is the simplicity of product isolation. 280

The nucleophilic halogenation of $\mathbf{8 2}$ has been realized in moderate to good yield with a variety of halogenating reagents : $\mathrm{POCl}_{3},{ }^{278,281,282} \mathrm{PPh}_{3} / \mathrm{CCl}_{4},{ }^{283} \mathrm{SOCl}_{2}{ }^{284}$ for chlorination, and $\mathrm{PPh}_{3} / \mathrm{CBr}_{4},{ }^{285} \mathrm{PPh}_{3} \mathrm{Br}_{2} / \mathrm{Py},{ }^{285} \mathrm{CH}_{2}=\mathrm{CHCH}_{2} \mathrm{Br} / \mathrm{CDI},{ }^{286} \mathrm{SOBr}_{2}{ }^{284}$ for bromination, to produce the corresponding $\alpha$-halophosphonates $\mathbf{8 3}(\mathrm{X}=\mathrm{Cl}, \mathrm{Br})$.

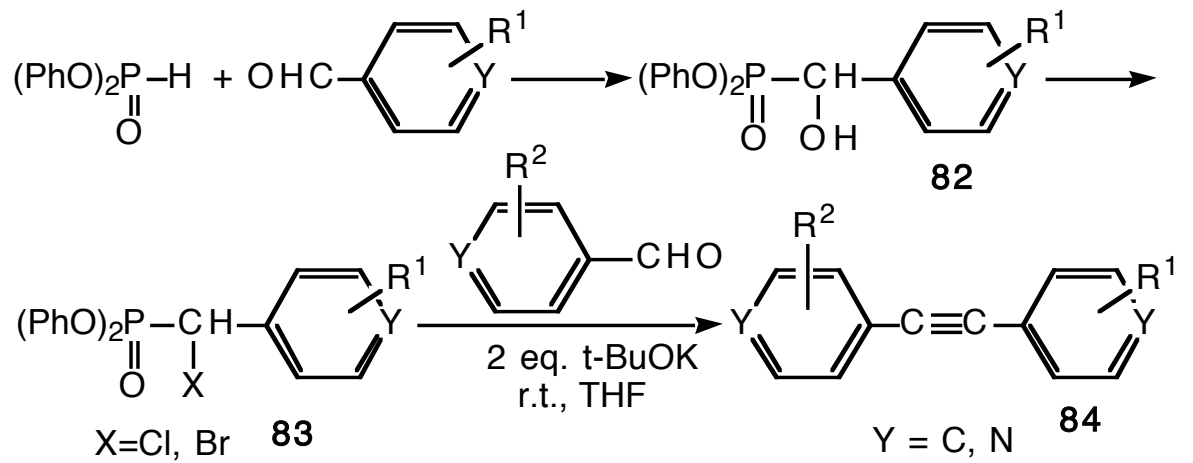

Scheme 40.

Owing to the facile olefination of the carbonyl group of aromatic or heteroaromatic aldehydes under the usual conditions of the Horner-Wadsworth-Emmons reaction, $\mathrm{NaH}$ or $t$-BuOK in THF (or DMSO) at room temperature are currently used as bases for the formation of $\alpha$ metallated chlorobenzylphosphonates. By using an excess of bases ( 2 eq.) the resulting $\alpha$ chlorostibenes are converted to internal alkynes 84. According to the sensitivity of the alkynes, the yields are good to excellent (Table 11). A number of compounds containing an additional triple bond and bearing electron-withdrawing and -donating groups in 4, 4' positions of the aromatic ring have recently been prepared with success by employing this method. $278,279,281,282,287$

\section{Table 11}

\begin{tabular}{ccccc}
\hline 84 & & $4-\mathrm{O}_{2} \mathrm{~N}-\mathrm{C}_{6} \mathrm{H}_{4}$ & $\begin{array}{c}\text { Yield } \\
(\%)\end{array}$ & Ref. \\
\hline a & $4-\mathrm{O}_{2} \mathrm{~N}-\mathrm{C}_{6} \mathrm{H}_{4}$ & & 67 & 278
\end{tabular}




\begin{tabular}{|c|c|c|c|c|}
\hline b & $4-\mathrm{O}_{2} \mathrm{~N}-\mathrm{C}_{6} \mathrm{H}_{4}$ & $4-\mathrm{NC}-\mathrm{C}_{6} \mathrm{H}_{4}$ & 80 & 278 \\
\hline c & $4-\mathrm{O}_{2} \mathrm{~N}-\mathrm{C}_{6} \mathrm{H}_{4}$ & 4-Pyridyl & 22 & 278 \\
\hline d & $4-\mathrm{O}_{2} \mathrm{~N}-\mathrm{C}_{6} \mathrm{H}_{4}$ & $\left(\mathrm{ClCH}_{2} \mathrm{CH}_{2}\right)_{2} \mathrm{~N}_{-} \mathrm{C}_{6} \mathrm{H}_{4}$ & 60 & 278 \\
\hline $\mathbf{e}$ & $4-\mathrm{O}_{2} \mathrm{~N}-\mathrm{C}_{6} \mathrm{H}_{4}$ & 4-MeO- $\mathrm{C}_{6} \mathrm{H}_{4}$ & 58 & 288 \\
\hline f & $4-\mathrm{O}_{2} \mathrm{~N}-\mathrm{C}_{6} \mathrm{H}_{4}$ & $4-\mathrm{Me}_{2} \mathrm{~N}-\mathrm{C}_{6} \mathrm{H}_{4}$ & 40 & 281 \\
\hline g & 4-Pyridyl & 4-MeO- $\mathrm{C}_{6} \mathrm{H}_{4}$ & 81 & 282 \\
\hline $\mathbf{h}$ & 4-Pyridyl & $4-\mathrm{Cl}-\mathrm{C}_{6} \mathrm{H}_{4}$ & 79 & 282 \\
\hline i & 4-Pyridyl & $4-\mathrm{Br}-\mathrm{C}_{6} \mathrm{H}_{4}$ & 76 & 282 \\
\hline $\mathbf{k}$ & 4-Pyridyl & $4-\mathrm{I}-\mathrm{C}_{6} \mathrm{H}_{4}$ & 22 & 282 \\
\hline 1 & 4-Pyridyl & 4-Pyridyl & 60 & 282 \\
\hline $\mathbf{m}$ & $4-\mathrm{Cl}-\mathrm{C}_{6} \mathrm{H}_{4}$ & $4-\mathrm{Me}_{2} \mathrm{~N}-\mathrm{C}_{6} \mathrm{H}_{4}$ & 32 & 288 \\
\hline $\mathbf{n}$ & $4-\mathrm{Br}-\mathrm{C}_{6} \mathrm{H}_{4}$ & 4-MeO- $\mathrm{C}_{6} \mathrm{H}_{4}$ & 26 & 288 \\
\hline $\mathbf{0}$ & $4-\mathrm{NC}-\mathrm{C}_{6} \mathrm{H}_{4}$ & $4-\mathrm{C}_{5} \mathrm{H}_{11} \mathrm{O}-\mathrm{C}_{6} \mathrm{H}_{4}$ & 34 & 288 \\
\hline
\end{tabular}

4-Iodophenyl-4-pyridylacetylene 84f. ${ }^{281}$ Diphenyl 1-Chloro-1-(4-pyridyl)methanephosphonate (1.4 g, 3.9 $\mathrm{mmol})$ and 4-iodobenzaldehyde $(1 \mathrm{~g}, 4.3 \mathrm{mmol})$ were treated with $t$-BuOK $(0.92 \mathrm{~g}, 8.2 \mathrm{mmol})$ in THF $(20 \mathrm{~mL})$ for $3 \mathrm{~h}$ at room temperature. After evaporation, water $(20 \mathrm{~mL})$ was added to the residue, which was extracted with $\mathrm{CH}_{2} \mathrm{Cl}_{2}$ and dried over $\mathrm{MgSO}_{4}$. The organic layer was removed and recrystallized from $\mathrm{EtOH}-\mathrm{CHCl}_{3}(1: 1)$ to give the product in $22 \%$ yield, m.p. $196^{\circ} \mathrm{C}$.

However, full utilization of this mild method for the synthesis of substituted diphenyl acetylenes is often handicapped by the availability of the two intermediates $\alpha$-hydroxy- $\mathbf{8 2}$ and $\alpha$-chlorophosphonates $\mathbf{8 3}$ (Scheme 40) which are obtained in modest yields and often contaminated with by-products. These disadvantages are overcome when the key intermediates, the diethyl $\alpha$-chlorobenzylphosphonates $\mathbf{8 8}$, are prepared from the readily available diethyl benzylphosphonates 85 via an electrophilic chlorination of the diethyl 1lithio-1-(trimethylsilyl)benzylphosphonates 86 with hexachloroethane. ${ }^{289,290}$ The TMSCl protecting group, which ensures a clean and complete chlorination in benzylic position, is easily removed from $\mathbf{8 7}$ to liberate the parent $\alpha$-chlorobenzylphosphonates $\mathbf{8 8}$ in analytically pure form and high yields (90-95\%). ${ }^{289,290}$ This recently reported one-pot procedure offers a shorter, more efficient route to $\alpha$-chlorobenzylphosphonates 88 (Scheme 41) than the previously described.

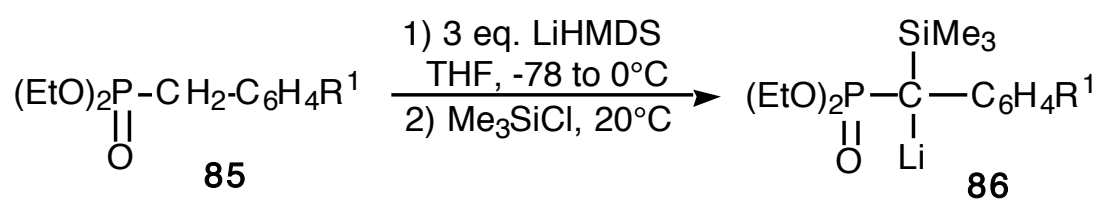

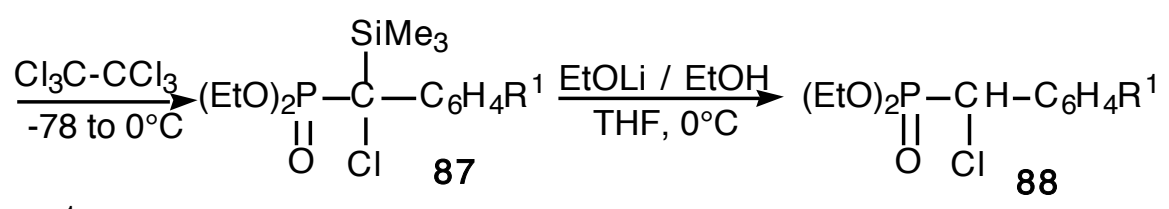

$\mathrm{R}^{1}=\mathrm{H}, 2-\mathrm{F}, 3-\mathrm{Me}, 4-\mathrm{Me}, 4-\mathrm{F}, 4-\mathrm{Cl}, 4-\mathrm{Br}, 4-\mathrm{MeO}$ 


\section{Scheme 41.}

General procedure for the synthesis of diethyl $\alpha$-chlorobenzylphosphonates 88.290 A freshly titrated solution of $n$-BuLi (18.75 mL of a $1.6 \mathrm{M}$ solution in hexane; $30 \mathrm{mmol}$ ) was added to THF (20 mL) cooled to $78^{\circ} \mathrm{C}$. A mixture of HMDS $(5.15 \mathrm{~g}, 32 \mathrm{mmol})$ and diethyl benzylphosphonate 85 (10 mmol) in THF (20 mL) was slowly added at this temperature via a dropping funnel. Few minutes later, the reaction mixture was allowed to warm slowly to $20^{\circ} \mathrm{C}$ and TMSCl $(1.3 \mathrm{~g}, 12 \mathrm{mmol})$ in THF $(10 \mathrm{~mL})$ was rapidly added. After $15 \mathrm{~min}$, the reaction mixture was cooled to $-78^{\circ} \mathrm{C}$ and the hexachloroethane $(11 \mathrm{mmol})$ in THF $(20 \mathrm{~mL})$ was slowly added. After $15 \mathrm{~min}$, the reaction mixture was allowed to warm-up to $0^{\circ} \mathrm{C}$ and then treated with an excess of EtOLi in EtOH. After $15 \mathrm{~min}$, the reaction mixture was poured with stirring into a mixture of $3 \mathrm{M} \mathrm{HCl}\left(20 \mathrm{~mL}^{2}, \mathrm{CH}_{2} \mathrm{Cl}_{2}\right.$ $(20 \mathrm{~mL})$ and ice $(10 \mathrm{~g})$ and the aqueous layer was extracted with $\mathrm{CH}_{2} \mathrm{Cl}_{2}(2 \times 20 \mathrm{~mL})$. The combined organic extracts are dried over $\mathrm{MgSO}_{4}$ and evaporated under reduce pressure to afford the desired product as a paleyellow oil. The isolated products were pure enough to make further purification useless. The chloro derivatives can be distillated under reduce pressure with a bulb-to-bulb apparatus or chromatographed on a silica column (70-230 mesh) and eluted with hexane/AcOEt (70/30).

Another useful technique for the olefination of the carbonyl group of aldehydes into chlorostibene derivatives is based upon the electrophilic chlorination of metallated diethyl benzylphosphonates with $\mathrm{CCl}_{4}$. For example, treatment of diethyl benzylphosphonates $\mathbf{8 5}$ with $n$-BuLi in THF at low temperature followed by addition of $\mathrm{CCl}_{4}$ gave the diethyl chlorobenzylphosphonate $\mathbf{8 8}$ which is slowly deprotonated by the trichloromethyllithium produced in the reaction medium to generate the diethyl 1-chloro-1-lithiobenzylphosphonates 86. When 89 were allowed to react at low temperature with aldehydes, chlorostilbenes 90 were obtained in $69-87 \%$ yields (Scheme 42$) .291$

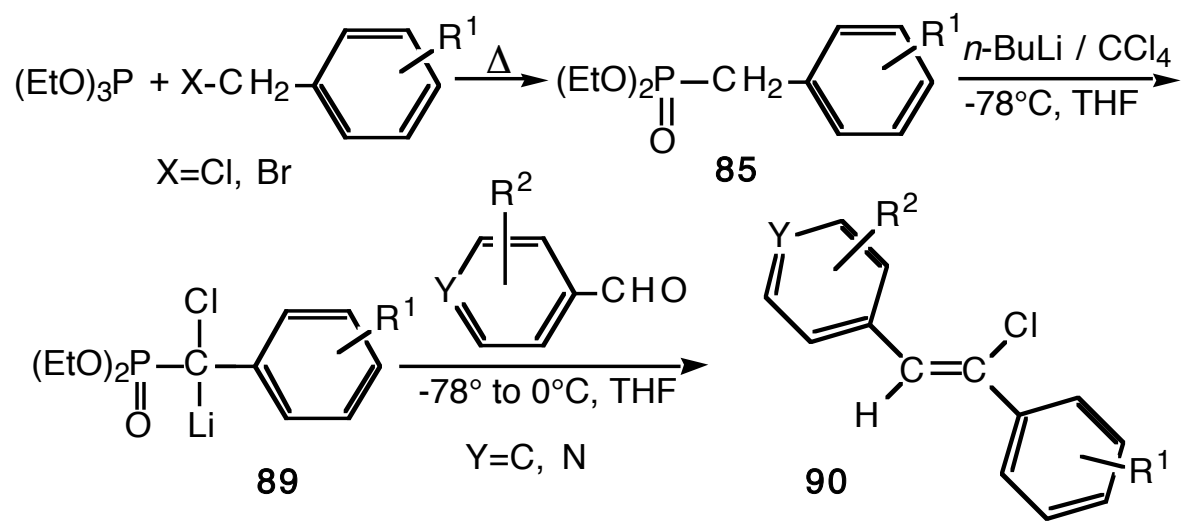

Scheme 42.

A more recent procedure for the synthesis of substituted diphenyl acetylenes involves the participation of $\alpha$-bromobenzylphosphonates. A one-pot procedure for the high yielding synthesis of pure diethyl $\alpha$-bromobenzylphosphonates has also been described. It involves the sequential electrophilic bromination of the diethyl 1-lithio-1-(trimethylsilyl)benzylphosphonates 86 with dibromotetrachloro- or dibromotetrafluoroethane to form the diethyl $\alpha$ bromo(trimethylsilyl)benzylphosphonate, from which the parent diethyl $\alpha$-bromobenzylphosphonates can be liberated in analytically pure form and high yields (85-95\%) (Scheme 41) by removal of the TMS group with an ethanolic solution of EtOLi. 290 
Similarly, acetylenic sulfones can be prepared by reaction of diethyl chloro(phenylsulfonyl)methylphosphonate with aromatic aldehydes in the presence of $t$-BuOK in excess. ${ }^{292}$

\subsection{Triethyl $\alpha$-Iodophosphonoacetate and Dialkyl 1-Chloro-2-Oxoalkyl-phosphonates}

The same approach for effecting a geminal halogenation-functionalization at a carbonyl group via an olefination reaction associated with an 1,2-elimination has also been reported from phosphonoacetate and $\beta$-ketophosphonate for the synthesis of terminal functional acetylenes. For example, a one-pot procedure for the transformation of the carbonyl group of aldehydes into propiolate has been described (Scheme 43). ${ }^{293-296}$ The reaction involves $\alpha$ iodination in DME at room temperature of the sodium phosphonate anion of triethyl phosphonoacetate 91 followed by olefination of benzaldehyde at room temperature to give the 1-iodo-1-(carboxyethyl)-2-phenylethylene 92 which was converted in the presence of $\mathrm{NaH}$ in excess at $40^{\circ} \mathrm{C}$ into ethyl phenylpropiolate 93 with $59 \%$ yield. ${ }^{293}$ Thus, a one-pot synthesis of substituted acetylenes is possible using halophosphonates directly or halophosphonates prepared in situ without the isolation of intermediate vinyl halides.
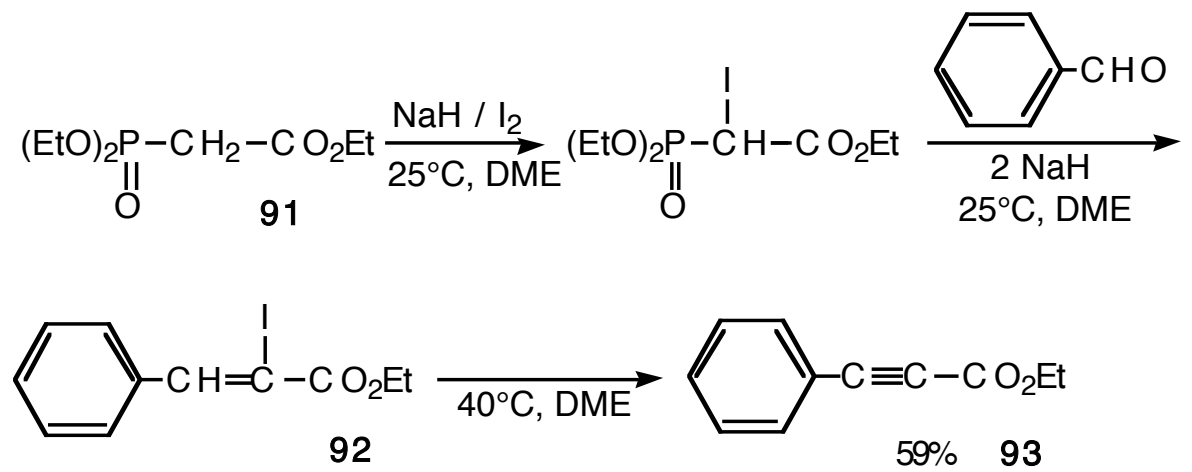

Scheme 43.

Ethyl $\beta$-phenylpropiolate $93 .{ }^{293}$ Triethyl phosphonoacetate $91(11.2 \mathrm{~g}, 0.05 \mathrm{~mol})$ was added at $25^{\circ} \mathrm{C}$ dropwise to a slurry of $50 \% \mathrm{NaH}(2.4 \mathrm{~g}, 0.05 \mathrm{~mol})$ in $100 \mathrm{~mL}$ of dry DME. The solution was stirred for $1 \mathrm{~h}$ until hydrogen gas evolution ceased. To the homogeneous solution was added dropwise iodine $(12.7 \mathrm{~g}, 0.05 \mathrm{~mol})$ dissolved in a minimum of solvent. After the addition, the solution was stirred at r.t. for $1 \mathrm{~h}$ and cooled to $10^{\circ} \mathrm{C} ; 50 \% \mathrm{NaH}(4.8$ $\mathrm{g}, 0.10 \mathrm{~mol}$ ) was added to the chilled solution all at once. The mixture was allowed to come to r.t. gradually during which time rapid gas evolution took place. Benzaldehyde $(5.3 \mathrm{~g}, 0.05 \mathrm{~mol})$ was added dropwise keeping the temperature at $25^{\circ} \mathrm{C}$. After the addition the solution was heated slowly to $40^{\circ} \mathrm{C}$ at which temperature rapid gas evolution took place. After gas evolution had ceased, the solution was cooled and a large excess of water added. The aqueous solution was extracted with $\mathrm{Et}_{2} \mathrm{O}(2 \times 100 \mathrm{~mL})$, and the ether extract dried over $\mathrm{MgSO}_{4}$ and evaporated. The residue now was distilled giving 5.1 g. $(59 \%)$ of distillate, b.p. $78-80^{\circ} \mathrm{C}(0.1 \mathrm{~mm})$.

Due to the inherent instability of natural prostacyclin toward hydrolytic conditions, many efforts have been made to develop chemically stable prostacyclin analogues by introducing several structural modifications and especially a triple bond in the lower side chain. The grafting of $\omega$-chains was achieved by Horner-Wadsworth-Emmons reaction with the appropriate halogenated $\beta$-ketophosphonates. ${ }^{297-299}$ Thus, the chlorinated or brominated $\beta$ - 
ketophosphonates were prepared in about $50 \%$ yield by reaction of $\beta$-ketophosphonates anion (NaH, DME, $0^{\circ} \mathrm{C}$ ) with $N$-chloro-299 or $N$-bromosuccinimide. ${ }^{297,298}$ Then the aldehydes 94 were condensed with sodium salt of $\beta$-ketophosphonate to give a mixture of $E$ and $Z$ - $\alpha$ chloro- or bromoenones 95, whose reduction with $\mathrm{NaBH}_{4}$ in $\mathrm{MeOH}$ at $-40^{\circ} \mathrm{C}$ produced a mixture of the allylic alcohols 96. Dehydrochlorination with $t$-BuOK in THF-DMSO at room temperature or dehydrobromination with $50 \%$ aqueous $\mathrm{NaOH}$ in toluene, catalytic $\mathrm{NBu}_{4} / \mathrm{HSO}_{4}$ at room temperature, converted the 13,14-double bond into the desired triple bond 97 (Scheme 44). ${ }^{299}$

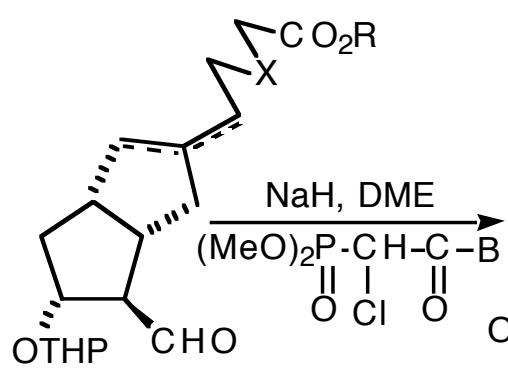

94

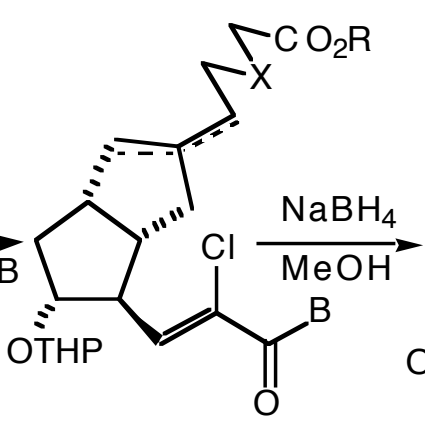

95

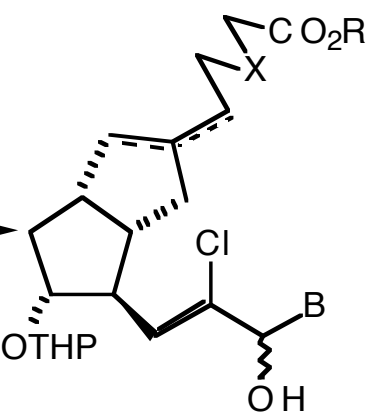

96

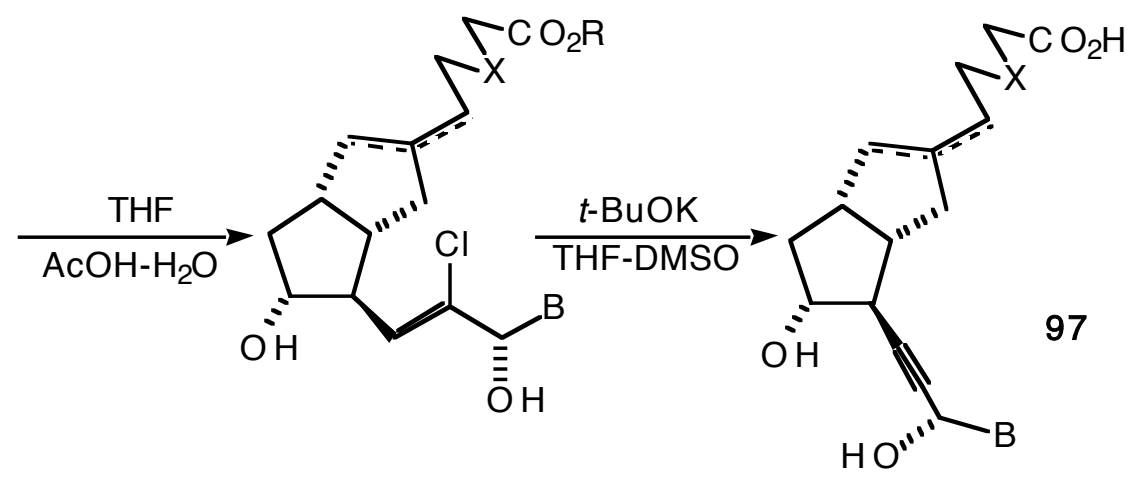

Schema 44.

\subsection{The Diethyl 2-Perfluoroalkenylphosphonate}

Extremely restricted methods are known for synthesizing perfluoroalkylsubstituted terminal acetylenes 100. An efficient method has been reported by dephosphorylation of 99 at the $\mathrm{sp}^{2}-$ hybridized carbon atom catalyzed by fluoride ion, which provides a method for the synthesis of perfluoroalkylacetylenes $\mathbf{1 0 0}$ from perfluoroalkanoyl chlorides 98 (Scheme 45). ${ }^{300-302}$

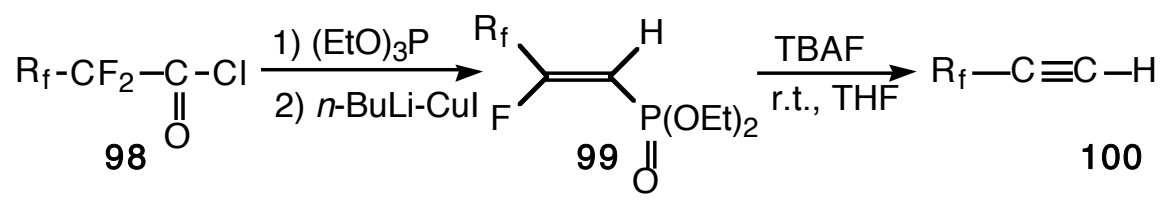

\section{Scheme 45.}


The perfluoroalkanoyl chlorides 98 were converted to $Z$-1H-F-1-alkene-1-phosphonates 99 by reaction with triethylphosphite followed by the reduction with $n-\mathrm{BuLi} / \mathrm{CuI}$ reagent. When phosphonates 99 thus prepared were treated with catalytic amount of $\mathrm{TBAF}$ at $0^{\circ} \mathrm{C}$ in $\mathrm{THF}$, the corresponding perfluoroacetylenes 100 were produced in good yields (74-89\%) (Table 12), together with a quantitative amount of (toxic) diethyl fluorophosphate.

Table $12^{300}$

\begin{tabular}{ccc}
\hline $\mathbf{1 0 0}$ & $\mathbf{R f}$ & Yield (\%) \\
\hline $\mathbf{a}$ & $\mathrm{CF}_{3} \mathrm{CF}_{2}$ & 89 \\
$\mathbf{b}$ & $\mathrm{CF}_{3}\left(\mathrm{CF}_{2}\right)_{5}$ & 85 \\
$\mathbf{c}$ & $\mathrm{CF}_{3}\left(\mathrm{CF}_{2}\right)_{7}$ & 74 \\
d & $\mathrm{CHF}_{2}\left(\mathrm{CF}_{2}\right)_{8}$ & 75 \\
\hline
\end{tabular}

General procedure ${ }^{300}$ To a solution of (Z)- $1 H$ - $F$-1-alkene-1-phosphonate $95(3 \mathrm{mmol})$ in anhydrous THF (8 $\mathrm{mL}$ ) was gradually added a solution of TBAF $(1 \mathrm{M}$ in THF, $0.3 \mathrm{~mL})$ under a nitrogen atmosphere at $0^{\circ} \mathrm{C}$. After being stirred at room temperature for $2 \mathrm{~h}$, the reaction mixture was poured onto ice-water followed by extraction $\left(\mathrm{Et}_{2} \mathrm{O}\right)$, drying $\left(\mathrm{Na}_{2} \mathrm{SO}_{4}\right)$, and evaporation. Silica gel chromatography or distillation of the crude product gave pure fluoroalkylacetylene 96. In the case of $\mathrm{R}_{\mathrm{f}}=\mathrm{C}_{2} \mathrm{~F}_{5}$, fluoroethylacetylene was collected at $-70^{\circ} \mathrm{C}$ from the reaction mixture (TG used as a solvent) under reduced pressure.

\section{Enol Phosphates Precursors of Acetylenic Compounds}

The first transformation of an enol phosphate into an acetylene was recorded in 1957. It was reported the formation of diethyl 1-propynylphosphonate $\mathbf{1 0 2}$ in $69 \%$ yield by the action of sodium ethoxide in refluxing ethanol on 2-(diethoxyphosphoryl)-1-methylvinylphosphate 101 (Scheme 46). ${ }^{303-305}$ This transformation into terminal acetylene was achieved with conservation of the carbon chain. However, owing to the constraints introduced by the structural requirement, and the difficulties frequently encountered in the choice of the base and elimination conditions, for a long period of time this method has not been developed. 306

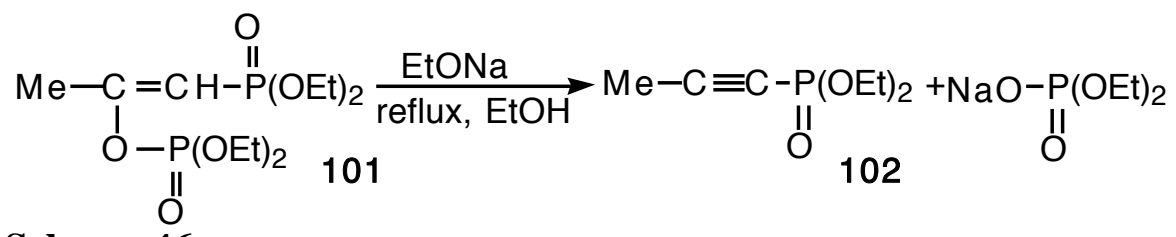

Scheme 46.

Starting vinyl phosphates may be obtained from enolizable ketones by reaction of the sodium enolate with a chlorophosphate; the reaction affords the trans isomers exclusively. With ketones that enolize little or not at all the interaction of the $\alpha$-chloroketone with triethylphosphite by the Perkow reaction yields predominantly the cis-enol phosphate. The Perkow reaction may also be used to obtain cis-enol phosphate from enolizable ketones. Finally, methyl ketones are transformed, through their chloromethyl derivatives, into vinyl phosphates containing a terminal methylene group. In all cases the yields of vinyl phosphates 
are good to excellent. A number of enol phosphates were prepared and their base-catalyzed elimination was examined under a variety of conditions. ${ }^{306}$

Many efforts have been done to discover a base which might cause elimination of the phosphate from the enol without also bringing about isomerization or hydrolysis. Thus, taking the trans-enol phosphate of ethyl benzoylacetate as model, it has been shown that the experimental conditions are crucial, and that successful elimination of phosphate with aqueous base at room temperature requires the presence of activating groups on both sides of the carbon system. For example, aqueous sodium hydroxide in aqueous dioxane or aqueous ethanol at room temperature gave only acetophenone and sodamide in liquid ammonia at $70^{\circ} \mathrm{C}$ gave phenylpropiolamide in $72 \%$ yield while at $-33^{\circ} \mathrm{C}$ phenylacetylene was the sole product. 306

Fortunately, in 1980 several innovations have significantly extended the synthetic utility of the formation of alkynes by elimination of a phosphate anion. In search of a practical and efficient method to convert dihydro- $\beta$-ionone $\mathbf{1 0 3}$ into the required acetylenic intermediate 105, several highly basic and sterically hindered amides (LDA, LTMP) were tested in order to form cleanly the "kinetic" enol phosphate 104 which on basic treatment eliminate regioselectively the phosphate anion (Scheme 47). 307,308

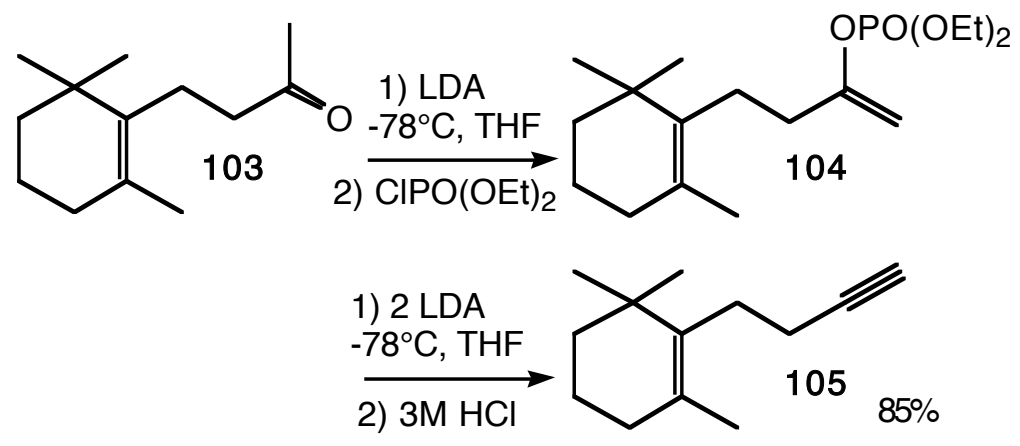

Scheme 47.

It was found that sequential but one-pot treatment of dihydro- $\beta$-ionone 103 with LDA (1.05 eq.) at low temperature in THF, then with diethyl chlorophosphate (1.1 eq.) between 78 and $25^{\circ} \mathrm{C}$ and again LDA (2.25 eq.) at low temperature, produces the acetylide intermediate which upon acidification and usual workup affords the desired alkyne $\mathbf{1 0 5}$ in $85 \%$ isolated yield. $\beta$-Ionone itself was cleanly converted into the corresponding terminal acetylene in $72-85 \%$ yield. ${ }^{307}$ This procedure was quite satisfactory in a few other cases where no isomer formation was possible. However, when it was applied to 2-octanone and 6methyl-5-hepten-2-one, both of which gave the desired acetylenes in only 20-25\% yields. Since both ketones are cleanly and regioselectively converted into the corresponding enol phosphates, the difficulty must lie in the $\beta$-elimination step. ${ }^{307}$ Later, the method has been applied with success in the conversion of geranylacetone into geranylacetylene in $67 \%$ yield, 
using LTMP as base (3.15 eq.), in the synthesis of silasqualene, ${ }^{309}$ and in the muli-step synthesis of manoalide 310 and aphidicolin 311,312 in the terpene field. On the basis of the enol phosphate route, several fluorophenylproparginols having hebicidal activity have been prepared from ketones. ${ }^{313}$ A thermal variant has also been reported, but the conversion was not complete. Thus, heating the diethyl 3-(fluoren-9-ylidene)-1,3-diphenylpropen-1-yl phosphate at $120^{\circ} \mathrm{C}$ for $100 \mathrm{~h}$ gave the 3-(fluoren-9-ylidene)-1,3-diphenylpropyne in modest yield $(10.1 \%) .314$

1-(3-Butynyl)-2,6,6-trimethyl-1-cyclohexene. ${ }^{307}$ The following is representative of the LDA procedure for the conversion of methyl ketones into terminal acetylenes. To a solution of LDA prepared at $0^{\circ} \mathrm{C}$ from diisopropylamine (10.6 g, $105 \mathrm{mmol})$ and $n$-BuLi in hexane $(2.3 \mathrm{M}, 45.6 \mathrm{~mL}, 105 \mathrm{mmol})$ in $200 \mathrm{~mL}$ of dry THF is added dropwise dihydro- $\beta$-ionone $(19.4 \mathrm{~g}, 100 \mathrm{mmol})$ in $20 \mathrm{~mL}$ of $\mathrm{THF}$ at $-78^{\circ} \mathrm{C}$. After the solution was stirred for $1 \mathrm{~h}$, diethyl chlorophosphate $(19.0 \mathrm{~g}, 15.9 \mathrm{~mL}, 110 \mathrm{mmol})$ was added at this temperature. After the reaction mixture was gradually warmed to room temperature it was added dropwise to a solution of LDA in THF $\left(225 \mathrm{mmol}\right.$ ) prepared at $-78^{\circ} \mathrm{C}$ as described above. The resultant mixture was warmed to room temperature over $3 \mathrm{~h}$ and quenched with water. The organic compounds were extracted with pentane, washed with $1 \mathrm{~N} \mathrm{HCl}$, water, and aqueous $\mathrm{NaHCO}_{3}$, dried over $\mathrm{MgSO}_{4}$, and distilled to give $15.0 \mathrm{~g}(85 \%)$ of the title compound.

\section{Conclusion}

Undoubtedly, the preparation of terminal or internal alkynes from carbonyl compounds using phosphoranes or phosphonates by a two-step procedure, including a Wittig or a HornerWadsworth-Emmons reaction and an elimination reaction, is a valuable and fairly general synthetic method. They may each be employed as reagents to produce in large scale common alkynes with good purity or to introduce the triple bond in complex polyfunctional molecules. Therefore, the procedure involving the formation of the carbon-carbon double bond prior to unmasking the alkynes, the more reactive phosphonate reagents appear to have the greater synthetic utility. Not only a number of phosphonate reagents are now available, but the more recent innovations have been accomplished in this field. They may be used for the preparation in mild conditions either of terminal or internal alkynes, and in addition the elimination of diethylphosphate salt in water simplifies considerably the purification of the alkynes. Finally the formation of alkynes by the enol phosphates route, instead of ponctual utility, should merit an exhaustive study. Henceforth, it appears that the phosphorus reagents are versatile precursors and there will be of increasing importance in preparative chemistry of alkynes.

\section{Acknowledgements}

We are grateful to Elf Atochem S.A. for financial support to B.I., to M. Multan from the Ecole Polytechnique (BCX) for technical assistance in collecting the literature and the Centre National de la Recherche Scientifique (CNRS).

\section{References}

(1) Viehe, H. G., Ed. In Chemistry of Acetylenes, Marcel Dekker, New-York, 1969. 
(2) Houben-Weyl-Müller, In Methoden der Organischen Chemie, Alkine. Di- und Polyine Allene, Kumulene, 1977, Vol. V/2a, pp. 33.

(3) Patai, S., Ed. In The Chemistry of the Carbon-Carbon Triple Bond, Parts 1 and 2, John Wiley, Chichester, 1978.

(4) Brandsma, L. In Preparative Acetylenic Chemistry, 2nd ed., Elsevier, Amsterdam, 1988.

(5) Stang, P. J.; Diederich, F. In Modern Acetylene Chemistry, VCH, Weinheim, 1995.

(6) Staudinger, H., Hauser, E. Helv. Chim. Acta 1921, 4, 861-886.

(7) Trippett, S., Walker, D. M. J. Chem. Soc. 1959, 3874-3876.

(8) Gough, S. T. D.; Trippett, S. Proc. Chem. Soc. London 1961, 302.

(9) Märkl, G. Chem. Ber. 1961, 94, 3005-3010.

(10) Gough, S. T. D.; Trippett, S. J. Chem. Soc. 1962, 2333-2337.

(11) Johnson, A. W., Kaska, W. C., Ostoja Starzewski, K. A., Dixon, D. A. In Ylides and Imines of Phosphorus, John Wiley \& Sons, Inc., New-York, 1993.

(12) Gough, S. T. D.; Trippett, S. J. Chem. Soc. 1964, 543-544.

(13) Kobayashi, Y.; Yamashita, T.; Takahashi, K.; Kuroda, H.; Kumadaki, I. Tetrahedron Lett. 1982, 23, 343-344.

(14) Listvan, V. N.; Stasyuk, A. P.; Kurgan, L. N. Zh. Org. Khim. 1987, 57, 1534-1540 ; J. Gen. Chem. USSR (Engl. Transl.) 1987, 57, 1366-1371.

(15) Listvan, V. N.; Stasyuk, A. P.; Kornilov, M. Yu.; Komarov, I. V. Zh. Obshch. Khim. 1990, 60, 704-707 ; J. Gen. Chem. USSR (Engl. Transl.) 1990, 60, 804-807.

(16) Brittain, J. M.; Jones, R. A.; Taheri, S. A. N. Tetrahedron 1992, 48, 7609-7618.

(17) Bestmann, H. J.; Kamberger, W.; Röder, T.; Zimmermann, R. Liebigs Ann. Org. Bioorg. Chem. 1996, 5, 845-852.

(18) Märkl, G. Angew. Chem. 1962, 74, 217.

(19) Petragnani, N.; Schill, G. Chem. Ber. 1964, 97, 3293-3297.

(20) Chopard, P. A.; Searle, R. J. G.; Devitt, F. H. J. Org. Chem. 1965, 30, 1015-1019.

(21) Nakamura, N.; Kishida, Y.; Ishida, N. Chem. Pharm. Bull. 1971, 19, 1389-1394.

(22) Bohlmann, F., Skuballa, W. Chem. Ber. 1973, 106, 497-504.

(23) Cleve, G., Herrmann, Ch., Hoyer, G.-A., Seeger, A., Strehlke, P. Liebigs Ann. Chem. 1976, 1531-1536.

(24) Bestmann, H. J.; Geismann, C. Justus Liebigs Ann. Chem. 1977, 282-287.

(25) Babin, P.; Dunogues, J.; Petraud, M. Tetrahedron 1981, 37, 1131-1139.

(26) Babin, P.; Dunogues, J.; Duboudin, F. J. Heterocycl. Chem. 1981, 18, 519-523.

(27) Babin, P.; Dunogues, J.; Duboudin, F.; Petraud, M. Bull. Soc. Chim. Fr. 1982, $125-$ 128. 
(28) Gramenitskaya, V. N.; Inozemtseva, L. V.; Koz'mina, E. A.; Vul'fson, N. S. Zh. Org. Khim. 1982, 18, 2260-2267 ; J. Org. Chem. USSR (Engl. Transl.) 1982, 18, 25612570 .

(29) Tokuda, M.; Nishio, O. J. Org. Chem. 1985, 50, 1592-1596.

(30) Abell, A. D.; Heinicke, G. W.; Massy-Westropp, R. A. Synthesis 1985, 764-766.

(31) Andrews, P. R.; Brinkworth, R. I.; Partridge, A. C.; Reiss, J. A. Aust. J. Chem. 1988, $41,1717-1726$.

(32) D'Agostini, A.; D'Auria, M. J. Chem. Soc., Perkin Trans. 1 1994, 1245-1250.

(33) Bestmann, H. J.; Geismann, C.; Zimmermann, R. Chem. Ber. 1994, 127, 1501-1510.

(34) Zehnter, R.; Gerlach, H. Liebigs Ann. Org. Bioorg. Chem. 1995, 12, 2209-2220.

(35) Himbert, G.; Fink, D. J. Prakt. Chem. / Chem.-Ztg. 1997, 339, 233-242.

(36) Shen, Y.; Zheng, J. J. Fluorine Chem. 1987, 35, 513-522.

(37) Abramovitch, R. A.; Cue, B. W. J. Org. Chem. 1980, 45, 5316-5319.

(38) Huang, Y. Z.; Shen, Y. C.; Ding, W.; Zheng, J. Tetrahedron Lett. 1981, 22, 52835284.

(39) Rehman, H; Rao, J. M. Tetrahedron 1987, 43, 5335-5340.

(40) Rehman, H.; Rao, J. M. Synth. Commun. 1987, 17, 1119-1128.

(41) Bestmann, H. J.; Schmidt, M. Angew. Chem. Int. Ed. Engl. 1987, 26, 79-81.

(42) Yadla, R.; Rao, J. M. Heterocycles 1987, 26, 329-331.

(43) Yadla, R.; Rao, J. M. Indian J. Chem. Sect. B 1988, 27, 1125-1127.

(44) Heard, N. E.; Turner, J. L. J. Org. Chem. 1995, 60, 4302-4304.

(45) Heard, N. E.; Turner, J. L. J. Org. Chem. 1995, 60, 7074.

(46) Koller, M.; Karpf, M.; Dreiding, A. S. Helv. Chim. Acta 1983, 66, 2760-2768.

(47) Hussain, S.; Agosta, W. C. Tetrahedron 1981, 37, 3301-3305.

(48) Blitzke, T.; Sicker, D.; Wilde, H. Synthesis 1995, 236-238.

(49) Bestmann, H. J.; Roth, K. Tetrahedron Lett. 1981, 22, 1681-1684.

(50) Braga, A. L.; Comasseto, J. V.; Petragnani, N. Tetrahedron Lett. 1984, 25, 1111-1114.

(51) Braga, A. L.; Comasseto, J. V.; Petragnani, N. Synthesis 1984, 240-243.

(52) Wang, L.; Huang, Z.-Z.; Li, H.; Huang, X. Org. Prep. Proced. Int 1995, 27, 213-215.

(53) Shen, Y.; Lin, Y.; Xin, Y. Tetrahedron Lett. 1985, 26, 5137-5138.

(54) Shibuya, M.; Chou, H.-M.; Fountoulakis, M.; Hassam, S.; Kim, S.-U.; Kobayashi, K.; Otsuka, H.; Rogalska, E.; Cassady, J. M.; Floss, H. G. J. Am. Chem. Soc. 1990, 112, 297-304.

(55) Hamper, B. C. J. Org. Chem. 1988, 53, 5558-5562.

(56) Hamper, B. C.; Kurtzweil, M. L.; Beck, J. P. J. Org. Chem. 1992, 57, 5680-5686.

(57) Ohmori, H.; Maeda, H.; Tamaoka, M.; Masui, M. Chem. Pharm. Bull. 1988, 36, 613620.

(58) Hamper, B. C. Org. Synth. 1992, 70, 246-255. 
(59) Schweizer, E. E.; Lee, K.-J. J. Org. Chem. 1982, 47, 2768-2773.

(60) Schweizer, E. E.; Hsueh, W.; Rheingold, A. L.; Durney, R. L. J. Org. Chem. 1983, 48, 3889-3894.

(61) Schweizer, E. E.; Lee, K.-J. J. Org. Chem. 1984, 49, 1959-1964.

(62) Akiyama, S.; Nakasuji, K.; Nakagawa, M. Bull. Chem. Soc. Jpn. 1971, 44, 2231-2236.

(63) Nakasuji, K.; Akiyama, S.; Nakagawa, M. Bull. Chem. Soc. Jpn. 1972, 45, 883-891.

(64) Kawada, Y.; Sakai, H.; Oguri, M.; Koga, G. Tetrahedron Lett. 1994, 35, 139-142.

(65) Huang, Y. Z.; Shen, C.; Xin, Y. K.; Wang, Q.; Wu, W. C. Sci. Sin. (Engl. Ed.) 1982, $25 B, 21$.

(66) Fabron, J.; Pastor, R.; Cambon, A. J. Fluorine Chem. 1987, 37, 371-386.

(67) Dunn, P. J.; Rees, C. W. J. Chem. Soc., Perkin Trans. 1 1987, 1579-1584.

(68) Shen, Y.; Zheng, J.; Huang, Y. J. Fluorine Chem. 1988, 41, 363-370.

(69) Zarif, L.; Greiner, J.; Pace, S.; Riess, J. G. J. Med. Chem. 1990, 33, 1262-1269.

(70) Barlow, M. G.; Suliman, N. N. E.; Tipping, A. E. J. Fluorine Chem. 1995, 70, 59-70.

(71) Shen, Y.; Gao, S. J. Fluorine Chem. 1993, 61, 105-109.

(72) Shen, Y.; Cen, W.; Huang, Y. Synthesis 1985, 159-160.

(73) Shen, Y.; Xin, Y.; Cen, W.; Huang, Y. Synthesis 1984, 35-37.

(74) Shen, Y.; Qiu, W.; Xin, Y.; Huang, Y. Synthesis 1984, 924-926.

(75) Shen, Y.; Xiang, Y.; Qiu, W. J. Chem. Soc., Perkin Trans. 1 1991, 2965-2968.

(76) Filler, R.; Heffern, E. W. J. Org. Chem. 1967, 32, 3249-3251.

(77) Kobayashi, Y.; Yamashita, T.; Takahashi, K.; Kuroda, H.; Kumadaki, I. Chem. Pharm. Bull. 1984, 32, 4402-4409.

(78) Shen, Y.; Qiu, W. Synthesis 1987, 42-43.

(79) Shen, Y.; Cen, W.; Huang, Y. Synthesis 1987, 626-628.

(80) Xin, Y.; Wu, X.; Shen, Y.J. Fluorine Chem. 1988, 40, 15-22.

(81) Ohmori, H.; Maeda, H.; Ueda, C.; Masui, M. J. Chem. Soc., Chem. Commun. 1988, 874-875.

(82) Aitken, R. A.; Atherton, J. I. J. Chem. Soc., Chem. Commun. 1985, 1140-1141.

(83) Aitken, R. A.; Atherton, J. I. J. Chem. Soc., Perkin Trans. 1 1994, 1281-1284.

(84) Aitken, R. A.; Horsburg, C. E. R.; McCreadie, J. G.; Seth, S. J. Chem. Soc., Perkin Trans. 1 1994, 1727-1732.

(85) Aitken, R. A.; Burns, G. Tetrahedron Lett. 1987, 28, 3717-3718.

(86) Aitken, R. A.; Burns, G. J. Chem. Soc., Perkin Trans. 1 1994, 2455-2460.

(87) Aitken, R. A.; Herion, H.; Janosi, A.; Karodia, N.; Raut, S. V.; Seth, S.; Shannon, I. J.; Smith, F. C. J. Chem. Soc., Perkin Trans. 1 1994, 2467-2472.

(88) Koz'minykh, E. N.; Berezina, E. S.; Koz'minykh, V. O.; Aitken, R. A.; Karodia, H.; Massil, T. Russ. J. Gen. Chem. (Engl. Transl) 1998, 68, 390-394.

(89) Aitken, R. A.; Seth, S. J. Chem. Soc., Perkin Trans. 1 1994, 2461-2466. 
(90) Aitken, R. A.; Herion, H.; Horsburgh, C. E. R.; Karodia, N.; Seth, S. J. Chem. Soc., Perkin Trans. 1 1996, 485-490.

(91) Aitken, R. A.; Boeters, C.; Morrison, J. J. J. Chem. Soc., Perkin Trans. 1 1994, 2473 2880 .

(92) Aitken, R. A.; Cooper, H. R.; Mehrotra, A. P. J. Chem. Soc., Perkin Trans. 1 1996, 475-483.

(93) Aitken, R. A.; Boeters, C.; Morrison, J. J. Tetrahedron Lett. 1995, 36, 1303-1306.

(94) Aitken, R. A.; Boeters, C.; Morrison, J. J. J. Chem. Soc., Perkin Trans. 1 1997, 26252632.

(95) Aitken, R. A.; Karodia, N. J. Chem. Soc., Chem. Commun. 1996, 2079-2080.

(96) Aitken, R. A.; Karodia, N. Liebigs Ann., Recl. 1997, 4, 779-784.

(97) Braga, A. L.; Comasseto, J. V. Synth. Commun. 1989, 19, 2877-2884.

(98) Bestmann, H. J.; Kumar, K.; Schaper, W. Angew. Chem. Int. Ed. Engl. 1983, 22, 167168.

(99) Zbiral, E. Monatsh. Chem. 1966, 97, 180-202.

(100) Zbiral, E.; Hengstberger, H. Monatsh. Chem. 1968, 99, 412-428.

(101) Orlov, V.Yu.; Lebedev, S. A.; Ponomarev, S. V.; Lutsenko, I. F. Zh. Obshch. Khim. 1975, 45, 696-697 ; J. Gen. Chem. USSR (Engl. Transl.) 1975, 45, 708-709.

(102) Al-Hakim, A. H.; Haines, A. H. Tetrahedron Lett. 1982, 23, 5295-5298.

(103) Abell, A. D.; Hoult, D. A.; Morris, K. M.; Taylor, J. M.; Trent, J. O. J. Org. Chem. 1993, 58, 1531-1537.

(104) Kita, Y.; Tsuzuki, Y.; Kitagaki, S.; Akai, S. Chem. Pharm. Bull. 1994, 42, 233-236.

(105) Rabinowitz, R.; Marcus, R. J.Am. Chem. Soc. 1962, 84, 1312-1313.

(106) Ramirez, F.; Desai, N. B.; McKelvie, N. J. Am. Chem. Soc. 1984, 84, 1745-1747.

(107) Miller, B. In Topics in Phosphorus Chemistry, Grayson, M. and Griffith, E. J. Eds., John Wiley and Sons, New-York, 1965, 133-199.

(108) Raulet, C.; Levas, E. C. R. Acad. Sci. Paris 1970, 270C, 1467-1470.

(109) Corey, E. J.; Fuchs, P. L. Tetrahedron Lett. 1972, 3769-3772.

(110) Beny, J.-P.; Dhawan, S. N.; Kagan, J.; Sundlass, S. J. Org. Chem. 1982, 47, 22012204.

(111) Feldman, K. S.; Simpson, R. E. J. Am. Chem. Soc. 1989, 111, 4878-4886.

(112) Chung, J. Y. L.; Wasicak, J. Tetrahedron Lett. 1990, 31, 3957-3960.

(113) Rey, G. J.; Rodriguez, J.; de Lera, A. R. Tetrahedron Lett. 1993, 34, 6293-6296.

(114) Morris, J.; Wishka, D. G. Synthesis 1994, 43-46.

(115) Reginato, G.; Mordini, A.; Degl'Innocenti, A., Caracciolo, M. Tetrahedron Lett. 1995, 36, 8275-8278.

(116) Haley, M. M.; Biggs, B.; Looney, W. A.; Gilbertson, R. D. Tetrahedron Lett. 1995, $36,3457-3460$. 
(117) D'Auria, M.; Ferri, T. J. Org. Chem. 1995, 60, 8360-8364.

(118) Shaw, A. N.; Dolle, R. E.; Kruse, L. I. Tetrahedron Lett. 1990, 31, 5081-5084.

(119) Chuche, J.; Grandjean, D.; Pale, P. Bull. Soc. Chim. Belg. 1992, 101, 415-432.

(120) Grandjean, D.; Pale, P.; Chuche, J. Tetrahedron Lett. 1994, 35, 3529-3530.

(121) Bestmann, H. J.; Frey, H. Liebigs Ann. Chem. 1980, 12, 2061-2071.

(122) Salmond, W. G.; Sobala, M. C.; Maisto, K. D. Tetrahedron Lett. 1977, 1237-1238.

(123) Seyferth, D.; Grim, S. O.; Read, T. O. J. Am. Chem. Soc. 1960, 82, 1510-1511.

(124) Seyferth, D.; Grim, S. O.; Read, T. O. J. Am. Chem. Soc. 1961, 83, 1613-1616.

(125) Seyferth, D.; Grim, S. O.; Read, T. O. J. Am. Chem. Soc. 1961, 83, 1617-1620.

(126) Appel, R.; Morbach, W. Synthesis 1977, 699-700.

(127) Miyano, S.; Izumi, Y.; Fujii, K.; Ohno, Y.; Hashimoto, H. Bull. Chem. Soc. Jpn. 1979, $52,1197-1202$.

(128) Wolinski, J.; Erickson, K. L. J. Org. Chem. 1965, 30, 2208-2211.

(129) Seyferth, D.; Heeren, J. K.; Singh, G.; Grim, S. O.; Hughes, W. B. J. Organomet. Chem. 1966, 5, 267-274.

(130) Hoffmann, H. Angew. Chem. 1960, 72, 77.

(131) Wittig, G.; Schlosser, M. Angew. Chem. 1960, 72, 324.

(132) Wittig, G.; Schlosser, M. Chem. Ber. 1961, 94, 1373-1383.

(133) Schlosser, M. Chem. Ber. 1964, 97, 3221-3233.

(134) Köbrich, G.; Trapp, H.; Flory, K.; Drischel, W. Chem. Ber. 1966, 99, 689-697.

(135) Schlosser, M.; Ladenberger, V. Chem. Ber. 1967, 100, 3901-3915.

(136) Köbrich, G. Angew. Chem. 1962, 74, 33.

(137) Köbrich, G.; Breckoff, W. E.; Drischel, W. Liebigs Ann. Chem. 1967, 704, 51-69.

(138) Nicolaou, K. C.; Duggan, M. E.; Hwang, C.-K. J. Am. Chem. Soc. 1989, 111, 66766682 .

(139) Miyano, S.; Izumi, Y.; Hashimoto, H. J. Chem. Soc., Chem. Commun. 1978, 446-447.

(140) Wittig, G.; Witt, H. Ber. Dtsch. Chem. Ges. 1941, 74, 1474-1491.

(141) Wittig, G.; Harborth, G. Ber. Dtsch. Chem. Ges. 1944, 77, 306.

(142) Wittig, G.; Harborth, G. Ber. Dtsch. Chem. Ges. 1944, 77, 315.

(143) Köbrich, G. Angew. Chem. 1965, 77, 75-94.

(144) Schlosser, M; Ladenberger, V. Chem. Ber. 1967, 100, 3877-3892.

(145) Schlosser, M; Ladenberger, V. Chem. Ber. 1967, 100, 3893-3900.

(146) Yeh, C.-L.; Dawson, M.; Hemler, M. E.; Lands, W. E. M. Tetrahedron Lett. 1977, 4257-4260.

(147) Hanzawa, Y.; Yamada, A.; Kobayashi, Y. Tetrahedron Lett. 1985, 26, 2881-2884.

(148) Frye, L. L.; Robinson, C. H. J. Chem. Soc., Chem. Commun. 1988, 129-131.

(149) Corey, E. J.; Ruden, R. A. Tetrahedron Lett. 1973, 1495-1499.

(150) Fujimoto, R.; Kishi, Y.; Blount, J. F. J. Am. Chem. Soc. 1980, 102, 7154-7156. 
(151) Metcalf, B. W.; Wright, C. L.; Burkhart, J. P.; Johnston, J. O. J. Am. Chem. Soc. 1981, $103,3221-3222$.

(152) Morris, J.; Wishka, D. G. Tetrahedron Lett. 1986, 27, 803-806.

(153) Field, D. J.; Jones, D. W.; Kneen, G. J. Chem. Soc., Perkin Trans. 1 1978, 1050-1058.

(154) Mehta, G.; Panda, G. Tetrahedron Lett. 1997, 38, 2145-2148.

(155) Fienemann, H.; Köbrich, G. Chem. Ber. 1974, 107, 2797-2803.

(156) Arnold, D. P.; Johnson, A. W.; Mahendran, M. J. Chem. Soc., Perkin Trans. 1 1978, 366-370.

(157) Arnold, D. P.; Nitschinsk, L. J. Tetrahedron 1992, 48, 8781-8792.

(158) Matsumoto, M.; Kuroda, K. Tetrahedron Lett. 1980, 21, 4021-4024.

(159) Sakai, K.; Fujimoto, T.u; Yamashita, M.; Kondo, K. Tetrahedron Lett. 1985, 26, 20892092 .

(160) Sugai, T.; Tojo, H.; Mori, K. Agric. Biol. Chem. 1986, 50, 3127-3132.

(161) Drewes, S. E.; Emslie, N. D.; Hemingway, M. Synth. Commun. 1990, 20, 1671-1679.

(162) Iguchi, S.; Iwamura, H.; Nishizaki, M.; Hayashi, A.; Senokuchi, K.; Kobayashi, K.; Sakaki, K.; Hachiya, K.; Ichioka, Y.; Kawamura, M. Chem. Pharm. Bull. 1992, 40, 1462-1469.

(163) Kuwayama, T.; Nakasawa, M.; Asanuma, G.; Shiono, M. Patent 1999, JP 11124345; C.A. 1999, 130, 311558 .

(164) Stork, G.; Zhao, K. Tetrahedron Lett. 1989, 30, 2173-2174.

(165) Bestmann, H. J.; Rippel, H. C.; Dostalek, R. Tetrahedron Lett. 1989, 30, 5261-5262.

(166) Torrado, A.; Iglesias, B.; Lopez, S.; de Lera, A. R. Tetrahedron 1995, 51, 2435-2454.

(167) Märkl, G. Chem. Ber. 1961, 94, 2996-3004.

(168) Denney, D. B.; Ross, S. T. J. Org. Chem. 1962, 27, 998-1000.

(169) Speziale, A. J.; Ratts, K. W. J. Org. Chem. 1963, 28, 465-469.

(170) Grigorenko, A. A.; Shevchuk, M. I.; Dombrovskii, A. V. J. Gen. Chem. USSR (Engl. Transl.) 1965, 35, 1232.

(171) Chenault, J.; Dupin, J.-F. E. Synthesis 1987, 498-499.

(172) Iman, M.; Bouyssou, P.; Chenault, J. Synthesis 1990, 631-632.

(173) Corey, E. J.; Shulman, J. I.; Yamamoto, H. Tetrahedron Lett. 1970, 447-450.

(174) Zbiral, E.; Rashberger, M. Tetrahedron 1969, 25, 1871-1874.

(175) Ziegler, C. B.; Harris, S. M.; Baldwin, J. E. J. Org. Chem. 1987, 52, 443-446.

(176) Seyferth, D.; Marmor, R. S.; Hilbert, P. J. Org. Chem. 1971, 36, 1379-1386.

(177) Lewis, R. T.; Motherwell, W. B. Tetrahedron 1992, 48, 1465-1484.

(178) Ohira, S. Synth. Commun. 1989, 19, 561-564.

(179) Colvin, E. W.; Hamill, B. D. J. Chem. Soc., Perkin Trans. 1 1977, 869-874.

(180) Brown, D. G.; Velthuisen, E. J.; Commerford, J. R.; Brisbois, R. G.; Hoye, T. R. J. Org. Chem. 1996, 61, 2540-2541. 
(181) Colvin, E. W.; Hamill, B. D. J. Chem. Soc., Chem. Commun. 1973, 151-152.

(182) Gilbert, J. C.; Weerasooriya, U. J. Org. Chem. 1979, 44, 4997-4998.

(183) Gilbert, J. C.; Weerasooriya, U. J. Org. Chem. 1982, 47, 1837-1845.

(184) Delpech, B.; Lett, R. Tetrahedron Lett. 1989, 30, 1521-1524.

(185) Ragan, J. A.; Nakatsuka, M.; Smith, D. B.; Uehling, D. E.; Schreiber, S. L. J. Org. Chem. 1989, 54, 4267-4268.

(186) Nakatsuka, M.; Ragan, J. A.; Sammakia, T.; Smith, D. B.; Uehling, D. E.; Schreiber, S. L. J. Am. Chem. Soc. 1990, 112, 5583-5601.

(187) Ireland, R. E.; Highsmith, T. K.; Gegnas, L. D.; Gleason, J. L. J. Org. Chem. 1992, 57, 5071-5073.

(188) Nerenberg, J. B.; Hung, D. T.; Somers, P. K.; Schreiber, S. L. J. Am. Chem. Soc. 1993, 115, 12621-12622.

(189) (a) Hauske, J. R.; Dorff, P.; Julin, S.; DiBrino, J.; Spencer, R.; Williams, R. J. Med. Chem. 1992, 35, 4284-4296.

(b) Hung, D. T.; Nerenberg, J. B.; Schreiber, S. L. J. Am. Chem. Soc. 1996, 118, 11054-11080.

(190) Kabat, M.; Kiegiel, J.; Cohen, N.; Toth, K.; Wovkulich, P. M.; Uskokovic, M. R. Tetrahedron Lett. 1991, 32, 2343-2346.

(191) Huang, P.-Q.; Sabbe, K.; Pottie, M.; Vandewalle, M. Tetrahedron Lett. 1995, 36, 8299-8302.

(192) Kabat, M. M.; Kiegiel, J.; Cohen, N.; Toth, K.; Wovkulich, P. M.; Uskokovic, M. R. J. Org. Chem. 1996, 61, 118-124.

(193) Zhou, S.-Z.; Anne, S.; Vandewalle, M. Tetrahedron Lett. 1996, 37, 7637-7640.

(194) Wu, Y.; Zhao, X.-Y.; De Clercq, P.; Vandewalle, M.; Bouillon, R.; Verstuyf, A. Bioorg. Med. Chem. Lett. 1997, 7, 929-932.

(195) Rao, M. N.; McGuigan, M. A.; Zhang, Y.; Shaked, Z.; Kinney, W. A.; Bulliard, M.; Laboue, B.; Lee, N. E. J. Org. Chem. 1997, 62, 4541-4545.

(196) Kim, T.-S.; White, J. D. Tetrahedron Lett. 1993, 34, 5535-5536.

(197) McDermott, T. S.; Mortlock, A. A.; Heathcock, C. H. J. Org. Chem. 1996, 61, 700709.

(198) Ha, J. D.; Lee, D.; Cha, J. K. J. Org. Chem. 1997, 62, 4550-4551.

(199) Comins, D. L.; LaMunyon, D. H.; Chen, X. J. Org. Chem. 1997, 62, 8182-8187.

(200) Wovkulich, P. M.; Shankaran, K.; Kiegiel, J.; Uskokovic, M. R. J. Org. Chem. 1993, $58,832-839$.

(201) Ohira, S.; Moritani, M.; Ida, T.; Yamato, M. J. Chem. Soc., Chem. Commun. 1993, 1299-1300.

(202) Semmelhack, M. F.; Epa, W. R.; Cheung, A. W-H.; Gu, Y.; Kim, C.; Zhang, N.; Lew, W. J. Am. Chem.Soc. 1994, 116, 7455-7456. 
(203) Semmelhack, M. F.; Gallagher, J. J.; Minami, T.; Date, T. J. Am. Chem. Soc. 1993, 115, 11618-11619.

(204) McAlonan, H.; Stevenson, P. J. Tetrahedron: Asymmetry 1995, 6, 239-244.

(205) De Brabander, J.; Vandewalle, M. Synthesis 1994, 8, 855-865.

(206) Buszek, K. R.; Sato, N.; Jeong, Y. J. Am. Chem. Soc. 1994, 116, 5511-5512.

(207) Clark, D. A.; De Riccardis, F.; Nicolaou, K. C. Tetrahedron 1994, 50, 11391-11426.

(208) (a) Martin, S. F.; Assercq, J.-M.; Austin, R. E.; Dantanarayana, A. P.; Fishpaugh, J. R.; Gluchowski, C.; Guinn, D. E.; Hartmann, M.; Tanaka, T.; Wagner, R.; White, J. B. Tetrahedron 1995, 51, 3455-3482.

(b) De Brabander, J.; Kulkarni, B. A.; Garcia-Lopez, R.; Vandewalle, M. Tetrahedron: Asymmetry 1997, 11, 1721-1724.

(209) White, J. D.; Holoboski, M. A.; Green, N. J. Tetrahedron Lett. 1997, 38, 7333-7336.

(210) Marshall, J. A.; Sehon, C. A. J. Org. Chem. 1997, 62, 4313-4320.

(211) Guo, J.; Duffy, K. J.; Stevens, K. L.; Dalko, P. I.; Roth, R. M.; Hayward, M. M.; Kishi, Y. Angew. Chem. Int. Ed. Engl. 1998, 37, 187-192; Angew. Chem. 1998, 110, 198-202.

(212) Hayward, M. M.; Roth, R. M.; Duffy, K. J.; Dalko, P. I.; Stevens, K. L.; Guo, J.; Kishi, Y. Angew. Chem. Int. Ed. Engl. 1998, 37, 192-196; Angew. Chem. 1998, 110, 202-206.

(213) Yau, E. K.; Coward, J. K. J. Org. Chem. 1990, 55, 3147-3158.

(214) Hauske, J. R.; Dorff, P.; Julin, S.; Martinelli, G.; Bussolari, J. Tetrahedron Lett. 1992, $33,3715-3716$.

(215) Logan, C. F. Tetrahedron Lett. 1995, 36, 8765-8766.

(216) De Brabander, J.; Kulkarni, B. A.; Garcia-Lopez, R.; Vandewalle, M. Bull. Soc. Chim. Belg. 1997, 106, 665-670.

(217) Crisp, G. T.; Gore, J. Tetrahedron 1997, 53, 1505-1522.

(218) Gilbert, J. C.; Weerasooriya, U. Tetrahedron Lett. 1980, 21, 2041-2044.

(219) Gilbert, J. C.; Giamalva, D. H.; Weerasooriya, U. J. Org. Chem. 1983, 48, 5251-5256.

(220) Gilbert, J. C.; Blackburn, B. K. Tetrahedron Lett. 1984, 25, 4067-4070.

(221) Gilbert, J. C.; Blackburn, B. K. J. Org. Chem. 1986, 51, 3656-3663.

(222) Gilbert, J. C.; Blackburn, B. K. J. Org. Chem. 1986, 51, 4087-4089.

(223) Gilbert, J. C.; Blackburn, B. K. Tetrahedron Lett. 1990, 31, 4727-4730.

(224) Gilbert, J. C.; Weerasooriya, U. J. Org. Chem. 1983, 48, 448-453.

(225) Callant, P.; D'Haenens, L.; Vandewalle, M. Synth. Commun . 1984, 14, 155-161.

(226) Müller, S.; Liepold, B.; Roth, G. J.; Besrmann, H. J. Synlett 1996, 521-522.

(227) Meffre, P.; Gauzy, L.; Perdigues, C.; Desanges-Levecque, F.; Branquet, E.; Durand, P.; Le Goffic, F. Tetrahedron Lett. 1995, 36, 877-880. 
(228) Meffre, P.; Gauzy, L.; Branquet, E.; Durand, P.; Le Goffic, F. Tetrahedron 1996, 52, 11215-11238.

(229) Evina, C. M.; Guillerm, G. Tetrahedron Lett. 1996, 37, 163-166.

(230) Saito, M.; Kawamura, M.; Hiroya, K.; Ogasawara, K. J. Chem. Soc., Chem. Commun. 1997, 765-766.

(231) Corey, E. J.; Liu, K. J. Am. Chem.Soc. 1997, 119, 9929-9930.

(232) Taber, D. F.; Wang, Y.J. Am. Chem. Soc. 1997, 119, 22-26.

(233) Waschbüsch, R.; Carran, J.; Marinetti, A.; Savignac, P. Synthesis 1997, 727-743.

(234) Kosolapoff, G. M. J. Am. Chem. Soc. 1947, 69, 1002-1003.

(235) Kinnear, A. M.; Perren, E. A. J. Chem. Soc. 1952, 3, 3437.

(236) Rosin, H.; Asscher, M. J. Org. Chem. 1975, 40, 3298-3299.

(237) Corallo, M.; Pietrasanta, Y. Phosphorus Sulfur 1978, 4, 19.

(238) Kwon, B. M.; Oh, D. Y. Phosphorus Sulfur 1981, 11, 177.

(239) Bartle, K. D.; Edmunson, R. S.; Jones, D. W. Tetrahedron 1967, 23, 1701-1711.

(240) Sharma, R. K.; Sampath, K.; Vaidyanathaswamy, R. J. Chem. Res. (M) 1980, 217.

(241) Kennard, K. C.; Hamilton, C. S. J. Am. Chem. Soc. 1955, 77, 1156-1159.

(242) Makarov, A. M.; Gabov, N. I. Zh. Org. Khim. 1981, 51, 963; J. Gen. Chem. USSR (Engl. Transl.) 1981, 51, 804.

(243) Villieras, J. ; Perriot, P.; Normant, J. F. Synthesis 1975, 458-461.

(244) Alexakis, A. ; Normant, J.; Villieras, J. J. Organomet. Chem. 1975, 96, 471-485.

(245) Marcacci, F.; Giacomelli, G.; Menicagli, R. Gazz. Chim. Ital. 1980, 110, 195-200.

(246) Roedig, A.; Ganns, E. M.; Henrich, C.; Schnutenhaus, H. Liebigs Ann. Chem. 1981, 9, 1674-1684.

(247) Roedig, A.; Ganns, E. M. Liebigs Ann. Chem. 1981, 9, 1685-1692.

(248) Miyaura, N.; Suginome, H. Tetrahedron Lett. 1984, 25, 761-764.

(249) Brown, M. J.; Harrison, T.; Overman, L. E. J. Am. Chem. Soc. 1991, 113, 5378-5384.

(250) Ebe, H.; Nakagawa, T.; Iyoda, M.; Nakagawa, M. Tetrahedron Lett. 1981, 22, 44414444.

(251) Iyoda, M.; Nakagawa, T.; Ebe, H.; Oda, M.; Nakagawa, M.; Yamamoto, K.; Higuchi; H.; Ojima, J. Bull. Chem. Soc. Jpn. 1994, 67, 778-791.

(252) Lowen, G. T.; Almond, M. R. J. Org. Chem. 1994, 59, 4548-4550.

(253) Atkinson, R. E.; Cadogan, J. I.G.; Dyson, J. J. Chem. Soc. 1967, 2542.

(254) Eymery, F.; Iorga, B.; Savignac, P. unpublished results.

(255) Seyferth, D.; Marmor, R. S. J. Organomet. Chem. 1973, 59, 237.

(256) Savignac, P., Petrova, J.; Dreux, M.; Coutrot, P. Synthesis 1975, 535-536.

(257) Pflieger, D.; Muckensturm, B. Tetrahedron 1989, 45, 2031.

(258) Benkeser, R. A.; Smith, W. E. J. Am. Chem. Soc. 1968, 90, 5307-5309. 
(259) Carran, J.; Waschbüsch, R.; Marinetti, A.; Savignac, P. Synthesis 1996, 12, 14941498.

(260) Marinetti, A.; Savignac, P. Org. Synth. 1997, 74, 108-114.

(261) Kabachnik, M. I.; Schepeleva, E. S. Dokl. Akad. Nauk SSSR 1950, 75, 219; Chem. Abstr. 1951, 6569.

(262) Crofts, P. C.; Kosolapoff, G. M. J. Am. Chem. Soc. 1953, 75, 5738-5740.

(263) Kabachnik, M. I.; Medved, T. Ya. Izv. Akad. Nauk SSSR Ser. Khim. 1950, 635; Chem. Abstr. 1951, 8444.

(264) Kabachnik, M. I.; Schepeleva, E. S. Izv. Akad. Nauk SSSR Ser. Khim. 1951, 185; Chem. Abstr. 1951, 10191.

(265) Korshak, V.V.; Gribova, I. A.; Andreeva, M. A. Izv. Akad. Nauk SSSR Ser. Khim. 1957, 631; Bull. Acad. Sci. USSR, Div. Chem. Sci. (Engl. Transl). 1957, 641.

(266) McConnell, R. L.; McCall, M. A.; Coover Jr., H. W. J. Org. Chem. 1957, 22, 462.

(267) Savignac, P.; Petrova, J.; Dreux, M.; Coutrot, P. J. Organomet. Chem. 1975, 91, C45.

(268) Savignac, P.; Dreux, M.; Coutrot, P. Tetrahedron Lett. 1975, 609-610.

(269) Stang, P. J. Chem. Rev. 1978, 78, 383-405.

(270) Stang, P. J. Acc. Chem. Res. 1982, 15, 348-354.

(271) Mouriès, V., Waschbüsch, R.; Carran, J.; Savignac, P. Synthesis 1998, 271-274.

(272) Savignac, P.; Coutrot, P. Synthesis 1976, 197-199.

(273) Harada, T.; Katsuhira, T.; Hattori, K.; Oku, A. Tetrahedron 1994, 50, 7987-8002.

(274) Sato, H.; Isono, N.; Miyoshi, I.; Mori, M. Tetrahedron 1996, 52, 8143-8158.

(275) Mori, M.; Isono, N.; Wakamatsu, H. Synlett 1999, 269-280.

(276) Cade, J. A. J. Chem. Soc. 1959, 2266.

(277) Bonnet, B.; Le Gallic, Y.; Ple, G.; Duhamel, L. Synthesis 1993, 1071-1073.

(278) (a) Zimmer, H. ; Bercz, P. J.; Maltenieks, O. J.; Moore, M. W. J. Am. Chem. Soc. 1965, 87, 2777-2778.

(b) Gascoyne, J. M.; Mitchell, P. J.; Phillips, L. J. Chem. Soc., Perkin Trans. 2 1977, 1051-1057.

(279) Zimmer, H.; Hickey, K. R.; Schumacher, R. J. Chimia 1974, 28, 656-657.

(280) Engel, R. in Synthesis of Carbon-Phosphorus Bonds, CRC Press, Boca Raton, Florida, 1988, 101-136.

(281) Gallagher, M. J.; Noerdin, H. Aust. J. Chem. 1985, 38, 997-1005.

(282) Kondo, K.; Ohnishi, N.; Takemoto, K.; Yoshida, H.; Yoshida, K. J. Org. Chem. 1992, $57,1622-1625$.

(283) Gajda, T. Synthesis 1990, 717-718.

(284) Kumaraswamy, S.; Senthamizh, R.; Kumara Swamy, K. C.Synthesis 1997, 207-212.

(285) Gajda, T. Phosphorus Sulfur Silicon Relat. Elem. 1990, 53, 327-331. 
(286) Green, D.; Elgendy, S.; Patel, G., Baban, J. A.; Skordalakes, E.; Husman, W.; Kakkar, V. V.; Deadman, J. Tetrahedron 1996, 52, 10215-10224.

(286) Nakatsuji, S.; Matsuda, K.; Uesugi, Y.; Nakashima, K.; Akiyama, S.; et al. J. Chem. Soc., Perkin Trans. 2 1991, 861-867.

(288) Kondo, K.; Fujitani, T.; Ohnishi, N. J. Mater. Chem. 1997, 7, 429-433.

(289) Iorga, B.; Eymery, F.; Savignac, P. Tetrahedron Lett. 1998, 39, 3693-3696.

(290) Iorga, B.; Eymery, F.; Savignac, P. Tetrahedron 1999, 55, 2671-2686.

(291) Petrova, J.; Coutrot, P.; Dreux, M.; Savignac, P. Synthesis 1975, 658-660.

(292) Lee, J. W.; Kim, T. H.; Oh, D. Y. Synth. Commun. 1989, 19, 2633-2638.

(293) Wadsworth Jr., W. S.; Emmons, W. D. J. Am. Chem. Soc. 1961, 83, 1733-1738.

(294) Brown, D; Stevenson, R. J. Org. Chem. 1965, 30, 1759-1762.

(295) Klemm, L. H.; Klemm, R. A.; Santhanam; P. S.; White, D. V. J. Org. Chem. 1971, 36, 2169-2172.

(296) Musicki, B.; Vevert, J.-P. Tetrahedron Lett. 1994, 35, 9391-9394.

(297) Skuballa, W.; Schillinger, E.; Stürzebecher, C.-St., Vorbrüggen, H. J. Med. Chem. 1986, 29, 313-315.

(298) Iseki, K.; Shinoda, M.; Ishiyama, C.; Hayasi, Y.; Yamaha, S.; Shibasaki, M. Chem. Lett. 1986, 559-562.

(299) Tomiyama, T.; Wakabayashi, S.; Yokota, M. J. Med. Chem. 1989, 32, 1988-1996.

(300) Ishihara, T.; Maekawa, T.; Ando, T. Tetrahedron Lett. 1984, 25, 1377-1378.

(301) Ishihara, T.; Yamasaki, Y.; Ando, T. Tetrahedron Lett. 1985, 26, 79-82.

(302) Ishihara, T.; Maekawa, T.; Ando, T. Tetrahedron Lett. 1986, 27, 357-360.

(303) Jacobson, H. I.; Griffin, M. J.; Preis, S.; Jensen, E. V. J. Am. Chem. Soc. 1957, 79, 2608-2612.

(304) Craig, J. C.; Moyle, M. Proc. Chem. Soc. 1962, 149.

(305) Craig, J. C.; Moyle, M. J. Chem. Soc. 1963, 3712-3718.

(306) Craig, J. C.; Bergenthal, M. D.; Fleming, I.; Harley-Mason, J. Angew. Chem. Int. Ed. Engl. 1969, 8, 429-437.

(307) Negishi, E.; King, A. O.; Klima, W. L.; Patterson, W.; Silveira Jr., A. J. Org. Chem. 1980, 45, 2526-2528.

(308) Negishi, E.; King, A. O.; Tour, J. M. Org. Synth. 1986, 64, 44-49.

(309) Prestwich, G. D.; Wawrzenczyk, C. Tetrahedron Lett. 1989, 30, 403-406.

(310) Bury, P.; Hereau, G.; Kocienski, P.; Dhanak, D. Tetrahedron 1994, 50, 8793-8808.

(311) Toyota, M.; Nishikawa, Y.; Fukumoto, K. Tetrahedron Lett. 1995, 36, 5379-5382.

(312) Toyota, M.; Nishikawa, Y.; Fukumoto, K. Tetrahedron 1996, 52,10347-10362.

(313) Parlow, J. J.; Clark, R. D. J. Agric. Food Chem. 1994, 42, 2600-2609.

(314) Dougherty, T. K.; Lau, K. S. Y. Hedberg, F. L. J. Org. Chem. 1983, 48, 5273-5280. 
(315) Baumeler, A.; Brade, W.; Haag, A.; Eugster, C. H. Helv. Chim. Acta 1990, 73, 700715. 